Portland State University

PDXScholar

\title{
Exploring the Role of Transformational Leaders in the Mentorship of Top-Level Administrators: a Case Study of the Veterans Health Administration (VHA) VISN LEAD Program
}

Frederick Giovanni White Jr. Portland State University

Follow this and additional works at: https://pdxscholar.library.pdx.edu/open_access_etds

Part of the Business Administration, Management, and Operations Commons, and the Organizational Behavior and Theory Commons

Let us know how access to this document benefits you.

\section{Recommended Citation}

White, Frederick Giovanni Jr., "Exploring the Role of Transformational Leaders in the Mentorship of TopLevel Administrators: a Case Study of the Veterans Health Administration (VHA) VISN LEAD Program" (2020). Dissertations and Theses. Paper 5468.

https://doi.org/10.15760/etd.7340

This Dissertation is brought to you for free and open access. It has been accepted for inclusion in Dissertations and Theses by an authorized administrator of PDXScholar. Please contact us if we can make this document more accessible: pdxscholar@pdx.edu. 
Exploring the Role of Transformational Leaders in the Mentorship of Top-Level

Administrators: A Case Study of the Veterans Health Administration (VHA) VISN LEAD

Program

by

Frederick Giovanni White Jr.

A submittal of a dissertation in partial fulfillment of the requirements for the degree of

Doctor of Philosophy

In

Public Affairs and Policy

Dissertation Committee:

Neal Wallace, Chair

Marcus Ingle

Jill Rissi

Maura Kelly

Robert Calabrisi

Portland State University

2020 


\begin{abstract}
Despite the proliferation of studies focused on transformational leadership, there is a lack of clarity related to how transformational leaders are developed in public organizations and the impact of mentors in this process. This is particularly troubling given a 2017 Bureau of Labor Statistics estimate that over 44\% of the current U.S. workforce is 45 years or older.

In public and private settings, organizations are challenged to develop the competencies critical at higher levels of management in their future leaders, specifically advanced human and conceptual skills (Yukl, 2006). These skills are most useful for emerging leaders that will have the responsibilities to analyze difficult problems, engage and solicit feedback from staff, establish systematic processes, and deploy solutions throughout the organization. With an aging workforce and an increasing number of senior leaders eligible to retire, the Veterans Health Administration (VHA) has recognized the urgency to ingrain leadership development and succession planning into its agency-wide strategic and operational plans.

Utilizing complexity theory and social learning theory to better understand this phenomenon, this study examined the leadership development program of the Veterans Health Administration (the largest and most complex integrated health care system in the nation) to explore the role that senior-leader mentors have on developing a pipeline of competent and effective transformational leaders. Specifically, the study
\end{abstract}


examines the impact that mentors that demonstrate four foundational transformational leadership (TL) behaviors: Idealized Influence, Inspirational Motivation, Individualized Consideration, and Intellectual Stimulation, have on the development of leadership skills and the demonstration of similar behaviors in the protégé (Bass \& Riggio, 2006).

Applying a cross-sectional survey methodology that included both correlation and regression analyses, the study assessed the impact of each of the mentor's TL characteristics on the development of protégé leadership capabilities. Results showed positive, significant relationships between each of the mentor's TL characteristics and the development of the protégé's human skills, conceptual skills, and corresponding TL characteristics. The results revealed that mentors that demonstrate TL characteristics facilitated the effective development and growth of their protégé. The results also showed that mentors that spent time with their protege (ideally 4-6 hours/month) and purposefully introduced them to influential people or other key leaders in the organization helped them to develop key leadership skills.

This study contributes to the literature by strengthening researchers' theoretical understanding of how to develop transformational leadership skills and characteristics in protégé and suggest specific characteristics that organizations should incorporate into their formal mentoring programs to develop effective public organizational leaders. 


\section{Dedication}

To GOD first,

who gave me the perseverance to finish this process,

when many times I wanted to give up.

To my wife, Monique White,

who tirelessly labors with me and demonstrates patience, even when I do not deserve it.

To my father, Frederick White, and my grandfather, Robert White, who set an example and taught me how to be a transformational leader before I ever read a book.

To my mother, Nedra White, who models servant-leadership behaviors daily, as she strives to put the needs of others before her own.

To my son, Frederick G. White III., who is learning every day how to become a stronger leader.

To my Portland State University Chair, Dr. Neal Wallace, and my dissertation committee: Dr. Marcus Ingle, Dr. Jill Rissi, Dr. Maura Kelly, and Dr. Robert Calabrisi.

My deepest thanks to each of you for your encouragements, instructions, and guidance.

Thank you!

iii 


\section{TABLE OF CONTENTS}

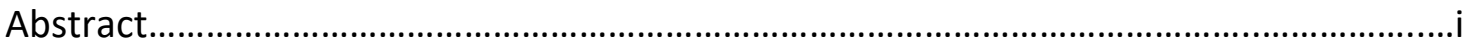

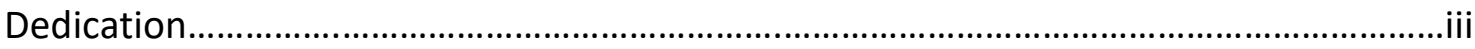

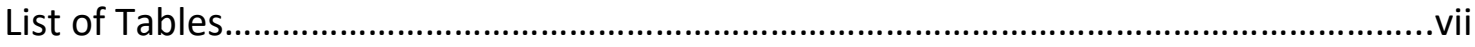

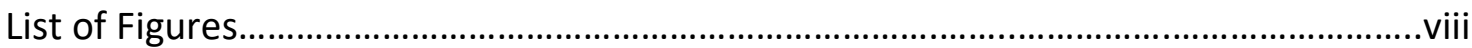

Chapter I: INTRODUCTION TO THE STUDY PROBLEM

Statement of the Problem.................................................................................

The Premise of the Study...............................................................................

Research Questions \& Justification.................................................................12

Chapter II: REVIEW OF LITERATURE AND THEORY

Leadership Development...................................................................................14

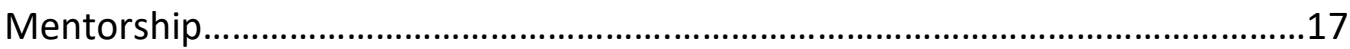

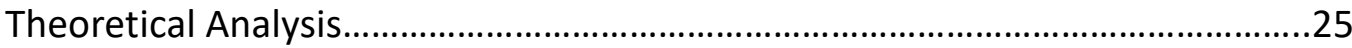

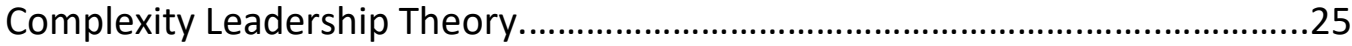

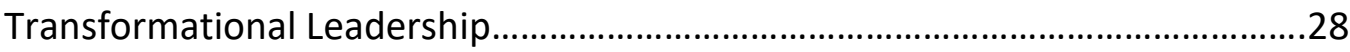

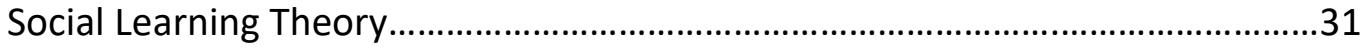

Katz's Three Skill Approach.....................................................................................33

Chapter III: RESEARCH DESIGN

Purpose

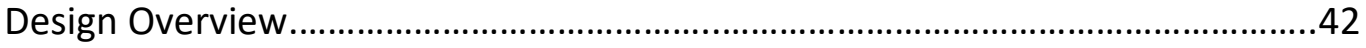

Study Setting: VHA VISN LEAD Program..............................................................44

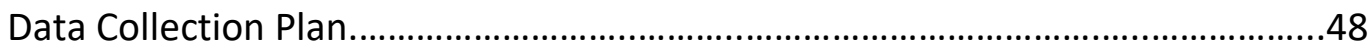




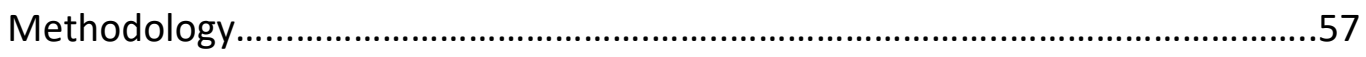

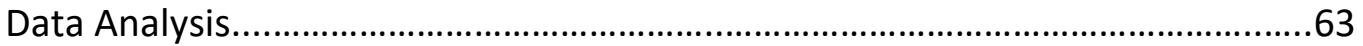

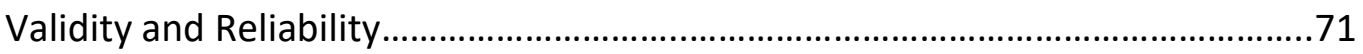

Chapter IV: RESULTS

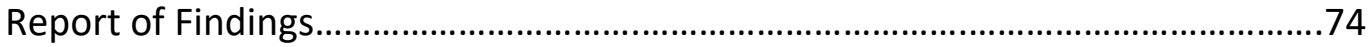

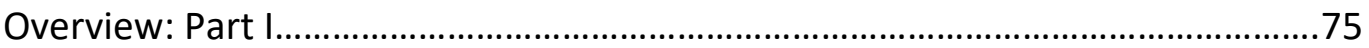

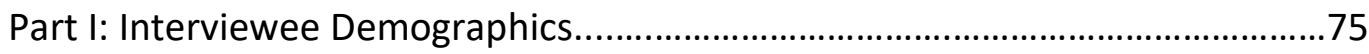

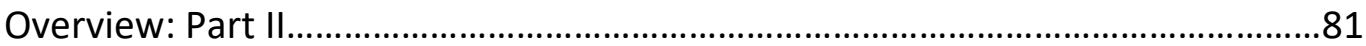

Study Demographics, Themes, and Frequencies....................................................81

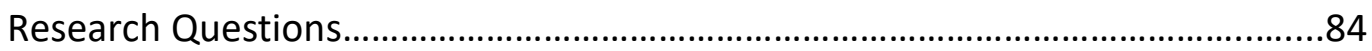

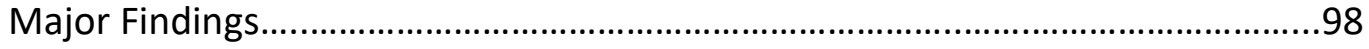

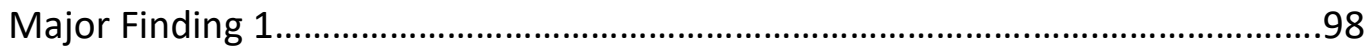

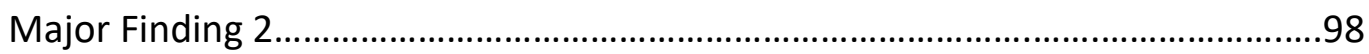

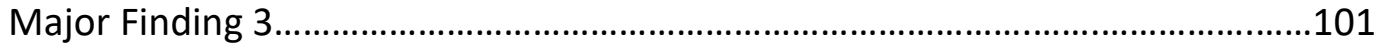

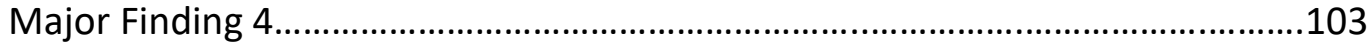

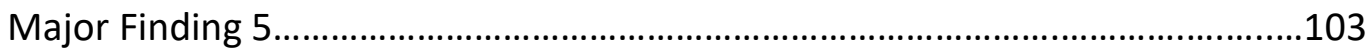

Chapter V: DISCUSSION

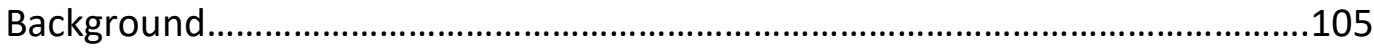

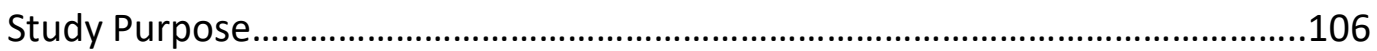

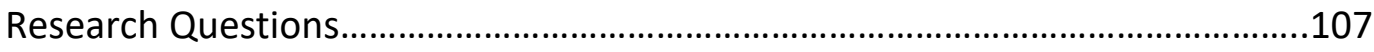

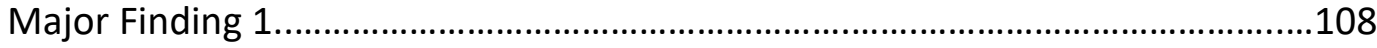

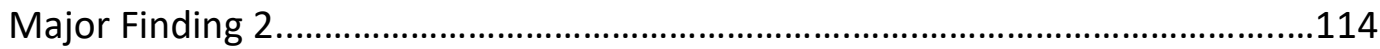

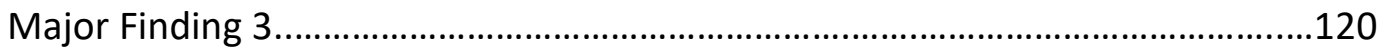




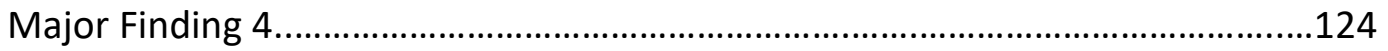

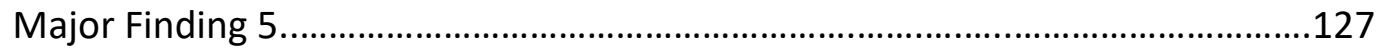

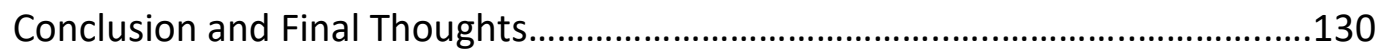

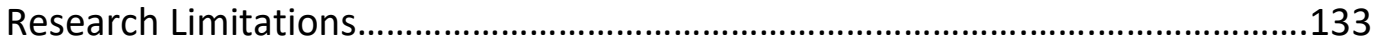

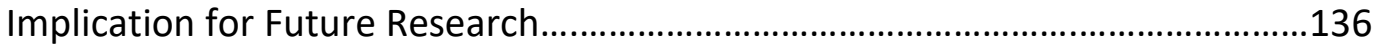

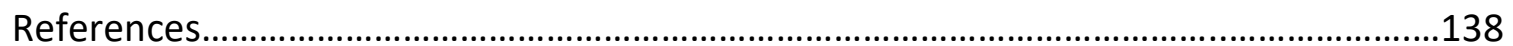

\section{APPENDICES:}

- Appendix A: Program Administrator Interview Script .............................................153

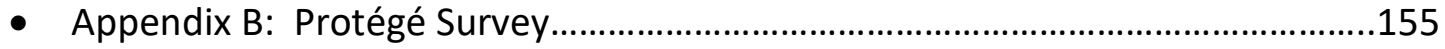

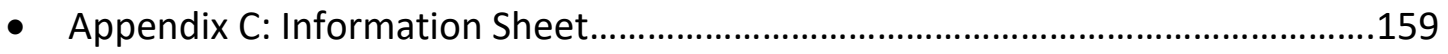

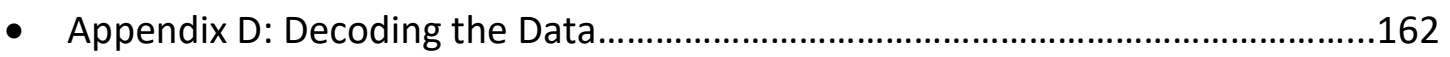

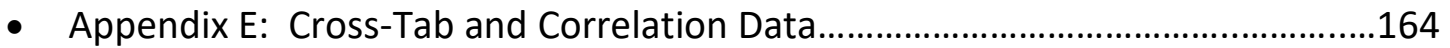




\section{List of Tables}

Table 3.1 - Summary of Data Collection, Source, and Research for Part I/II.....................54

Table 3.2 - Summary of the Program Evaluation Categories...........................................57

Table 4.1 - Summary of the Distributions for Gender, Ethnicity, \& Experience...................75

Table 4.2 - VISN Leadership Development Program Description Matrix.............................76

Table 4.3 - Summary of the Distributions for Gender, Ethnicity, \& Experience.................81

Table 4.4 - Summary of the Distributions for the Goodness of Fit Domain........................82

Table 4.5 - Summary of the Distributions of the T.L. Characteristics.................................84

Table 4.6 - Descriptive Statistics Table for Presence of Mentee Skills...............................86

Table 4.7 - Multiple Regression Analysis Predicting Mentee Human Skill.......................88

Table 4.8 - Multiple Regression Analysis Predicting Mentee Conceptual Skill..................90

Table 4.9 - Impact of Mentor's T.L. Characteristics on Mentee's T.L.................................91

Table 4.10 - Descriptive Statistics Table for Mentee Certification Status.........................96

Table 4.11 - Regression Coefficients and S.E. Mentee Certification Status......................97 


\section{List of Figures}

Figure 1.1 - VA Competency Framework....................................................................

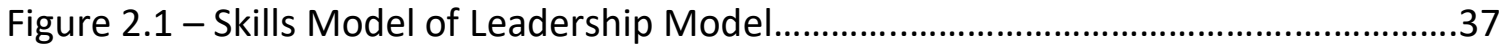

Figure 2.2 - Leadership Development Model.....................................................................37

Figure 3.1 - VHA Veterans Integrated Service Networks.................................................44

Figure 3.2 - Relationship between Variables (Q1/Q2) .................................................68

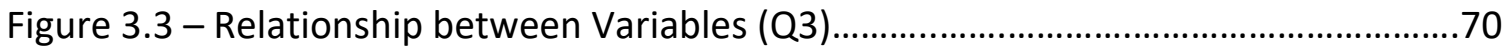

Figure 4.1 - Time That Mentee Spent with Mentor per Month...........................................82 


\section{CHAPTER I: INTRODUCTION TO THE STUDY PROBLEM}

"The worst thing in your own development as a leader is not to do it wrong.

$$
\text { It's to do it for the wrong reasons." - Stan Slap }
$$

\section{Statement of the Problem}

According to an August 2017 report by the Bureau of Labor Statistics

(www.data.bls.gov), over $44 \%$ of the current U.S. workforce is 45 years or older, a group that may number 115 million by the end of 2020 (Heidkamp, Mabe, \&DeGraaf, 2012). For most industries, this trend forecasts significant employment challenges, as many of their more knowledgeable and experienced leaders will be leaving the workforce. As this shift continues to occur, public, private, and non-governmental organizations are forced to strategize ways to retain talented, seasoned leaders, keeping them active as long as possible while they replace and develop new staff. One industry especially vulnerable to the effects of an aging workforce is healthcare. The Institute of Medicine (IOM) (2008) reported that by 2030, the nation will need an extra 3.5 million formal health care providers just to maintain the existing ratio of providers to the total population.

To respond to these impending challenges and continue the provision of highquality programs and services despite workforce vulnerabilities, organizations are challenged to invent structures and systems that require new thinking, values, skills, designs, and leadership (Clawson, 2002). Organizations are further challenged to 
develop the competencies critical at higher levels of management in their future leaders, specifically advanced human and conceptual skills (Yukl, 2006). These skills are most useful for emerging leaders that will have the responsibilities to analyze difficult problems, engage and solicit feedback from staff, establish systematic processes, and deploy solutions throughout the organization. High-level leaders acquire and utilize these skills as visionaries and agents of change that enlist support from multi-level stakeholders and engage staff in an organizational learning environment where building trust and empowering individuals are essential (Hurst, 1995).

In both public and private organizations, the ability to improve performance and strive during turbulent times is based on their capacity to produce and sustain high quality leadership. For some institutions, building this capacity occurs through formal leadership development and succession planning programs. Often, these leadership development programs incorporate formal mentorship as a tool to facilitate the individual growth and career development of employees. Important in the mentoring relationship are the transformational skills of the mentor that help to ensure the protégé's growth and development.

With an aging workforce and an increasing number of senior leaders eligible to retire, the Veterans Health Administration (VHA) has recognized the urgency to ingrain leadership development and succession planning into its agency-wide strategic and operational plans. To accomplish its mission and continually improve the services and programs offered to veterans, VA has committed to maintaining a talented, mission- 
focused workforce to provide exceptional health care that improves the health and wellbeing of the veterans served. Accordingly, the VHA created, developed, reprogrammed, and deployed a continuum of programs to produce a highly diversified and talented cadre of potential leaders for the future (National Academy of Public Administration, 2008). These programs are aligned with VHA national policy for the provision of leadership development utilizing the Leadership, Effectiveness, Accountability, and Development (LEAD) criteria to ensure that individuals at every level of the organization have the knowledge, skills, and competencies to benefit both themselves and the organization.

One development program that has been particularly important to VHA's ability to sustain high levels of performance is the Veterans Integrated Service Network (VISN) LEAD program. In 1997, VA Central Office mandated that each of the 21 regional VISNs across the country develop a program to train middle managers and facilitate their development into future senior leaders. In response to the mandate, each VISN established a LEAD (Leadership, Effectiveness, Accountability and Development) program to help alleviate the significant loss of leadership and technical expertise created from the impending baby boomer generation's retirement.

The VISN LEAD criteria outlined six core leadership competencies that were to be included into each VISN program and utilized to develop leaders: leading people, partnering, leading change, global perspective, business acumen, and results-driven. Below are the behaviors associated with each competency. These competencies were 
espoused in the curriculum requirements and were outlined in the VA Competency Framework (Figure 1.1).

The foundation of the Competency Framework is the seven core values/characteristics of the organization: integrity, excellence, compassion, stewardship, commitment, accountability, and professionalism. Every employee of the organization is expected to demonstrate these values. In addition, the framework outlines specific competencies that staff are supposed to develop, based on their roles. For example, all employees have the responsibility to grow in the competencies of communication, interpersonal effectiveness, critical thinking, organizational stewardship, Veteran and customer focus, and personal mastery. In addition to these competencies, technical staff (e.g. plumbers, surgeons) also have the responsibility to maintain their job-specific certifications, knowledge, skills and abilities.

As employees transition to management and leadership positions, they are challenged to develop and exemplify the six leadership competencies: leading people, partnership, leading change, global perspective, business acumen, and results-driven. These are further defined below. 
Figure 1.1 - VA Competency Framework

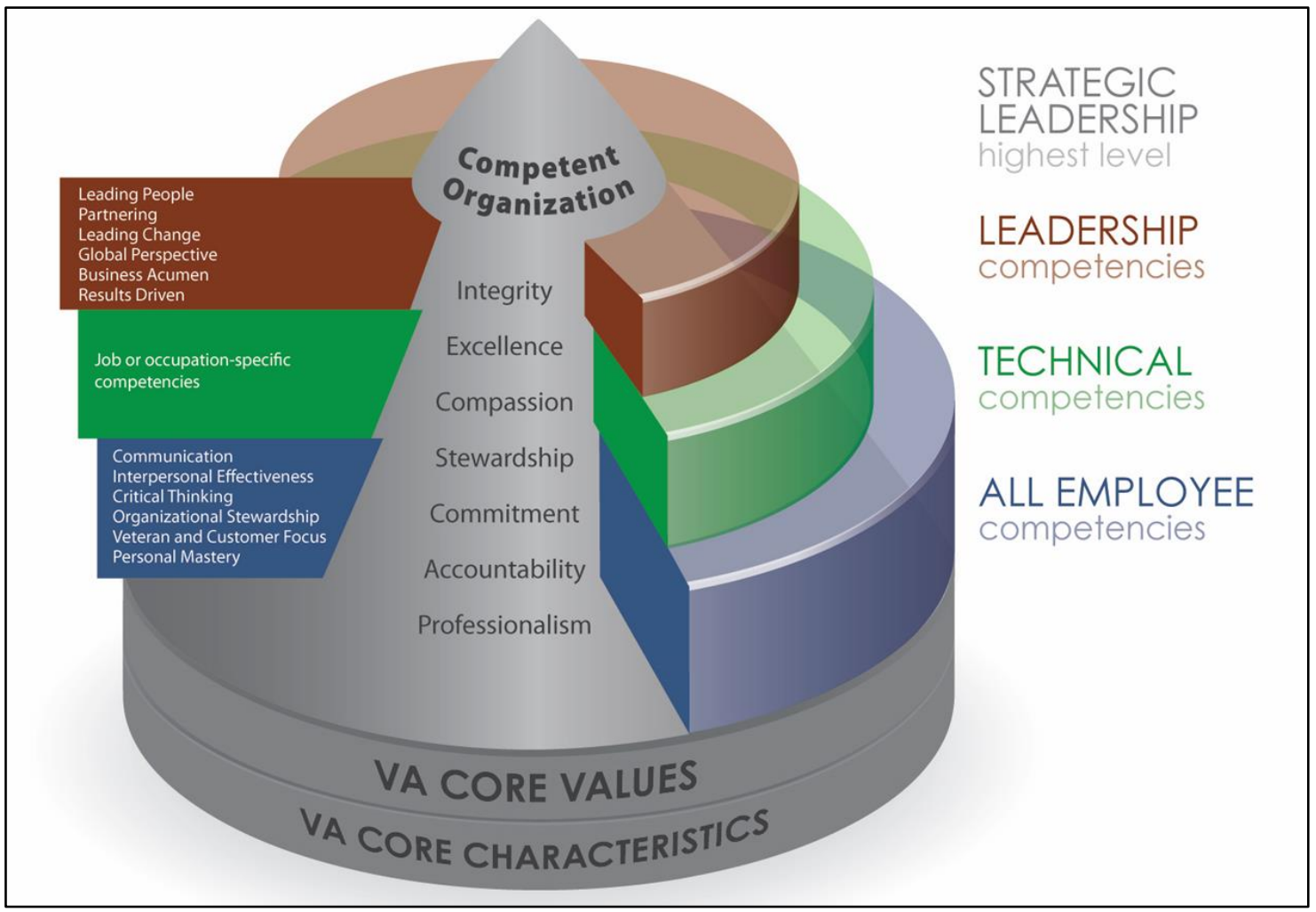

\section{Leadership Competencies:}

- $\quad$ Leading People $=$ Promotes leadership at all levels, Inspires continual learning and development, Builds high-performing, diverse teams.

- Partnering $=$ Drives integration, Builds and maintains partnerships, Demonstrates political savvy, Effectively manages conflict.

- $\quad$ Leading Change $=$ Champions innovation, Communicates vision and drives change.

- $\quad$ Results Driven = Foster reasonable risk taking and drives execution, Fosters accountability to Veterans.

- $\quad$ Global Perspective $=$ Ensures strategic alignment, Enhances outcomes for Veterans.

- Business Acumen = Applies forward-looking human capital management principles, Applies sound financial and resource management principles, Employs technology effectively. 
Each VISN (through the LEAD program) had the responsibility to develop leaders that would demonstrate these competencies. The LEAD criteria standardized the curriculum requirements; however, the criteria did not specify the structural components of the program. Accordingly, each VISN utilized the criteria to develop a regional program to ensure the development of its leaders. Today, these VISN programs vary on frequency of meetings, length of the program, modality, pre-work requirements, assignments, and learning methods.

To support the LEAD program and the development of future leaders, VISNs made significant investments of time, resources, and funding. For example, the VISN LEAD programs included a mandatory, formal mentoring program component to ensure that participants received guidance and coaching from a senior leader within the organization. While these investments have been valuable, it is unclear what impact mentors in the VISN LEAD programs had on the participant's ability to develop the necessary higher-level skills necessary for emerging leaders in the $21^{\text {st }}$ Century. Moreover, additional data is required to show evidence of leadership effectiveness through the mentoring program and to link that evidence to performance outcomes. 


\section{The Premise of the Study}

Leadership development programs provide a proven approach for learning organizations to increase employee leadership abilities (Bodinson, 2005; Kim, 2007; Melum, 2002) and realize positive organizational results (Fuller, Patterson, Hester, \& Stronger, 1996; Sashkin \& Rosenbach, 2001). McGonagill and Reinelt (2011) further note that investing in leadership development contributes to the effectiveness of programs to which the organization is already committed, thus helping to more effectively achieve its mission. This observation was echoed by various U.S. foundations that successfully invested in leadership development to build organizational capacity (Hubbard, 2005; Enright, 2006).

Although leadership development programs provide a proven approach for accomplishing these objectives, several factors affect the ability of these programs to be most effective. According to Olivares, Peterson, \& Hess (2007), leaders operate in a dynamic and complex environment, where they are required to integrate and understand the "context of others, social systems, and organizational strategies, missions, and goals (p. 79). In this environment, effective leaders transform to become more relational and value-based, affirming the need to consider people and tap into the collective wisdom of members of organization at every level (Uhl-Bien, Marion, McKelvey, 2007). Within this environment, leadership development becomes essential because it focuses on developing the capacity of individuals to cultivate and leverage peer relationships, teams to align their goals and activities with the organization and 
across boundaries, and of the organization to foster internal and external collaborations (McGonagill and Reinelt, 2011).

At least three levels of analysis are important to consider when evaluating leadership development programs within organizations: individual, group, and organizations (Grove, Kibel, Haas, 2005; Hersey, Blanchard, Johnson, 2007). At the individual level, most assessments involve the study of learning, perception, creativity, motivation, personality, turnover, task performance, cooperative behavior, deviant behavior, ethics, and cognition. At the group level, concepts like group dynamics, intraand intergroup conflict and cohesion, leadership, power, norms, interpersonal communication, networks, and roles are studied.

At the organizational level, assessment involves the consideration of topics such as organizational culture, organizational structure, cultural diversity, inter-organizational cooperation and conflict, change, technology, and external environmental forces. Grove et al. (2005) found that the individual domain is where most of the direct benefits of leadership development occur and where the most program-associated results are expected. Results are easiest to measure at this level of analysis by program administrators (i.e. through pre/post surveys or questionnaires) and have been the focus of much of the leadership development literature.

In 1994, Kirkpatrick introduced the Four Levels of Learning Model that identifies four levels of evaluation for leadership development programs: I) Satisfaction, or the feelings participants have about the program; II) Learning, or the degree to which 
participants learn the required material and changes occur in their knowledge, skills, and attitudes; III) Behavior, or their ability to transfer knowledge from the training to the work site evidenced by changes in their "on the job" performance; and IV) Results, or the impact of training on the organization's bottom line.

Currently, most leadership assessments focus on the satisfaction of the participants immediately following the program (Level I). Additionally, administrators seldom assess needs, establish specific objectives, or evaluate beyond the participant's reaction to the training (Clarke, 2004). Martineau and Hannum (2004) agree and argue that evaluation techniques should measure more than just the participant's perception of the program. Cromwell \& Kolb (2004) further noted that only about $15 \%$ of learning transfers to the job.

In many formal leadership development programs, mentorship plays a significant role in the individual growth and career development of employees. Despite the well documented value of mentors to develop the potential talents of protégé, public sector mentoring research accounts for a small fraction of the mentoring literature, and few mentoring studies include any outcome measure other than reported satisfaction (Bozeman and Feeney, 2009). This is surprising given the growth of formal mentoring programs in the public sector. For example, in the federal government, formal mentorship programs have been used to foster effective mentorship relationships that produce accelerated personal learning, upward career mobility, and psychosocial support (Kram, 1985; Ragin \& Cotton, 1999). 
Mentoring is often a critical component in developmental programs like the Senior Executive Service Candidate Development Program (SESCDP), the Presidential Management Fellow Program (PMF), the Veterans Health Administration (VHA) Leadership, Effectiveness, Accountability, and Development (LEAD) Program, or the USDA Graduate School Executive Leadership Program (ELP). These programs have structure, oversight, and clear and specific organizational goals. The U.S. Office of Personnel Management (2008) even published a guide entitled, Best Practices: Mentoring, that intended to aid public organizations who were developing a business case for mentoring and outline critical steps for developing and implementing a formal mentoring program.

From the literature, we know that mentorship plays a key role in protégé success; however, it is unclear what characteristics of mentors are most important to the protégé's growth (development of human and conceptual skills) and their subsequent change in behavior. The Leadership Skills Model (Figure 2.1) frames leadership as the capabilities (knowledge and skills) that make effective leadership possible and helps to elucidate the capabilities necessary to make an effective leader. However, it does not discuss how these skills are acquired by or further developed in emerging leaders. The Social Learning Theory (SLT) highlights the idea that imitation, as a modeling behavior, can help individuals learn from example (Bandura, 1977). SLT clarifies how the behaviors of mentors can positively affect those of the protégé, but it 
does not fully consider the multiply effects that transformational mentors can have on protégé behavior.

From the literature, we also know that transformational leaders have been associated with creating and inspiring a shared vision for a group. They are expected to impact behavior by lifting those that they lead to extraordinary heights. What is unclear is what type of impact a mentor that exhibits transformational behaviors has on the behaviors of the protégé. My research hopes to clarify some of these questions and my results may suggest areas where current development models around leadership development and mentorship may be expanded. 


\section{Research Questions and Justification}

This research will focus on exploring formal mentorship programs in the public sector. More specifically, this study will seek to better understand the influence that senior public sector mentors have on the development of protégé skills and behaviors. Utilizing the Veterans Health Administration as the study setting, this research will explore the questions:

1. To what extent do mentees perceive their mentors to be transformational leaders as defined in the literature?

2. What transformational characteristics of the mentors are most important to the mentee's growth of leadership capabilities, as perceived by the mentee? Does this perception vary depending on time with mentor, and gender and race of mentee and mentor?

3. How does this perception relate to the mentees willingness to become mentors in the VISN LEAD program?

My research is important to the study of leadership and to the vast amount of literature devoted to leadership theory and practice in the public sector. This research intends to explore the role of transformational leadership and mentorship in contemporary public organizations and show that transformational senior leaders can positively affect the growth and development of aspiring leaders (protégé), and ultimately the culture within their organizations.

This study intends to explore the validity of the Leadership Development Model, which suggests that leadership capabilities are acquired by modeling, and further developed primarily through mentoring and training. Specifically, this study intends to 
examine if transformational leadership characteristics modeled by mentors during a formal leadership development program positively affects the development of human skills, conceptual skills, and similarly transformational leadership behaviors in the mentee or protégé. This study will also use both qualitative and quantitative methods to explore these questions, in an attempt to unmask less visible differences among formal mentoring programs (e.g. goodness of fit and individual characteristic variables) and assist in better understanding the significance of the program from the perspective of the participants (Patton, 1990). 


\section{CHAPTER II: REVIEW OF LITERATURE AND THEORY}

"In any given moment we have two options: to step forward into growth or to step back into safety". - Abraham Maslow

\section{Leadership Development}

Leadership development is one of the top priorities for many of today's organizations (Steinhilber \& Estrada, 2015). Traditionally focused on developing the leadership abilities and attitudes of individuals, leadership development refers to any activity that enhances the quality of leadership within an individual or organization. Formally, organizations deploy leadership development programs to develop the capabilities of future leaders and ensure the sustainability and effectiveness of the organization. In these programs, leaders are developed by strengthening the connection between, and alignment of, the efforts of individual leaders and the systems through which they influence organizational operations (Fulmer \& Wagner, 1999; Ayers, 2015).

Baldwin \& Ford (1988) linked the effectiveness of leadership development efforts to three variables: 1 ) individual learner characteristics, 2) the quality and nature of the leadership development program, and 3) the genuine support for behavioral change from the leader's supervisor. Yukl (2008) further demonstrated that leader characteristics were important to improve leadership effectiveness and organization 
performance. Dhar and Mishra (2001) added that the most commonly used measure of leader effectiveness is assessing group performance and the extent to which the goals and objectives of the group are met. This is important because leaders must be able to lead groups and minimize the disruptions necessary to lead and manage a change effort (Kotter, 2011).

Leadership development programs are important to improve quality of care, professional advancement, and patient satisfaction (Frich et al., 2014; Steinhilber \& Estrada, 2015); and they help boost business performance and enhance leadership team skills (Kur \& Bunning, 2002). Watson Wyatt (2003) found that the quality of an organization's leadership development activities has a direct impact on the organization's financial outcomes such as revenue growth, profitability, and market share. Similarly, Bersin \& Associates' study (2009) revealed that strategically designed leadership development programs were associated with strong executive engagement (e.g. mentoring relationships) and a high-impact leadership development strategy that generated improved business results; increased quality in the leadership pipeline; improved teamwork, engagement, and retention of leaders; and increased overall employee retention.

Leadership development programs focus on equipping leaders with the skills they need to enable and empower people at every level by using networking, knowledge sharing, partnerships, skill development and innovation. These programs also focus on building a strong organizational culture that will support the organization's 
ability to lead and manage change. For example, a strong culture aligned with the transformational change will ensure a united and stable focus on the goal (Lawrence \&Lorsch, 1967). Additionally, cultural alignment is important to ensure the required change is initiated, implemented, and sustained (Taylor, 2013). In many formal leadership development programs, mentors play a significant role in developing protégé and ensuring cultural alignment to the organization's mission, vision, and values. 


\section{Mentorship}

There is increasing evidence that mentors play a major role in people's career success and advancement (Roche, 1979; Mincemoyer \& Thomson, 1998; Lauber, 2012; and Fieldman, Davidson, \& Sutherland, 2009). Mentors have become essential in today's workplace and contribute to increasing job satisfaction, personal productivity, and employment stability within organizations (Fielden, Davidson, Sutherland, 2009). Bozeman and Feeney (2008) define mentoring as "a process for the reciprocal, informal transmission of knowledge, social capital, and psycho-social support perceived by the recipient as relevant to work, career, or professional development" (p. 469). Accordingly, mentoring usually entails face to face communication over a sustained period, between a person who is perceived to have greater relevant knowledge, wisdom, or experience (the mentor), to a person who is perceived to have less (the protégé).

Mentoring focuses on developing leadership capability, encouraging a range of perspectives, and the transfer of information from the experience of the mentor. Sambunjak, Straus, and Marusic (2006) noted that mentoring was the single most important aspect of medical training. Middlebrooks and Haberkorn (2009) showed that mentoring places mentors in a position where they are the expert and are "expected to facilitate the job, learning, and to some extent the psychological well-being of the mentee" (p. 9). 
Mentor roles include "advisor, sponsor, tutor, advocate, coach, protector, role model and guide" (Hadden, 1997, p. 17). The roles of a mentor are directed toward the improvement of the protégé's skills, performance, and development that the protégé lacks at the beginning of the relationship. Mentoring focuses on developing the protégé's capability and facilitating the protégé's learning. It consists of a trusted person acting as a sounding board, encouraging a range of perspectives and providing the benefits of their own experience.

Early research on mentoring attempted to lay a foundation of knowledge about what mentors do and clarify the mentoring relationship. Kram (1985) overtook one of the earliest studies on mentoring and developed the "two factor" mentoring theory, identifying two key dimensions whereby mentors contribute to protégé development: career development (e.g. job skills, information sharing, and feedback) and psychosocial factors (self-esteem, confidence, and emotional support). In 1992, Scandura studies the relationship between the two dimensions and the career mobility outcomes of protégé and found that career mentoring was significantly and positively associated to managers' promotion rates, and psychosocial support was significantly and positively related to managers' salary levels. Allen, Russell, and Maetzke (1997) introduced a new measurement factor - protégés' satisfaction with a formal peer mentoring program and their resulting willingness to mentor others in the future. In addition to measuring career support and psychosocial support; their study also measured protégés' time with mentors, satisfaction with mentors, satisfaction with previous mentors, and willingness 
to mentor in the future. Their results showed the significance of goodness of fit (i.e. quality of the relationship) and demonstrated that the degree of career and psychosocial functions positively correlated with the protégé's overall satisfaction with the mentoring relationship. Results also showed that the amount of time spent with the mentor was not as important as the goodness of fit. According to these results, aspiring senior leaders are likely to have a higher need for support and encouragement (psychosocial needs) than for career related needs.

According to Kram (1985), the mentor is expected to provide two important functions for the protégé: 1) advise or model career development behaviors and 2) provide personal support, especially psycho-social support. In addition to the personal mentoring relationship, mentors can also inform leadership behaviors and provide personal support to protégé by helping them to build networks. Dansky (1996) notes that networks increase the protégés exposure and visibility to other networks outside of the protégé's organization, thus facilitating their knowledge and growth.

The mentor can also receive a myriad of potential benefits from the relationship, including access to information and networks, social feedback, assistance with job performance, personal satisfaction and fulfillment from teaching a protégé, recognition and respect from others, and career satisfaction (Mullen \& Noe, 1999; Allen, Poteet, \& Burrough, 1997; Busch, 1985; Kram, 1985; Johnson, Yust, \& Fritchie, 2001).

Mentoring, whether formal or informal, results in stronger job satisfaction outcomes and is critical to meeting organizational challenges, particularly turnover 
(DeLong, Gabarro, and Lees, 2008). Inzer and Crawford (2005) distinguished between informal and formal mentoring, noting that informal mentoring occurs in a relationship between two people where "one gains insight, knowledge, wisdom friendship, and support from the other" (p. 35). Informal mentoring occurs naturally as individual selectively come together through personal or professional friendships. These relationships are usually long-term and can be initiated by either the mentor or the protégé (Chao, Walz, and Gardner, 1992).

In contrast to informal mentoring, formal mentoring depends on the recruitment and training of select mentors that participate in a program (Ragins \& Cotton, 1999). In many cases, these mentors are matched to the protégés (either by designation or by selection of the protégé) so that they provide effective levels of mentoring to their assigned protégés over a specific period of time (Weinberg \& Lankau, 2011). As a result, the success of the formal mentoring programs depend, in part, on the motivation, knowledge, and abilities of the individuals that fulfill the roles of mentors in the program (Wanberg, Welsh \& Hezlett, 2003).

Mentors are critical to helping mentees to cultivate and leverage peer relationships, align their goal and activities with those of the organization and across boundaries, and foster internal and external collaborations (McGonagill and Reinelt, 2011). For this reason, training is also important for mentors, even those who are experienced. Tsen, Borus, Nadelson, Seely, Haas, and Fuhlbrigge (2012) showed that even experienced mentors widely desire mentor development training and that this 
need or desire is significantly underappreciated by the administration. Nakanjako et al. (2011) also found that mentors needed support in terms of training in mentoring skills and logistical/financial support to carry out successful mentorship.

Effective mentoring involves a dyadic relationship, tailored to the individual needs of the protégé, and established through person-to-person communication. To optimize the formal mentoring relationship, Bozeman and Feeney (2008) note three conditions that should exist for both the mentor and protégé: "the mentor has the knowledge preferred by the protégé, there is a value for transmitting that knowledge, and the mentor does so effectively to a protégé who has the capability to understand the knowledge transmitted and the learning skills to fully expropriate the knowledge being transmitted" (p. 473). Again, the role of the mentor is highlighted.

Bozeman and Feeney (2008) argue that the term formal mentoring is an oxymoron. Specifically, they note that although organizations may have a formal mentoring program to connect a mentor to a protege, these mentoring relationships do not develop on command. Moreover, Bozeman and Feeney (2008) assert that all mentoring relationships are not transformational, or clearly able to assist the protégé in changing their behavior or elevating their performance. This can be due to several reasons, including mentors not being trained, mentees not being open to learning and developing, bad goodness of fit, or a host of other reasons that the formal mentoring relationship is not optimal. Eby and Allen (2002) concluded that relationships based on formal program assignment, without consideration for goodness of fit, can lead to more 
negative experiences, higher turnover, and stress. As a result, it is important for formal mentorship programs to consider goodness of fit when matching mentors and protégés.

Goodness of fit is defined as the degree to which both the mentor's and the protégé's preferences are met in the mentoring relationship (Bozeman \& Feeney, 2008). Specific to the protégé, a good fit enables the mentor to expand the mentorship to areas that the mentor identifies as important to the protégé's professional development. Recognizing that some of the preferences of the mentor and the protégé will diverge or conflict, an optimal goodness of fit will accommodate for those conflicts and enable the mentor and protégé to adjust to the changing relationship.

Interesting to note, all mentoring relationships do not evolve into positive mentoring experiences, characterized by high levels of career and psychosocial support (Higgins, 2001). This is because some mentoring relationships involve individuals who have conflicting career stage needs (e.g. the protégé is ready to move on to greater responsibility and autonomy while the mentor may not feel the individual is ready) (Kram, 1985). In these or other cases, dysfunctional relationships and negative protégé experiences may result from dissimilar beliefs and attitudes (Eby, McManus, Simon, \& Russell, 2000).

In 1998, Scandura explored the "dark side" of mentoring and noted negative behaviors (e.g. harassment, deception, and sabotage) that could result in unhealthy mentoring relationships. Lin, Huang, Chen, and Huang (2017) identified pseudo transformational leadership attitudes and behaviors such as an over-dependence on, 
unconditional loyalty to, and a fear of their supervisors, which may discourage protégé from proactively working towards the company's long-term interests. These attitudes may occur when mentors model large egos (Price, 2003) or consistently demonstrate self-serving behaviors (Barling et al., 2008; Christie et al., 2011; and Schuh et al., 2013). Another factor important to the success of a formal mentoring program is how much time the mentor spends with the mentee. Baugh and Fagenson-Eland (2008) highlight frequency of meetings between mentors and protégés as an important factor in the protégés development and posits that communication frequency is positively correlated with positive results in formal programs. Despite this finding, much of the mentoring literature does not examine how formal mentoring relationships occurs or evolve over time.

Ragins (1997) examined diversity and power within mentoring relationships and showed that gender and race were also important to consider when examining formal mentorship programs. Ragins (1997) defined diverse mentoring relationships as those that have mentors and protégé that "differ on the basis of race, ethnicity, gender, sexual orientation, class, religion, disability, or other group memberships associated with power in organization" (p. 24).

Despite the importance of mentoring for all individuals, it has been purported that mentoring can be particularly critical for ethnic minorities and women endeavoring to overcome barriers to advancement (Kram, 1985). According to Thomas and Gabarro (1999), both women and minorities hold few senior level positions in organizations. 
Those that do "break through" to more senior roles face different obstacles and challenges than their White, male counterparts (Thomas \&Gabarro, 1999; Fox \& Schuhmann, 2001). Kosoko-Lasaki, Sonnino, and Voytko (2006) noted that providing guidance across differences in sex, race, and age are considered some of the most uncomfortable scenarios. As a result, it is important to also examine the diversity of participants in the VHA Mentor Coach Program and to consider its impact on goodness of fit.

Collins (2001) studied "great companies" and what makes great leadership and organizations. He wrote about building lasting organizational greatness and stated that truly great organizations prosper through multiple generations of leaders, as opposed to an organization built around a single great leader, great idea, or specific program. Wong and Modrow (2004) posit the intent of a LDP is "to build critical capacities and to achieve organizational needs" (p. 7). Accordingly, mentoring programs are a way to achieve transformative outcomes and establish generations of knowledgeable, welltrained leaders in public organizations. 


\section{Theoretical Analysis}

There are several theories that provide a foundational framework for this research. The first is Complexity Leadership Theory (CLT). CLT describes how leadership occurs in complex adaptive systems (CAS), or "neural-like networks of agents" with multiple, overlapping hierarchies that are bonded in a cooperative dynamic by a common goal (Uhl-Bien, Marion, \& McKelvey, 2007, p. 299). CAS are linked to one another in a dynamic, interactive network. To operate effectively and lead in this network requires that administrators and public leaders adopt the necessary conceptual skills to manage complex, wicked problems and to help generate the cultural clarity and consistency among members that enhances the organization's performance (Torfing, 2012; Head, 2008; O’Reilly, 1989; and Kotter \&Heskett, 1992).

The Complexity Leadership perspective requires that we distinguish between leader development and leadership development. Defined as "the expansion of a person's capacity to be effective in leadership roles and processes" (Van Velsor and McCauley (2004) p. 2), leader development implies that personal development is what improves leader effectiveness, and that individual-based knowledge, skills and competencies are most relevant (Day, 2001). In contrast, leadership development is defined as expanding the collective capacity of organizational members to engage effectively in leadership roles and processes (Van Velsor and McCauley, 2004). Day (2001) further distinguishes leadership development as a process, oriented toward developing individual leaders' abilities associated with their formal role. 
The distinction between leader development and leadership development "is the orientation toward developing either human capital (leader development) or social capital (leadership development)" (Popper, 2005, p. 62). Olivares, Peterson, and Hess (2007) argue that, "although individual-based leader development is necessary for leadership, it is not sufficient. Leadership requires that individual development is integrated and understood in the context of others, social systems, and organizational strategies, missions, and goals" (p. 79). Ideally, organizations would link both leader and leadership development such that the development of leadership transcends but does not replace the development of individual leaders (Day, 2001).

According to the complexity science, leadership is defined as "an emergent event or an outcome of relational interactions among agents (Bradbury and Lichtenstein, 2000). Specific to this definition, complexity leadership theory investigates the role of leadership in expediting those processes in organizations through which interdependent actions among many individuals combine into collective organizational goals and objectives (Drath, 2001; Meyer et al., 2005). CLT prioritizes leadership behaviors that enable organizational effectiveness and broadens the conceptualizations of leadership to include processes for managing change in matrix organizations (Meyer et al., 2005). To operate effectively in these dynamic systems, it is important that aspiring leaders are able to demonstrate proficiency in working with people (human skills) and managing change. 
In complex organizations, leadership often occurs in groups or team charged with accomplishing specific goals and objectives that are aligned with organizational vision. Within these teams, leaders must be able to manage change, or minimize the disruptions necessary to maintain a change effort (Kotter, 2011). In addition, leaders must be able to lead change, which requires that the leader establishes vision and identify necessary process improvements that drive large-scale transformation. Leaders must ensure the align of these processes with the organization's goals and objectives. To do this requires that the leader has conceptual leadership skills, which are often acquired slowly through experience or trial-and-error, or more quickly through formal mentoring relationships.

CLT is applicable to my study of public organizations because it details how hierarchical organizations seek to foster CAS dynamics while simultaneously enabling control structures for coordinating formal organizations and producing outcomes appropriate to the vision and mission of the organization. This theory is consistent with VHA's approach of using formal mentorship programs to develop protégé and their understanding of the social systems that foster organizational creativity, learning, and adaptability while subsequently operating effectively in national, regional, and local hierarchical environments.

Operating in complex adaptive systems characterized by substantial and often unpredictable technological, political, and economic change requires that leaders are transformational (Uhl-Bien, Marion, McKelvey, 2007). In today's dynamic environments, 
leaders are challenged to recognize butterfly wings (Gleick, 1987), black swans (Taleb, 2007), or other highly improbable, unpredictable, and unexpected events. These events are linked to one another in dynamic, interactive networks (CAS) that can have a huge impact on an organization and its ability to respond swiftly and effectively with agility, or the "judicious mix of stability and reconfigurability" (Dyer, 2001, p. 4). Leading in this environment requires continuous learning, flexibility, creativity, and adaptability.

According to Burns (1978), there are two main types of leaders in organizations: Transactional and Transformational Leadership. In transactional leadership, leaders view the relationship between leader and follower an as exchange process through which each receives something of value (Bass \& Avolio, 1993). According to these principles, good leaders facilitate transactions that are essential to the organization. Transactional leaders may offer positive reinforcement, praise, compliments, or rewards when goals are received or may use punishment when errors are made. In comparison, transformational leaders create and manage change by focusing on three key areas: culture, processes, and environment. Specific to culture, transformational leaders appreciate diversity and embrace the "whole-soul" person. As agents of change, transformational leaders conduct environmental scanning to evaluating processes and identify opportunities for improvement. To create change, they work collaboratively with key stakeholders, operating across jurisdictions in complex adaptive systems where building trust and empowering employees are essential (Hurst, 1995). 
Transformational leaders raise their followers' levels of consciousness and get them to transcend their own self-interests and address higher-level needs (Bass, 1985). Transformational leadership is not counter to transactional leadership, rather, it progresses transactional behaviors to also demonstrate concern for the "emotions, values, ethics, standards, and long-term goals [of the followers] and includes assessing followers' motives, satisfying their needs, and treating them as full human beings" (Northouse, 2007, p. 175). Transformational leaders create and inspire a shared vision for a group (e.g., Avolio, 1999; Kouzes \& Posner, 2003).

According to Bass \& Riggio (2006), there are four components to transformational leadership:

- Idealized Influence (II) - the leader serves as an ideal role model for followers; the leader "walks the talk," and is admired for their charisma and their ethical and moral orientation.

- Inspirational Motivation (IM) - the leader inspires, motivates, and calls out followers to reach ambitious goals, communication confidence in followers.

- Individualized Consideration (IC) - the leader demonstrates genuine concern for the needs and feelings of followers. This personal attention to each follower is a key element in bringing out their very best efforts and helps them grow beyond their expectations.

- Intellectual Stimulation (IS) - the leader challenges followers to be innovative and creative by challenging followers to question the status quo, challenge assumptions, and examine challenges with new lenses.

Each of these components are important to meet the human needs and promote the sustainable development of follower skills and behaviors. Transformational leaders are expected to impact followers' behavior by 'lifting ordinary people to extraordinary 
heights" (Boal \& Bryson,1988, p. 11). They utilize human skills to stimulate and challenge followers to perform beyond the levels of expectation (Yukl, 1989; Bass, 1985) and align the objectives and goals of individual followers and the larger organization (Bass \& Riggio, 2006, p. 3). This stimulates the organizational citizenship behavior (Podsakoff, MacKenzie, Moorman, \& Fetter, 1990), and enhances the quality and quantity of follower performance (Boerner, Eisenbeiss, \&Griesser, 2007).

Transformational leadership occurs in the face of adaptive challenges not just technical problems. Adaptive challenges are problems that require new learning, innovation, and new patterns of behavior (Heifetz \& Laurie, 2001). They are different from technical problems, which can be solved with knowledge and procedures already in hand (Parks, 2005). To resolve adaptive challenges require that leaders work together to think through and work with ideas and concepts (conceptual skills). Research has also shown a positive relation between transformational leadership and an employee' attitudes and behaviors (e.g. job satisfaction and performance) (DeGroot, Kiker \& Cross, 2000; Judge \& Piccolo, 2004), as well as organizational performance (Elenkov, 2002).This result has held for different organizational contexts and for different success criteria, including group performance (Dvir, Eden, Avolio, \& Shamir, 2002; Pillai \& Williams, 2004), project success in R\&D departments (Keller, 1992), and innovation (Howell \& Hall-Merenda, 1999; Shin \& Zhou, 2003). Transformational leaders help change attitudes to embrace teamwork and increase psychological safety in the workplace. 
Another theory important to my theoretical framework is the Social Learning Theory (SLT) by Bandura (1977). Bandura's SLT or "observational learning" highlights that the observation of others (imitation as a modeling behavior) can help individuals learn from example. Through observation and imitation, protégés may strengthen their own skills" (Lankau \& Scandura, 2002, p. 787). The extent to which the behaviors are imitated is determined in large part by the "characteristics of the models, the behavior observed, and the observed consequences of the behavior" (Akers and Sellers, 2004: 88). Additionally, imitation has also been found to be "more important in the initial acquisition and performance of novel behavior than in its maintenance or cessation of behavioral patterns once established" (Akers and Sellers, 2004: 89).

According to Bandura (1986), individuals eliminate needless errors by observing others and then thinking about their actions before performing them. Through the process of informative learning, modeling behaviors assist the individual's learning through exposure to guides (Black and Earnest, 2009). Bandura (1986) found that individuals change because the skills needed to be effective in their efforts to bring about change were demonstrated. According to Bandura (1986), "through modeling, we can transmit skills, attitudes, values, and emotional proclivities" (p. 5). He also noted that empowering people with creative mechanisms gave them the confidence to exercise influence in other areas of their life. Thus, individuals were empowered with the ability to exercise influence in areas of their lives through social experience and 
modeling. This modeling helps an individual develop the belief that they can accomplish what someone else has accomplished (McGowan, 1986).

Bass, Waldman, Avolio, and Bebb (1987) showed how, according to the Social Learning Theory, lower level supervisors and managers engage in role-modeling processes whereby they mimic and display the positive behaviors of higher-level managers or executives. Further studies linked intrinsic motivation with creativity citing that the more intrinsic motivation an employee has towards his job, the more he/she is likely to challenge the status quo, come up with novel and useful ideas, and adhere to innovative goals in the face of challenges, thereby becoming more creative (Grant \& Berry, 2011; Deci \& Ryan, 2008; and Zhou \& George, 2001). The SLT explains how the behaviors of the mentor can positively affect those of the developing leader.

Wiseman and McKeown (2010) found that the biggest differences between "multiplier," or those that build their team's skills quickly and "diminishers," those that interfere with their team's performance was the feedback from the mentor. Their findings showed that good feedback from a mentor can accelerate skill development and lead to transformative skills and behaviors, and poor feedback can and will interfere with it (Wiseman and McKeown, 2010) For this reason, organizations should be selective when choosing mentors for these programs and clearly articulate to them their role and relationship expectations.

Public administrators, frontline supervisors, mid-level managers, and CEOs need different technical, human, and conceptual skills to be successful (Katz, 1955). 
According to Katz's Three-Skill Approach, technical skill, or proficiency is based on specific knowledge in a particular area of work. To have technical skills mean that the leader is knowledgeable about the activities specific to their organization, its rules and standard operating procedures, and the organization's products and services (Yukl, 2006). Technical skills are most important at lower supervisory levels of management, less important for middle managers, and least important for top managers such as senior public administrators and Chief Executive Officers.

In contrast to technical skills, human (or interpersonal) skills demonstrate proficiency in working with people. Human skills are based on a leader's knowledge of people, how they behave, and how they operate in groups. Human skills guide how to communicate effectively with diverse populations in complex adaptive system and consider their motives, attitudes, and feelings (Yukl, 2006). These skills enable a leader to influence team or group members to work together to accomplish organizational goals and objectives. Human skill proficiency means that leaders are emotionally intelligent and know their thoughts on different issues, while simultaneously, remaining cognizant of the thoughts of others (Yukl, 2006). These leaders are more sensitive to the whole person and empathetic to what motivates others. They create an atmosphere of trust for their followers, and take others' needs and motivations into account when deciding what to do to achieve organizational goals. Interpersonal skills are required at all three levels of management: supervisory, middle management, and senior management (Katz, 1955; Yukl, 2006). 
Conceptual skills allow leaders to think through and work with ideas and concepts that have the ability to shape the organization in the future. Conceptual skills are most important at top management levels and include the ability to formalize a vision for the future and express those ideas through verbal and written form. Conceptual skills allow leaders to give abstract ideas meaning and to make sense of abstract ideas for their superiors, peers, and subordinates. This skill is most important for top managers, less important for middle managers, and least important for supervisory managers (Northouse, 2010).

Building on Katz's Three-Skill Model, Mumford, Zaccaro, Harding et al. (2000) introduced the Leadership Skill-Based Model, which frames leadership as the capabilities (knowledge and skills) that make effective leadership possible. The model focuses on a person's "skills and abilities that can be learned and developed" and consists of five components: competencies, individual attributes, leadership outcomes, career experiences, and environmental influences (Mumford, Zaccaro, and Harding et al., 2000, p. 23). At the heart of the model are three competencies: problem solving skills, social judgment skills, and knowledge.

Problem solving skills are a leader's creative ability to solve new and unusual, illdefined organizational problems (Mumford, Zaccaro, Harding, et al., 2000). These skills are conceptual and include the ability to be able to define, study, and solve significant complex problems. In addition to problem solving skills, effective leadership 
performance also requires social judgment skills, or the capacity to understand people and social systems (Zaccaro, Mumford, Connelly, Marks, \& Gilbert, 2000).

Social judgment skills are people or human skills that enable leaders to work within groups to solve problems and to implement and sustain the changes that lead to organizational improvement. The third aspect of competencies is knowledge, or the application and implementation of problem-solving skills in organizations. Knowledge results from having developed an assortment of information and mental models for learning and organizing data. These are high conceptual skills needed to understand complexity, deal with ambiguity, and influence performance in an organization (Zaccraro, 2001). This include planning-related skills of visioning, system perception, and emotional Intelligence (Mumford et al., 2000).

According to the model, the competencies are directly affected by the leader's individual attributes, including the leader's general and crystallized cognitive ability, motivation, and personality (Mumford, Zaccaro, Harding et al., 2000). The leader's competencies are also affected by his or her career experiences and the environment. The model postulates that "effective problem-solving and performance can be explained by the leader's basic competencies and that these competencies are in turn affected by the leader's attributes, experience, and environment" (Northouse, 2010, p. 71).

After proposing the model, Mumford and colleagues conducted several studies to investigate the propositions of the model and its components (e.g. Connelly, Gilbert, 
Zaccaro, Threlfall, Marks, \& Mumford, 2000; Mumford, Marks, Connelly, Zaccaro, \& Reiter-Palmon, 2000; Mumford, Zaccaro, Johnson, Diana, Gilbert, \& Threlfall, 2000; Mumford, Zaccaro, Connelly, \& Marks, 2000), however, no field tests of the model were performed at the time.

In 2010, Northouse modified the model to further explain key career experiences (or effectors) that impact the attributes, competencies, and outcomes of the leader (Figure 2.2). According to Northouse's model, modeling primarily impacted the individual attributes of the leader, while mentoring and training to develop leadership skills primarily affected the competencies of leader. In 2019, Flynn, Walker, \& Svyantek field tested Mumford's model and the results supported that cognitive ability predict performance, and that this relationship was fully mediated by ratings of leader skills ( $p$. 11). Interestingly, the model did not show that personality and motivation predicted the development of leader skills which then predicted performance (neither hypothesis was supported). Figure 2.1 shows Mumford's initial model and Figure 2.2 shows Northouse's model and the type of performance initiatives that affects the three parts of the Capability Model. 
Figure 2.1 Skills Model of Leadership (Mumford et al., 2000)

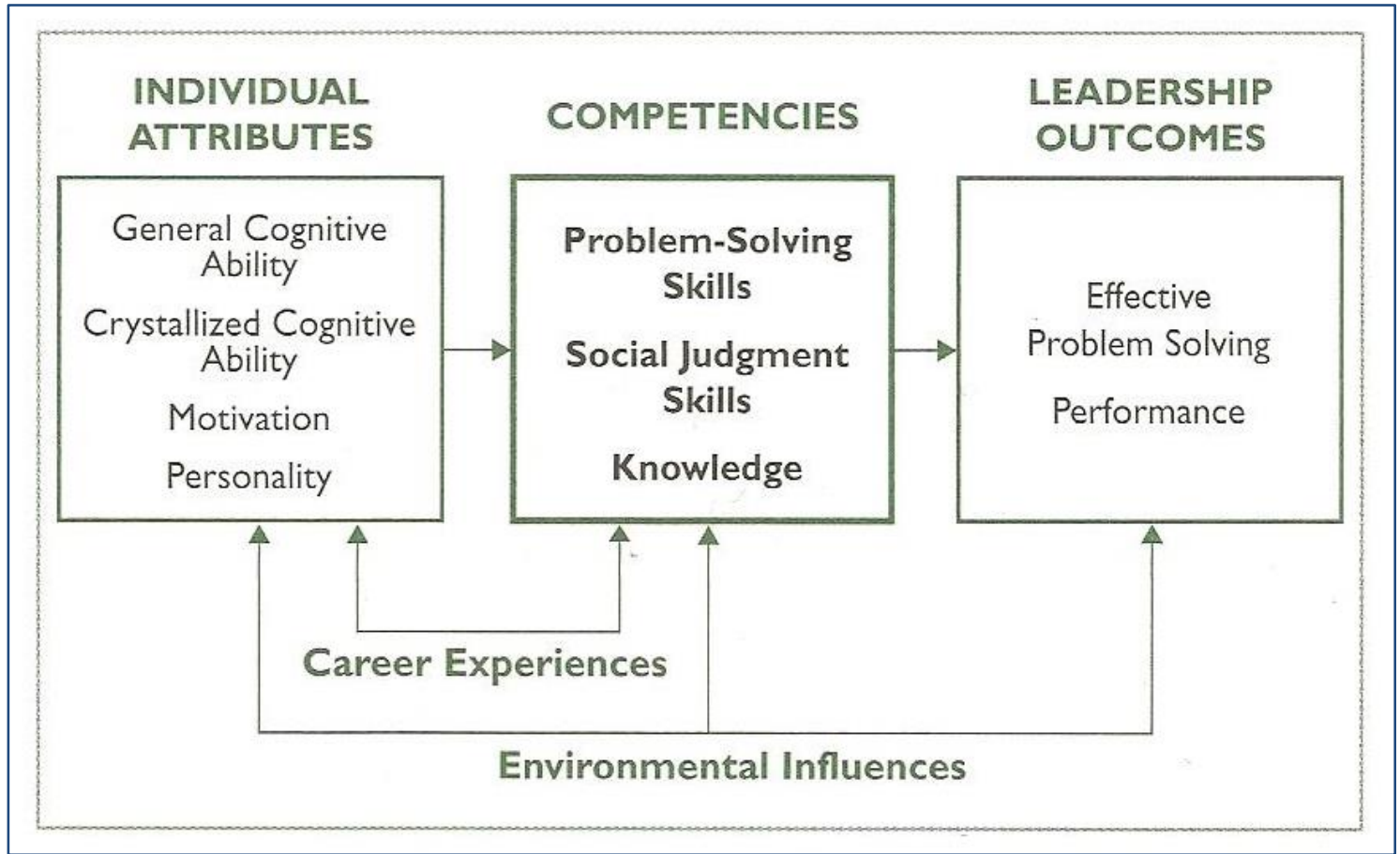

SOURCE: Adapted from “Leadership Skills for a Changing World: Solving Complex Social Problems," by M. D. Mumford, S. J. Zaccaro, F. Harding, T. Jacobs, and E. Fleishman, 2000, Leadership Quarterly, $11(1), 23$.

Figure 2.2 - Leadership Development Model

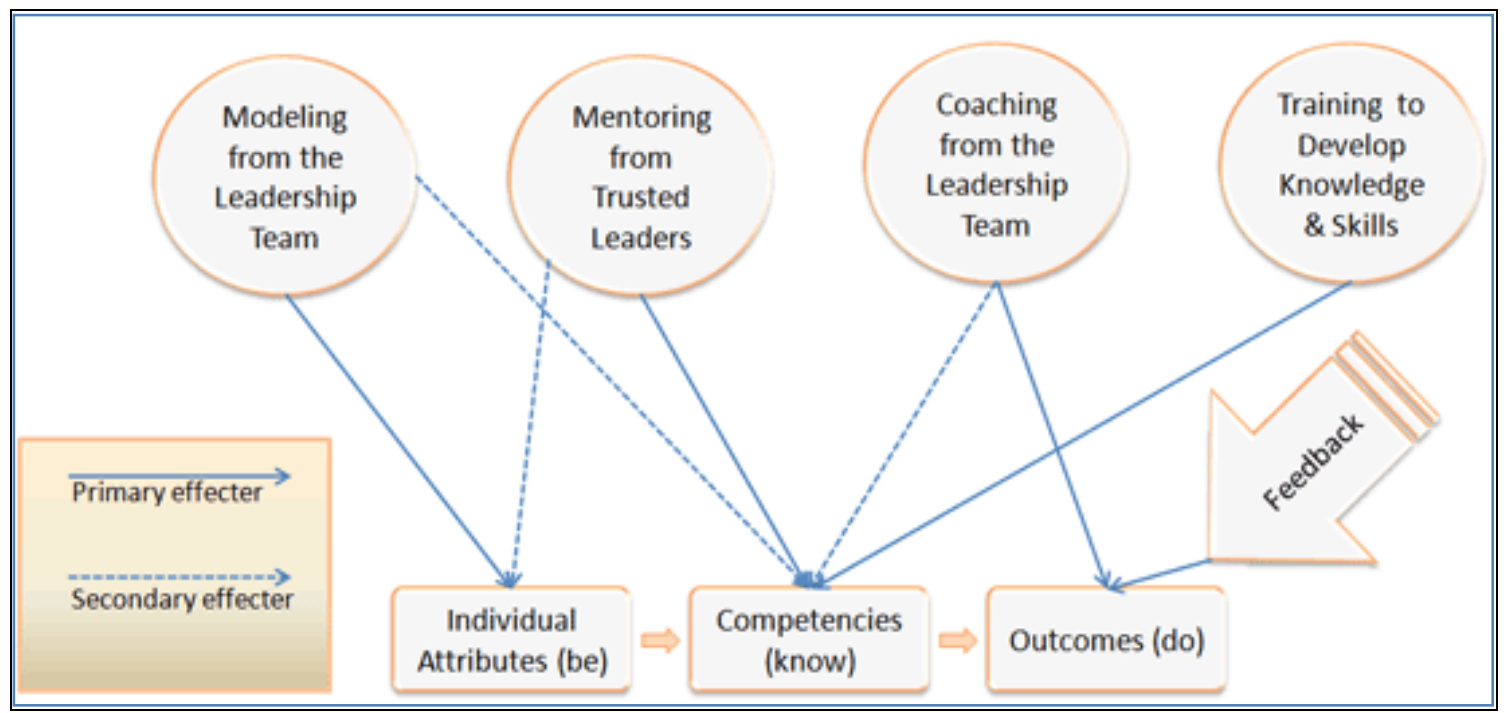

SOURCE: Clark, D.R. (2004). Leadership Development Model. Retrieved on 1/18/2020 from http://nwlink.com/ donclark/leader/leadcon.html, from Leadership: Theory and Practice. Northouse, 2004. 
According to Northouse (2004), there are five effectors on the Capability Model:

1) Modeling, which includes observational learning (Bandura, 1977) and other forms of social learning in which we learn from observing and being situated in common environments with others.

2) Mentoring, or the informal transmission of knowledge, social capital, and psychosocial support.

3) Coaching, or the individual encouragement to improve both job skills and knowledge.

4) Training/Development or learning that is provided to improve performance on the present job and helping others to acquire new horizons, technologies, or viewpoints.

5) Feedback, or the way the learner responds that reverses the direction of change. Learners act upon the world based on what they perceive and thereby change their environment and what they consequently perceive of it.

The Leadership Development Model is designed to demonstrate how the leader's attributes and competencies affect their ability to problem solve and manage change in organizations. The model introduces five effectors that impact the development of the leader's individual attributes and competencies that improve organizational performance. Per the model, mentoring from trusted leaders is a primary effector the protégé's competencies, coaching from the leadership team is a primary effector of outcomes, and modeling from the leadership team is a primary effector of individual attributes.

The model is informed by Katz's Three-Skill model which outlines the competencies most desirable for senior leaders and administrators (e.g. conceptual and 
human skills). Accordingly, the ability to problem solve, utilize social judgement skills, and understand the organizational are conceptual skills necessary for senior leaders to develop. The four Transformational Leadership characteristics further outline the leadership behaviors that senior leaders should demonstrate to effectively manage public organizations in the $21^{\text {st }}$ century. The model highlights the importance and impact that positive, transformational mentors (specifically through the process of observational learning and imitation) can have on the development of individual attributes and competencies that improve organizational performance. Finally, Bass \& Riggio (2006) define four characteristics of transformational leadership that are critical to develop in leaders/administrators responsible for managing public organizations in the $21^{\text {st }}$ century. 


\section{CHAPTER III: RESEARCH DESIGN}

"Design is not just what it looks like and feels like.

Design is how it works." - Steve Jobs

In the previous chapters, the researcher defined the leadership challenges and opportunities facing public organizations, documented the impact of transformational leadership on organizational performance and protégé behavior, and conducted a review of the literature to clarify what we know about leadership development and mentorship in public organizations. During the literature review, the Leadership SkillBased model was introduced as a framework to understand leadership development in public organizations and to illustrate that leader skills and competencies can be learned during formal mentoring programs, and that they affect the ability of the individual to problem solve and manage change in organizations. In this chapter, the researcher provides the design overview, the study setting, and the methods used to collect, measure, and analyze study data to answer the research question.

\section{Purpose}

Sellitz, Johoda, Deutsch, and Cook (1966) suggested that for any research to be purposeful, it should discover answers to the research questions. The purpose of this study is to better understand the influence that senior leader-mentors in the VA system 
have on the development of protégé (front-line and middle managers/leaders) skills and behaviors. To investigate the problem, the following research questions were analyzed:

1. To what extent do mentees perceive their mentors to be transformational leaders as defined in the literature?

2. What transformational characteristics of the mentors are most important to the mentee's growth of leadership capabilities, as perceived by the mentee? Does this perception vary depending on the goodness of fit, time with mentor, and gender and race of mentee and mentor?

3. How does this perception relate to mentees appraisal of their willingness to become mentors in the VISN LEAD program?

This study contains two parts. Part I focuses on understanding the environmental and structural components of the leadership development program, the similarities and differences among the programs, and the degree to which they are similar or dissimilar. Part I utilizes semi-structured interviews with each of the regional (VISN) program managers to gain a comprehensive understanding of each program and its components. Findings from the comparative analysis in Part I provide a setting for Part II and assisted in understanding the degree to which each program was similar or different.

Part II focuses on the specific research questions and uses a cross-sectional survey methodology that included both correlation and regression design. The purpose of the design is to determine if mentors participating in the formal leadership development program possess four characteristics/behaviors attributed to transformational leaders: Inspirational Motivation, Idealized Influence, Individualized Consideration, and Intellectual Stimulation. The design is also used to assess the 
relationship between the mentor's demonstration of those leadership behaviors and the presence of human skills, conceptual skills, and similar transformational leadership characteristics/behaviors in the mentee.

\section{Design Overview}

The Leadership Skill-Based Model (Northouse, 2010) identified that the organizational environment could have an impact on leadership development. Hershey, Blanchard, Johnson (2007) further noted that the organizational environment included the organizational structure, technology, and external forces. Part I utilized semistructured interviews with VISN LEAD Program Managers to identify and examine factors of the organizational environment and structure to determine how consistently they were present across the VISN programs.

Each of the VISN Program Managers had similar position descriptions and responsibilities to support the execution of the program across the 8-10 facilities in their region. Each VISN was given the LEAD criteria as a foundation and was instructed to build a program to develop leaders in their regional areas. Accordingly, these programs may share common structural similarities, to include: program structure, oversight, and clear and specific organizational goals necessary to support effective leadership development. The comparative analysis of data obtained in Part I will provide context for assessing the regression findings in Part II and determining if there are programmatic attributes that might relate to the research findings. Findings from Part I may also 
suggest which program elements should be included as foundational for public organizations seeking to develop transformational leaders and provide ideas for how organizations could improve leadership development programs.

Part II focused more specifically on the transformational characteristics of the mentor and examined how they related to the development of skills and behaviors in the protégé. It also assessed how that translation related to the mentee's personal characteristics and the "fit" characteristics of the mentor/mentee relationship. Finally, Part II examined if the mentor's characteristics impacted the protégé's willingness to become a certified mentor. The four transformational characteristics reviewed were Idealized Influence (II), Inspirational Motivation (IM), Individualized Consideration (IC), and Intellectual Stimulation (IM), as defined in Chapter 2.

Data was collected from leaders that participated in the VISN leadership development programs to examine and determine if their mentor exhibited each T.L. behavior and what impact (if any) they had on the protégé's development of human skills, conceptual skills, and subsequent demonstration of T.L. behaviors. The researcher also considered if goodness of fit, time with the mentor, gender, and race had an impact on this relationship. Part II provided direct quantitative data to make assessments and better understand how transformational leaders are developed. The procedures that were utilized to collect this data are further detailed in this chapter. 


\section{Study Setting: VHA VISN LEAD Program}

Within the VA, the Veterans Health Administration (VHA) is the component responsible for providing health care and medical assistance programs. The VHA is divided into 18 regional systems of care called Veterans Integrated Service Networks (VISN). Through VISNs, the VHA operates the largest integrated health care system consisting of over 1,700 hospitals, clinics, community living centers, Vet Centers, domiciliaries, readjustment counseling centers, and other facilities. Together these health care facilities and the more than 53,000 independent licensed health care practitioners who work within them provide comprehensive care to more than nine million enrolled Veterans each year (www.va.gov). VISNs were formed to decentralize VHA's bureaucracy, eliminate gratuitous layers of administration, and to promote decision making closer to the point of care at the medical centers and clinics.

Figure 3.1 - Veterans Integrated Service Networks (VISN)

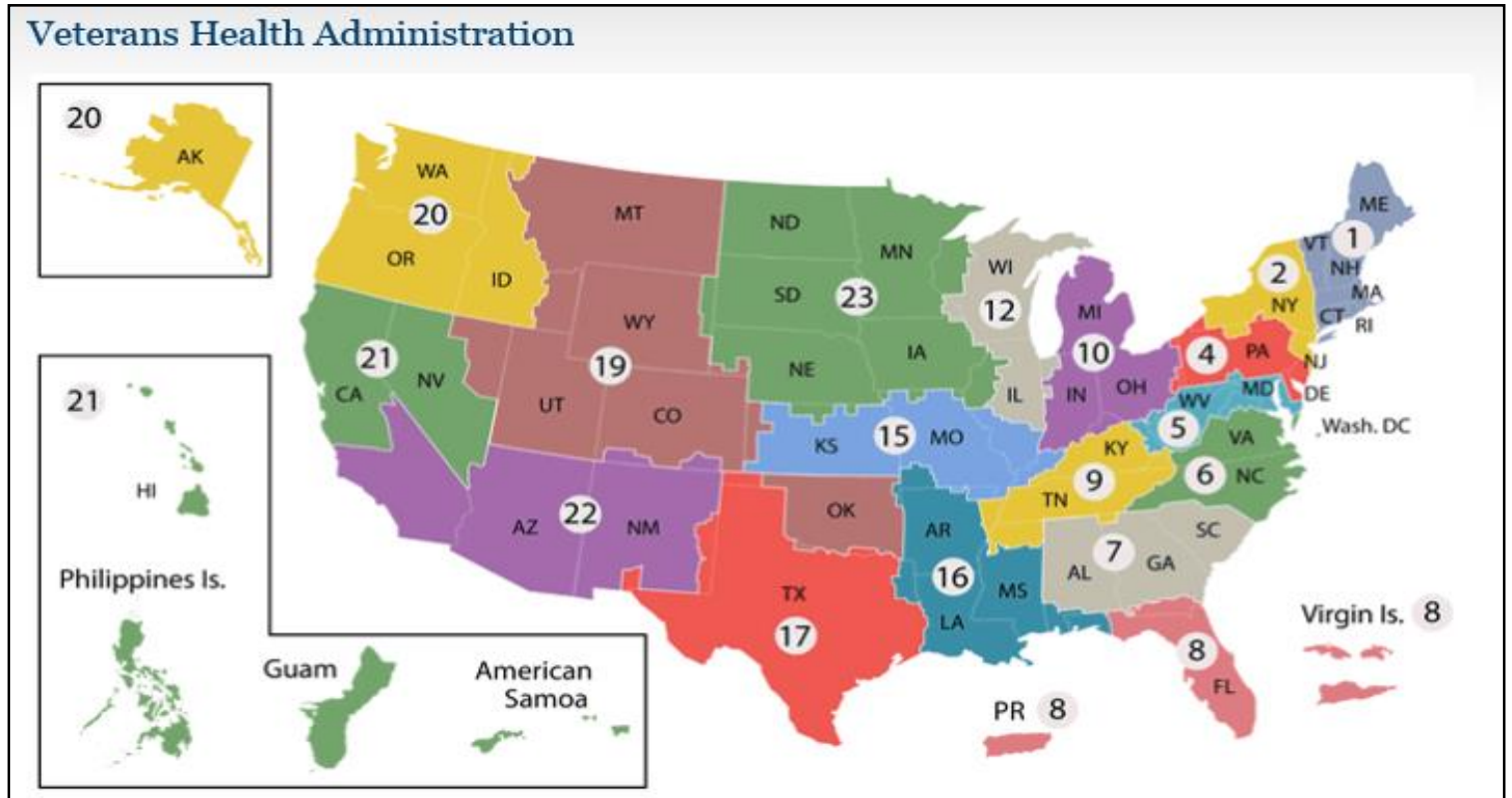


Each VISN endeavors to works with the organizations in their region to assist them in providing safe, effective, efficient, and accessible care to the Veterans. Over the years, some VISNs have merged to create new, combined networks. For example, VISN 13 and VISN 14 were merged to create VISN 23.

In 1997, VA Central Office mandated that each VISN develop a LDP to train middle managers and facilitate their development into future senior leaders. Accordingly, each VISN established a LEAD program to introduce participants to healthcare leadership and teamwork concepts using classroom instruction and practical exercises. Each program included a mandatory, formal mentoring component to ensure that participants received guidance and coaching from a senior leader within the organization.

The VISN LEAD program was part of an overall four-tiered leadership development strategy that outlined a process for developing leaders at every level. The tiers were based upon the federal government pay scale, or General Schedule (GS), and the paygrade of their job. Generally, as an individual's paygrade increases, so does their level of competency, responsibility, and job complexity.

- Tier I - Facility LEAD Program. At the facility level, the program is administered within the specific VA medical center and is aimed at developing entry-level, non-supervisory employees at GS levels 7-11. This program is usually a pre-requisite for Tier II and focuses on providing the knowledge and skills required to manage oneself, and prepare to plan, coordinate, and perform as a Team Leader. One example is the LEAD PATHWAYS program which lasts for four-months and includes in-person classroom instruction that is reinforced through team projects \& peer-topeer collaborations. Participants are encouraged to identify a mentor during the program. 
- Tier II - VISN LEAD Program. At the VISN level, the LEAD program consists of selected leaders (usually 2-5) from each VAMC that travel to a location within the VISN to participate in regional training. The program is aimed at developing middle managers (GS 11-14) and preparing them for executivelevel responsibilities. One example is the VISN 20 Executive Leadership Development Program, a two-year VISN-wide program. During the program, participants engage in a 1:1 mentoring experience with a senior leader in the VISN. Participants also receive didactic content in key leadership competencies. The capstone of the program is a network-level, group project where participants demonstrate their systems thinking, systems redesign, organizational stewardship competencies, project management, presentation skills, and their ability to work in teams.

- Tier III - VHA Health Care Leadership Development Program (HCLDP). This program is intended to further develop VHA leaders by providing a framework for leaders to develop emotional intelligence competencies and build executive-level conceptual skills. This program includes a 1:1 mentor experience with a senior leader working in the field of interest; and usually occurs outside of the participants VISN and follows Tier II training. The program is focused on developing employees at GS levels 13-15.

- Tier IV - Health Care Executive Fellowship (HCEF) Program. This is a one-year program intended for those who have already completed a senior leadership development program and are interested in one of the three tracks: Associate Director, Nurse Executive, or Chief of Staff. Each participant engages in a 1:1 mentoring experience with a certified mentor and even completes a one-year detail with a senior leader.

LEAD was provided to each Veterans Integrated Service Network (VISN) to use as criteria to design their regional, VISN programs intended to provide succession planning and supply a continuous pool of highly trained leaders. LEAD outlined the competencies that each program should develop in their participants (aligned with Figure 1.1). All VISNs designed their respective program according to this criterion and these programs have become essential components of the VHA learning environment. A critical component of the LEAD programs at every level was 1:1 mentoring. Each program 
participant was encouraged or mandated to establish a formal mentor before the beginning the program. At Level II and above, these mentors were usually required to be certified as a fellow through VHA's Certified Mentor Coach Program.

In 2005, VHA implemented a formal mentoring program (the VHA Certified Mentor Coach Program) to standardize mentor and/or coach training for all persons serving in this role with VHA Succession initiatives. According to the policy (VHA Directive 2012-015), each VISN was expected to provide core apprentice level mentor coach training to perspective mentors in leadership development programs. Following the completion of the program, participants were nationally recognized as a certified resident (after 25 hours of tracked mentorship) or as a certified fellow (after completing at least 50 hours of mentoring). Currently, VHA is in the process of revamping its leadership development programs and is evaluating which program elements are most critical to ensure effective development of future leaders. 


\section{Data Collection Plan}

Two main strategies (Part I and Part II) were utilized to collect the necessary data to answer the research questions.

Part I - To collect data in Part I, a program evaluation tool developed and provided by VHA's Employee Education System (EES) was utilized to conduct semi-structured interviews with VISN LEAD Program Managers (Appendix A). EES is the official education and training organization for VHA, specializing in providing quality workforce education and training to improve outcomes in Veteran clinical care, health care operations and administration.

EES offers accredited courses and programs, in association with 17 national and two state accrediting bodies. EES utilized the program evaluation tool to track training program activity at the local level and ensure that they included training requirements necessary for accreditations. Specifically, the EES program evaluation tool identified key Program Description components aimed at understanding the scope, modality, frequency and length, location, target audience, and facilitator qualifications of the VISN program. The tool was modified for use in this research by the addition of program design questions to help identify pre-work requirements, learning methods, training components used to develop participants, and assessment tools.

Semi-structured interviews (SSI) were selected as the data collection method to allow the researcher to consistently ask the same questions to each VISN manager, while also allowing for the researcher to clarify or gain additional insight in the program 
elements. SSIs provide a simple method of better understanding the meaning of what the interviewee is saying and they are useful for getting the story behind a participant's experience (McNamara, 1999; Kvale, 1996). The semi-structured interviews consisted of open-ended questions that were based on an interview guide (EES tool), which provided a schematic presentation of topics that needed to be explored by the interviewer (DiCicco-Bloom, 2006). The open-ended questions were utilized to allow the interviewee to represent accurately and thoroughly their point of view about the program (Patton, 1990). Sixty minutes was considered a reasonable maximum length for the SSI in order to minimize fatigue for both interviewers and respondents (Adams, 2015). All the interviews lasted $45-60$ minutes.

Prior to the interview, each of the Program Managers was called to explain the study, obtain their verbal informed consent, and schedule a date and time to conduct the phone interview. If the manager was available at the time of the introductory call, a copy of the Information Sheet was sent to them, detailing the purpose of the study, and the interview was conducted. If not available, an interview date and time was scheduled, and they were sent a copy of the Information Sheet (Appendix C). On the date indicated, the respective Program Manager was contacted by the primary researcher to conduct the interview and collect descriptive information about their program according to the EES evaluation tool (Appendix A).

At the beginning of the interview, the researcher introduced himself and clarified the purpose of the interview according to the Information Sheet. Throughout the 
interview, the researcher referred to the evaluation tool to ask questions and recorded responses from the interviewees. The researcher took detailed interview notes during the interview and transferred the data from VISN Managers responses to interview questions into an Excel spreadsheet directly following the interview to ensure accuracy of the data.

The characteristics of the VISN leadership development program that were used for Part I include: scope and modality of the program, frequency and length of the program, program location, type of participants/target audience, pre-work assignments and assessments, method for selecting projects, learning methods used during the program, training components, and program assessments. Each element is explained in detail in the Measurement section of this chapter.

Care was taken to avoid fatiguing respondents by keeping all interviews within 60 minutes. Respondents were told that they could terminate the interview at any time. Eligible participants included the $18 \mathrm{VHA}$ employees designated as the manager/administrator of their VISN LEAD program. Eight managers responded (44\%) and 10 managers did not participate because they could not be reached (2), did not respond (4), were new in their position and did not have the requested knowledge (3), or refused to participate (1). Interviews were used as a more active method for collecting the desired data and they focused on better understanding the components of each program's design and other factors that affected the effectiveness of the LEAD program. Following the completion of all interviews, results were grouped into a priori 
categories that were based upon EES criteria and were most consistent with the responses. Although most data fit into the EES criteria framework, during the coding process, additional categories were identified. Content within each category was analyzed and themes/keywords were identified and captured in an Excel spreadsheet (Table 4.1) to assist in understanding the similarities and differences of VISN LEAD programs across the nation.

Part II - The purpose of Part II was to better understand the impact of the mentoring relationship from the perspective of the protégé. An electronic, online survey was utilized in Part II because it provided a fast, inexpensive way to ask multiple survey questions, collect data from a number of participants, and analyze that data to produce numerical results (Denscombe, 2010). The electronic survey allowed for participants that had completed the VISN leadership development programs to respond anonymously and to provide data that could be statistically analyzed to determine if there were relationships between the variables. They were also used because they are relatively easy to analyze (Jackson, 2011).

To construct the survey, the researcher utilized previously used survey questions obtained from the Skills Inventory (Northouse, 2013) and the Transformational Leadership Survey translated by Middlebrook and Haberkorn (2009) to capture the impact of the mentor on the protégé's ability to develop human skills, conceptual skills, 
and demonstrate TL behaviors (Table 3.1). This ensured that questions were formulated in a way that had similar meaning for each respondent (Denscombe, 2010).

One component of the survey provided to mentees contained closed-ended questions designed to easily rank the responses received utilizing a five-point Likert scale. These questions were based on the four components of transformational leadership, as translated into mentoring activities by Middlebrook and Haberkorn (2009). Their translation provided a tested method for understanding and scoring each component of transformational leadership. Results from the online survey were ultimately utilized to determine if the transformational characteristics/behaviors of the mentor had an impact on their skill development and if that relationship varied based on goodness of fit, time with mentor, and gender and race of mentee and mentor. The survey also provided information on the protégé's willingness to become a certified mentor in the VISN LEAD program.

To solicit participation, an email was sent to each VISN Program Manager requesting that they send the email to protégé that participated in the VISN LEAD program. VISN Program Managers were selected to distribute the surveys initially because they normally already had a trusted relationship with the participants, and that relationship was leveraged to increase the response rate. The email included an introduction, an explanation of the study, and a link to the confidential electronic survey (Appendix C). 
In Part II, the survey asked protégé to rate the extent to which they felt their mentors exemplified the four transformational leadership behaviors (Chapter 2) during their relationship. Utilizing the same criteria, protégé also rated their own demonstration of the transformational leadership behaviors for those they lead, as a result of the mentoring experience. The survey included a Skills Inventory section (Northouse, 2013) to assess the participant's growth in leadership competencies, according to three domains: technical, human, and conceptual. Responses were captured via a 5-point Likert scale (Appendix B) and the three domains are described below.

- Technical skills - Leader is knowledgeable about the activities specific to their role in the organization.

- Human skills - Leader demonstrates interpersonal skills/ proficiency working with people.

- Conceptual skills - Leader demonstrates proficiency working with ideas and concepts.

The survey also contained a section that asked participants to provide information about their gender, ethnicity, and certification status. Additional questions from the Transformational Leadership Survey (Middlebrook \& Haberkorn, 2009) address goodness of fit (i.e. feeling of closeness with the mentor, frequency of mentor meeting the mentee's needs, and frequency of the mentor introducing the mentee to influential people inside and outside of the organization). All this information was combined to create a comprehensive online survey via survey monkey. 
Participants were initially given three weeks to complete the online questionnaire, however, only about 25 leaders (12.5\%) responded during that time. A second email was sent out about two weeks later to all VISN Managers and participants were given another two weeks to complete the survey. Additionally, the researcher worked with the VA National LEAD Program Manager, who discussed the importance of the study on their national calls and encouraged VISN Program Managers to send the survey out to their leaders. From these efforts, an additional 45 leaders responded to the survey. Participants were given an opportunity to opt out either by email or by nonresponse. 70 of the 200 potential respondents (35\%) responded to the survey via an online link (through survey.monkey.com) and were included in the study. All data was securely stored behind a firewall during this process (per IRB guide/restrictions). The entire data collection process, including Part I and Part II took about six months.

Table 3.1

Summary of Data Collection, Source, and Research for Part I/II

\begin{tabular}{|l|c|c|}
\hline & Part I & Part II (Core) \\
\hline Data Collection & $\begin{array}{c}\text { Description of Leadership } \\
\text { Program }\end{array}$ & $\begin{array}{c}\text { Assessment of the skills and behaviors of the } \\
\text { mentor and protégé }\end{array}$ \\
\hline Source Method & $\begin{array}{c}\text { Key Semi-Structured } \\
\text { Interviews utilizing the EES } \\
\text { Eval Tool }\end{array}$ & $\begin{array}{c}\text { Electronic, Online Survey based on translated } \\
\text { TL activities (Middlebrook \& Haberkorn, 2009) } \\
\text { and the Skills Inventory (Northouse, 2013) }\end{array}$ \\
\hline Type of Research & Qualitative & Quantitative \\
\hline
\end{tabular}

The primary risk to study participants as a result of this study was the possible inconvenience of the time involved in answering questions during the interview. In Part I, some of the questions were related to the management of their program and could 
have reflected negatively on the manager. However, many of the questions were adopted from VHA's EES Program Evaluation and Data Collection plan and may have been asked by a national evaluator assessing their leadership development program. For the safety of all participants, the researcher de-identify all and interviewees. The researcher also obtained IRB approval from PSU and VA IRBs. Special focus was directed to protecting the participants by removing all identifiers from the Part II survey; and these precautions prevented the researcher from linking the data collected in Part I VISNs to Part II based on the link to the VISN. Participants were assured that they could refuse to answer any question. There were also told (via the Information Sheet) that although there would be no direct benefit to them as participants, that the information they provided could be utilized to help improve the VISN LEAD programs and the development of future leaders across the nation.

All data obtained during the study was de-identified (e.g. each VISN program was assigned a random number that was used when reporting) to include the data shared with VA Central Office and other stakeholders responsible for the overall implementation of VISN LEAD programs in VHA.

Files contained no names or other personal identifiers and other potentially identifying information (such as the site of the program) was also removed. Data was recorded on de-identified interview forms and transcribed in an Excel spreadsheet using the random identifiers. A key was kept by the researcher on a secure file, behind a VA firewall, with restricted access. 
The researcher was responsible for reviewing the interview forms and the survey monkey results to identify any issues or concerns. The researcher was also responsible for ensuring the secure maintenance and appropriate sharing of study materials as required and allowed by IRB (e.g. information requested by national Program Managers). 


\section{Methodology}

Part I - The categories established in the EES tool was also used as the framework for

the analysis.

Table 3.2

Summary of the Program Evaluation Categories, Category Elements and Definitions

\begin{tabular}{|c|c|c|}
\hline Category & Definition & Category Elements \\
\hline $\begin{array}{l}\text { Program } \\
\text { Description }\end{array}$ & $\begin{array}{l}\text { Major components that describe the } \\
\text { program's framework. }\end{array}$ & $\begin{array}{l}\text { Scope, Modality (F2F, virtual, online } \\
\text { discussion, computer-based), } \\
\text { Frequency and Length of Program, } \\
\text { Program Location, \# of Participants, } \\
\text { Target audience, pre-requisites. }\end{array}$ \\
\hline $\begin{array}{l}\text { Pre-Work } \\
\text { Assignments }\end{array}$ & $\begin{array}{l}\text { Any work assigned to the } \\
\text { participants that they are } \\
\text { responsible for completing prior to } \\
\text { the start of the training. }\end{array}$ & $\begin{array}{l}\text { Reading materials, Pre-assessment } \\
\text { tests, Readiness exercises, } \\
\text { assignments, Research, selection of } \\
\text { projects. }\end{array}$ \\
\hline Learning Methods & $\begin{array}{l}\text { Details the learning methods used } \\
\text { during the program. }\end{array}$ & $\begin{array}{l}\text { Lecture, case studies, role plays, } \\
\text { simulation, discussion, activities, } \\
\text { project assignments, action plan } \\
\text { development, PDPs. }\end{array}$ \\
\hline $\begin{array}{l}\text { Conference } \\
\text { Components }\end{array}$ & $\begin{array}{l}\text { Components of the program } \\
\text { designed to facilitate group learning } \\
\text { and relationship building. }\end{array}$ & $\begin{array}{l}\text { Breakout Sessions, Networking, } \\
\text { Mentoring. }\end{array}$ \\
\hline Assessments & $\begin{array}{l}\text { Identifies any methods used to } \\
\text { assess leader development and } \\
\text { growth during the program. }\end{array}$ & $\begin{array}{l}\text { Competency Assessments, Pre/Post } \\
\text { Tests, Skill Assessments, Team } \\
\text { Assessments. }\end{array}$ \\
\hline $\begin{array}{l}\text { Follow-Up During } \\
\text { or after Program }\end{array}$ & $\begin{array}{l}\text { Additional homework to be } \\
\text { completed between sessions or after } \\
\text { program end. }\end{array}$ & $\begin{array}{l}\text { Assignments, Action Plan } \\
\text { Completion and Reporting, Project } \\
\text { Completion, Post Assessments. }\end{array}$ \\
\hline $\begin{array}{l}\text { Most Critical } \\
\text { Needs }\end{array}$ & $\begin{array}{l}\text { Feedback from program managers } \\
\text { about critical needs essential to the } \\
\text { sustainability of the LDP. }\end{array}$ & $\mathrm{N} / \mathrm{A}$ \\
\hline
\end{tabular}

The tool was adapted for this research and served as an interview guide for the

discussions with VISN LEAD Program Managers. During the interview, the researcher described each category and definition to the participants and asked them to provide relevant information about their program. 
The researcher's questions were guided by the specific categories, definitions, and category elements that are noted above in Table 3:2. Once all interviews were conducted, the information on the spreadsheet was grouped by the category elements identified on the EES guide, except for those noted below.

Program Description Category - For the Program Description category, the responses for "Scope" were naturally grouped by the target audience employee type and the GS grades of the program participants. The "Modality" was grouped into 1) face-to-face (F2F) training, 2) virtual training, 3) online training, or 4) computer-training modules. The modality also included the number of sessions (e.g. most programs had three F2F sessions that were three weeks each). For the "Locations," most managers stated that the location of the meetings occurred at various sites within their region. "Pre-requisites" were grouped into if they required participants to complete a Facility LEAD program (e.g. LDI) and if they required approval from the executive leadership team (i.e. Approvals).

Pre-Work Assignment Category - In the Pre-Work category, the selection of projects was grouped according to how the project that they would work on during the program was assigned. Projects could be identified and assigned by: 1) the participant, 2) the mentor, 3) the MC or the medical center executive leadership team, or 4) the VISN leadership team.

Conference Component Category - The Conference Components category included "Mentoring" and how participants were assigned a mentor. Participants could 
1) identify their own mentor, 2) be assigned a senior leader, or 3) be assigned a VHA certified mentor.

Follow-Up During or After Program Category - The category was group naturally according to the type of program evaluations that occurred: 1) program evaluated participant's perception of the program following end, 2) program evaluated if participants learned key concepts presented during the program, 3) program evaluated whether participants changed behaviors when they got back to their facility based on program concepts, 4) program evaluated whether participants created results at their facility, or 5) program evaluated if facilities had a return on investment as a result of the program. Even though the questions were semi-structured, all the information fit into the categories identified on the EES guide.

Part II - Dependent variables are defined as attributes or characteristics that are "dependent on or influenced by the independent variable" (Creswell, 2005, p. 121). The dependent variables used in Part II of this study were the mentee's development of human skills, the mentee's development of conceptual skills, and the mentee's development of transformational leadership skills (Idealized Influence, Inspirational Motivation, Individualized Consideration, and Intellectual Stimulation). These variables are the outcome or consequence variables that were being observed to determine if they changed as a result of the independent variables.

Independent, or antecedent variables are the "attitudes, attributes, behaviors, and knowledge the survey is measuring" and they are used to predict or explain the 
dependent variables (Fink, 2006, p. 53). The independent variables used in this study were organized into three domains:

- Mentor's TL Characteristics - Mentor's demonstration of Idealized Influence, Inspirational Motivation, Individualized Consideration, Intellectual Stimulation.

- Mentoring Process/Goodness of Fit - Time spent with mentor, how often the mentee felt close to their mentor, mentee's perception of if the mentor met their needs and preferences, the mentor introducing the mentee to influential people inside/outside of the organization.

- Individual Mentor/Mentee Characteristics - Mentee's gender, mentor's gender, mentee's ethnicity, mentor's ethnicity, mentor's certification status, mentor's years of experience.

This studied focused on understanding if there was a relationship between the dependent variables and the Mentor's TL Characteristics and the Mentoring Process/Goodness of Fit domains. The variables in the Individual Mentor/Mentee Characteristic domain were used as control variables.

Participants completing the survey scored the transformational characteristics of their mentor and themselves based on a five-point Likert scale, where: $1=$ Not at All, $2=$ Seldom, 3 = Occasionally, 4 = Quite a Bit, and 5 = All the Time. Responses corresponding to each T.L. characteristic were totaled, and the mentor was identified to exhibit the behavior if their scores were in the "average" or "high" category, as classified by Middlebrook \& Haberkorn (2009). Two question corresponded to the T.L. characteristics Inspirational Motivation (MTLIM) and Individualized Consideration (MTLIC). As a result, the low range was $\leq 4$, the average range was $5-7$, and the high range was 8-10. Three questions corresponded to the T.L. characteristics Intellectual 
Stimulation (MTLIS) and Idealized Influence (MTLII). As a result, their low range was < 6 , the average range was $7-11$, and high range was $12-15$. The questions asked on the survey are noted in Appendix B.

The survey also contained a skills inventory section focused on measuring three broad types of leadership skills: technical, human, and conceptual. Based on a fivepoint Likert scale ( 1 = Not at All Influential, 2 = Slightly Influential, 3 = Somewhat Influential, 4 = Very Influential, or 5 = Extremely Influential), participants completed this section to determine what influence their mentor had on their skill development in that area.

To score the questionnaire, the responses specific to each leadership skill were summed, as noted below. Also included is how each was coded for in the analysis (in parentheses):

> Technical Skill Score (TLSDTechnical) $=$ Sum of responses on items 1, 4, 7, 10, 13 , and 16.

$>$ Human Skill Score (TLSDHuman) $=$ Sum of the responses on items 2, 5, 8, 11, 14, and 17.

$>$ Conceptual Skill Score (TLSDConceptual) $=$ Sum of the responses for 3, 6, 9, 12,15 , and 18.

Each item received a maximum of five points based upon the scale developed by Northouse (2013). If the summed score were between 23-30, they were considered to be in the high range; scores between 14-22 were identified as average or moderate; and score in the 6-13 range were considered to be low. Both the transformational leadership characteristics and the skills were coded ( $1=$ low, $2=$ average, and $3=$ high $)$ and used as interval measures. 
To measure time spent with the mentor, a five-point Likert scale was utilized to score participants on their response. Participants chose from the following options: 0 Hours, 1 Hour, 2 Hours, 3-4 Hours, or 5 or More Hours. A five-point Likert scale (where: $1=$ Not at All, $2=$ Seldom, $3=$ Occasionally, $4=$ Quite a Bit, and $5=$ All the Time) was also used to measure the goodness of fit domain variables. Participants scored whether their mentor's demonstrated certain characteristics they would expect to be evident when there was a good fit between the mentor and the mentee: closeness with the mentor, the mentor meeting the needs of the mentee, and the mentor introducing the mentee to influential people inside and outside of the organization.

The Individual Mentor/Mentee Characteristics domain variables were also measured as part of the study. The ethnicity of the mentor and mentee was coded as 0 = White, 1 = Black, 2 = Hispanic, 3 = Native American/American Indians; and the gender of the mentor and mentee was coded as $0=$ male, $1=$ female. To measure the mentor's certification status, participants chose from the following options: $0=$ none, $1=$ resident (apprentice), or 2 = fellow. The mentee's willingness to become a mentor (mentee's certification status) was also measured using the same scale. The mentor's years of experience was also coded as $0=<1$ years, $1=2-5$ years, $2=6-10$ years, $3=11-15$ years, $4=16+$ years. 


\section{Data Analysis}

Data analysis utilized both qualitative and quantitative methods.

Part I - In Part I, the researcher utilized data analysis to transform data from description to interpretation (Vaismoradi, Bondas, \& Turunen, 2013). Specifically, the researcher utilized the EES tool as an interview guide and applied a deductive analysis process based on the tool's pre-established categories. Connections in the data were identified and mapped to the specific categories during multiple rounds of analysis. For example, during the first round of analysis, the researcher identified the need to further breakdown the Program Description category into additional categories: Prerequisite, Location, and \# of Participants. Some of the categories were very objective (e.g. \# of Participants, Location), while other categories were more subjective and required more analysis and coding (e.g. Program Description, Assessments).

Deductive analysis processes allowed the researcher to identify additional key categories essential to his research (Charmaz, 2006). Although audio recordings of the interviews are most common (Esterberg, 2002), they were not utilized in this study to ensure the participants felt comfortable and because of the sensitivity the interviews (i.e. the researcher ensured the Program Managers that participation would not affect or be related to their performance evaluation).

Once in the coding frames, the researcher utilized affinity diagraming to group the data into themes within each category or frame (Bauer, Duffy, \& Westcott, 2006; Oakland, 2004; Tague, 2005). The affinity diagramming process simplified the analysis 
by organizing and grouping the data into their natural relationships, which helped to bring out connections among them and identify patterns (Tague, 2005). Once organized into themes, a matrix was used to display the qualitative data and present the "information systematically so the researcher could draw conclusions and take needed action" (Miles, Huberman, Saldana, 1994, pg. 108). These themes are provided in the results section (Table 4.1).

Part II - In Part II, the electronic survey responses were entered into Statistical Package for the Social Science (SPSS) version 22 for Windows. SPPS was created for the management and statistical analysis of social science data. As a statistical analysis software, SPSS was utilized in this analytical research to identifying determinant/associated factors and relationships between variables, and to also compare and explore the differences between two or more questions (Akkerlin, 2014). The data was organized based on the questions asked on the survey and missing variables were coded as missing. Descriptive statistics (e.g. frequency tables, summary statistics) were used to describe the demographic information reported on the gender, ethnicity, and certified mentorship levels of both the mentor and mentee. Descriptive statistics (e.g. frequency tables, mean, standard deviation, variance) were also conducted on: the relationship the mentee had with the mentor, the time spent with the mentor, the feeling of closeness to the mentor, the mentor's ability to meet the mentee's needs, and the frequency of introduction to influential people internally and externally. 
To investigate the research question, the following hypotheses were proposed (below). The analysis was one-tailed because the researcher hypothesized that there would be a positive effect on mentee behavior.

* To what extent do mentees perceive their mentors to be transformational leaders as defined in the literature?

a) Mentor TL Characteristics

i) Hypothesis: Mentees will perceive their mentors to possess TL characteristics as defined by the literature.

To examine Hypothesis 1, frequency tables were conducted for each of the transformational leadership (TL) characteristics/behavior as observed and perceived by the mentee (IM, IS, II, and IC). Each of the categorical variables were classified as either low $(=1)$, average $(=2)$, or high $(=3)$ in accordance with survey criteria (Middlebrook \& Haberkorn, 2009). The frequency table provided a summary of the number and percentage of cases falling into each category of the variable (McCormick \& Salcedo, 2015) and the number of mentors that rated "low" on any characteristic. Mentors were considered to possess a specific T.L. characteristics if they scored average or high on the characteristic. In order to be considered "transformational," the mentor could not score "low" for any of the characteristics. The data revealed the percentage of mentees that perceived that their mentors had exhibit TL characteristics/behaviors during the mentoring relationship. A correlation analysis was also conducted to understand if the variables were interrelated.

What transformational characteristics of the mentors are most important to the mentee's growth of leadership capabilities, as perceived by the mentee? Does 
this perception vary depending on goodness of fit, time with mentor, and gender and race of mentee and mentor?

a) Mentee's Skill Development

i) Hypothesis: Mentees that perceive their mentors as transformational ( $M$, II, IS, and IC) will be more likely to demonstrate human and conceptual skills, controlling for the Mentoring Process/Good of Fit and Individual Mentor/Mentee Characteristics variables.

b) Mentee's Behaviors

i) Hypothesis: Mentees that perceive their mentors as transformational (IM, II, IS, and IC) will be more likely to demonstrate TL behaviors, controlling for the Mentoring Process/Good of Fit and Individual Mentor/Mentee Characteristics variables.

To examine Hypothesis 2, the researcher began analysis by conducting crosstabs and correlations between the mentor's demonstration of TL and the presence of human and conceptual skills in the mentees. Specifically, the Pearson chi-square test was used to understand the relationships among the independent variables and to assess for colinearity. The test revealed very strongly associations between the variables, which prompted the researcher to conduct regression analysis for each.

Multiple linear regression analyses were utilized to test the study hypotheses. Multiple regressions are often used to: (a) predict new values for the dependent variable given the independent variables; and (b) determine how much of the variation in the dependent variable is explained by the independent variables. Multiple regression allows for a relationship to be modeled between multiple independent variables and a single dependent variable where the independents variable is being used to predict the dependent variable. 
Figure 3.2 depicts the relationship between the independent and dependent variables in Part II, related to the impact that the mentor's TL characteristics had on human skills, conceptual skills, and the mentee's TL behaviors - while controlling for the goodness of fit and individual characteristics variables. Technical skills were not evaluated because in most cases, the protégé's mastery of technical skills informed their selection as a participant in the VISN LEAD Programs. 
Figure 3.2 Relationship between the Independent and Dependent Variables (Q1/Q2)

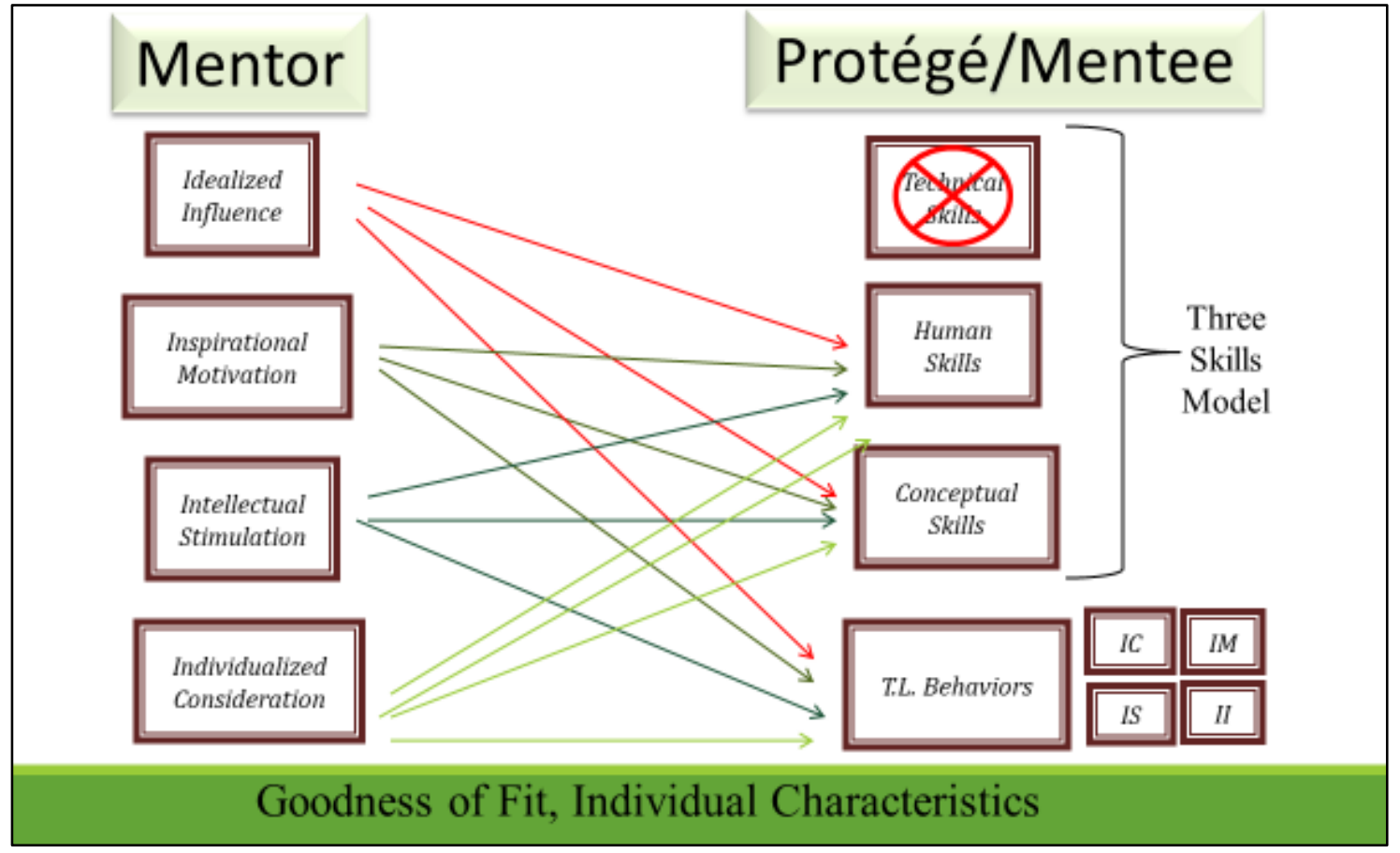

The researcher utilized multivariate ordinary least squares in SPSS to assess the relationship between the dependent and independent variables. The $\mathrm{R}$ was calculated and used to better understand the strength of the relationship. $\mathrm{R}$ (which can range from 0 to 1 ) is the "correlation between the dependent measure and the combination of the independent variables, so the closer R is to 1 , the better the fit" (McCormick \& Salcedo, 2015, p. 259).

Several of the variables required coding and dummy-coding (as noted in the measurement section). The researcher used a t statistic to determine the significance of the predictors and presented the beta coefficients to describe the linear relationship between the two variables. Before analysis, the researcher assessed the assumptions of multiple linear regression. The appropriate tests were detailed in the results to ensure 
linearity (assessed with a normal P-P plot), homoscedasticity, and a lack of multicollinearity. I used an alpha of .05 to determine significance, but also reported alpha levels at .01 and .001 .

- How does this perception relate to mentees appraisal of their willingness to become mentors in the VISN LEAD program?

a) Willingness to mentor

i) Hypothesis: Mentees that perceive their mentor as transformational will be more likely to become certified mentors (apprentice or fellow level), controlling for the Mentoring Process/Goodness of Fit and Individual Mentor/Mentee Characteristics variables.

To address hypothesis 3 , the researcher conducted a Pearson correlations analyses between the mentee's willingness to become a certified mentor and the demonstration of TL characteristics by the mentor. The test revealed associations between the variables, which prompted the researcher to conduct regression analyses to understand the relationship. Multiple regression analysis was conducted to assess whether there is a significant relationship between the mentor's TL characteristics and the mentee's willingness to become a certified mentor, controlling for the Mentoring Process/Good of Fit and Individual Mentor/Mentee Characteristics variables. Figure 3.3 shows the relationship between the independent variables on the left and the mentee's certification status on the right, while controlling for the Goodness of Fit and the Individual characteristics variables. 
Figure 3.3 Relationship between the Independent and Dependent Variables (Q3)

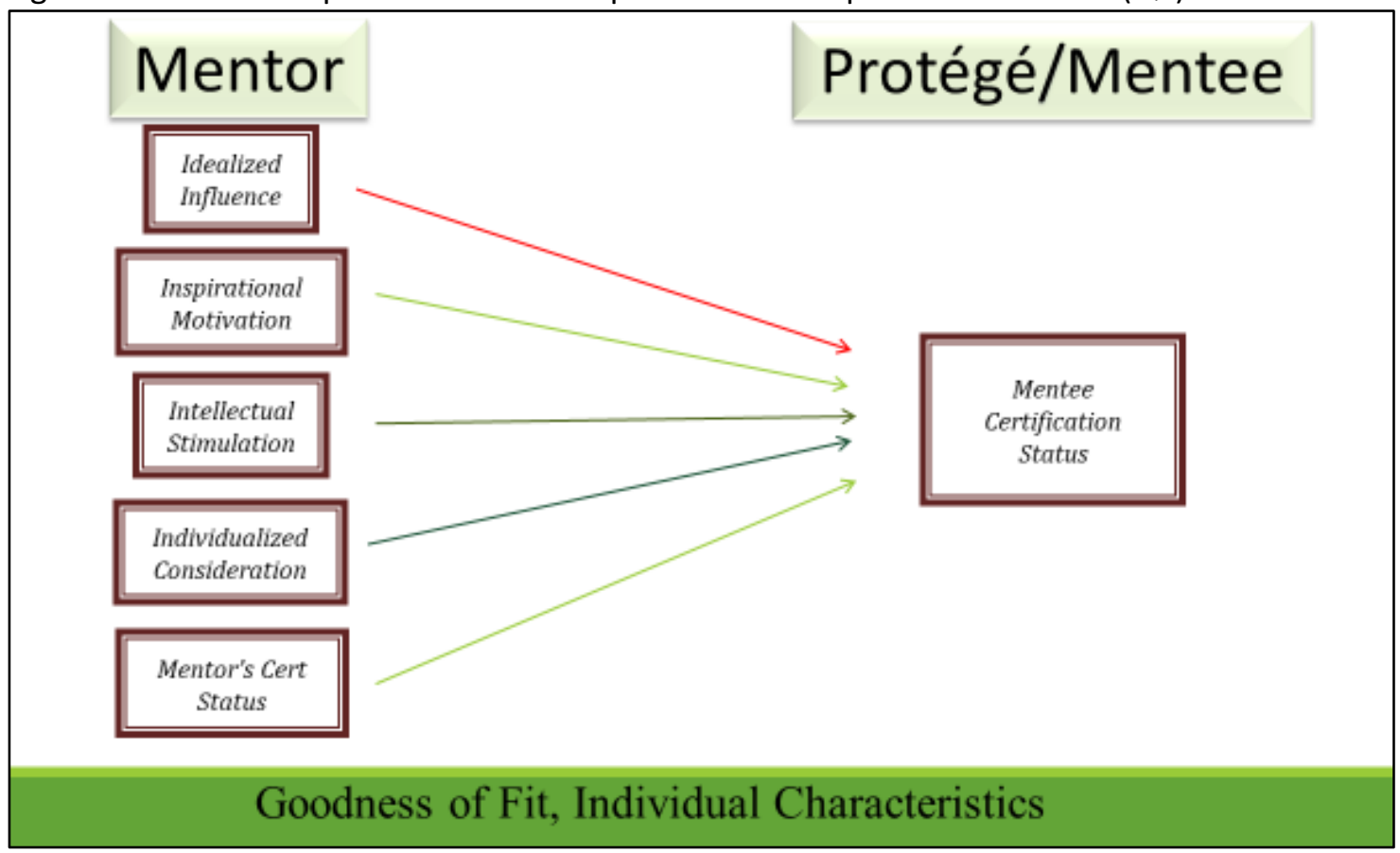




\section{Validity and Reliability}

This research was conducted with approval and in accordance with two research Institutional Review Boards associated with the VA Portland Healthcare System and Portland State University. The researcher referenced all sources of information, provided a detail of the methods utilized to conduct the study, and maintained data sources to ensure transparency. The study elements, including the informed consent process, were all conducted in accordance with the protocol and other approved study documents.

According to Cozby (2001), reliability is defined as the degree to which an assessment tool produces stable and consistent results; while validity refers to how well a test measures what it was intended to measure (Cozby, 2001). To ensure internal reliability, the researcher utilized already established measures for the transformational leadership characteristics (Middlebrook \& Haberkorn, 2009) and for the leadership skills (Northouse, 2013). To increase external reliability, the researcher focused on dyadic mentoring relationships that are consistent across multiple types of organizations (e.g. leaders are required to manage the diverse needs of the organization and pursue collective goals). For example, the Center of Creative Leadership (www.ccl.org) suggests that leaders from both public and private health systems manage similar leadership challenges and require similar leadership capabilities to manage unique challenges. Additionally, Morgan (2006) noted that these institutional forms share common boundaries when it comes to organizational theory. This consistency suggests that 
these results could reasonably be generalized to explain and predict the development of future leaders in general-purpose governments and for-profit private agencies (Davis, 2018).

Another dimension to consider related to external reliability is the makeup of VHA's LEAD Program. VHA is the largest integrated health system in the US with 18 different leadership programs spread across the nation. Each VISN shared the requirement to develop their program based on specific LEAD criteria; accordingly, the programs shared certain structural components. In addition to building their programs based on the LEAD criteria, the VISN Program Managers have also been creative and innovative in how they teach and reinforce the key criteria and program requirements. This study included participants that completed leadership development programs in different regions, with different instructors, and with varying activities to reinforce the learning objectives. Accordingly, the results of this study may be applicable to various types of organizations trying to identify optimal ways to develop future leaders.

In addition to reliability, Yin (2009) notes that three other tests are relevant to evaluate the quality of a research design: construct validity, internal validity, and external validity. Construct validity is the degree to which a test measures what it claims to be measuring. Attention to construct validity increases the likelihood of consistency between theory and the defined construct (Moon, 2007). Internal validity focuses on bias within causal studies and reflects the extent to which causal conclusions, 
based on a study, are warranted (Moon, 2007; Yin, 2009); while external validity tests whether the findings of a study are generalizable beyond the case under study. The researcher established validity by using survey instruments and evaluation tools that were tested in previous studies and deemed reliable. Additionally, previous literature validated the survey instrument and the categories used to describe the variables. The researcher also addressed validity concerns by utilizing random sampling and control variables (i.e. Individual Mentor/Mentee Characteristics) to better understand the relationship between variables. Significance values of the model/variables and reliability coefficients were also obtained (by use of the SPSS analytics tool) and reported. 


\section{Chapter IV: RESULTS}

"The achievements of an organization are the results of the combined efforts of each individual." - Vince Lombardi

\section{Report of the Findings}

The previous chapters have detailed the background, literature review, and the methodology of this doctoral study. In chapter 4, the results obtained through the detailed methodology outlined in Chapter 3 are provided. The purpose of this study was to answer the questions:

* To what extent do mentees perceive their mentors to be transformational leaders as defined in the literature?

* What transformational characteristics of the mentors are most important to the mentee's growth of leadership capabilities, as perceived by the mentee? Does this perception vary depending on time with mentor, and gender and race of mentee and mentor?

* How does this perception relate to mentees appraisal of their willingness to become mentors in the VISN LEAD program? 


\section{Overview: Part I}

The Program Managers had the same level of responsibility (about 6-8 facilities) and were responsible to implement a program based upon the national criteria.

\section{Part I Interviewee Demographics}

A summarization of the interviewee's distribution of gender, ethnicity, and experience are in Table 4.1.

Table 4.1

Interviewee Distributions for Gender, Ethnicity, and Experience

\begin{tabular}{llc}
\hline \multicolumn{2}{c}{ Characteristic } & Program Manager $(\mathrm{n}=8)$ \\
\hline Gender & Male & $3(37.5 \%)$ \\
& Female & $5(62.5 \%)$ \\
Ethnicity & White & $8(100.0 \%)$ \\
& Black & ---- \\
& Hispanic & --- \\
& Al/AN & --- \\
Years of & & \\
Experience & $3-4$ & $1(12.5 \%)$ \\
& $5-9$ & $1(12.5 \%)$ \\
& $10+$ & $5(62.5 \%)$ \\
& & $1(12.5 \%)$ \\
\hline
\end{tabular}

Note: $\mathrm{Al} / \mathrm{AN}=$ American Indian/Alaskan Native.

According to the table above, all the managers interviewed were White and most of the managers were female (62.5\%). $87.5 \%$ of the managers had more than three years of experience.

Table 4:2 shows a summary of information and themes collected during the interview. While transcribing, coding, and modifying the coding scheme, the researcher identified the need to further breakdown the Program Description into additional categories: Prerequisite, Location, and \# of Participants. The mentor assignment was 
separated from Pre-work, and Action Plan was separated from Assessments to create

additional categories.

Table 4.2 - VISN Leadership Development Program Description Matrix

\begin{tabular}{|c|c|c|c|c|c|c|c|c|}
\hline & V1801 & V1802 & V1803 & V1804 & V1805 & V1806 & V1807 & V1808 \\
\hline 1 & $\begin{array}{l}11 \mathrm{M} ; \\
\text { week-long } \\
\text { F2F (3), } \\
\text { Virtual \& } \\
\text { online } \\
\text { discussion }\end{array}$ & $\begin{array}{l}\text { 6M; week- } \\
\text { long F2F } \\
\text { (3); virtual } \\
\& \text { online } \\
\text { discussion }\end{array}$ & $\begin{array}{l}6 \mathrm{M} ; \\
\text { week-long } \\
\text { F2F (3) }\end{array}$ & $\begin{array}{l}\mathrm{MM} ; \\
\text { week- } \\
\text { long F2F } \\
(3)\end{array}$ & $\begin{array}{l}9 \mathrm{M} ; \mathrm{F} 2 \mathrm{~F} \\
(3)\end{array}$ & $\begin{array}{l}12 \mathrm{M} ; \\
\text { week- } \\
\text { long F2F } \\
\text { (3) }\end{array}$ & $\begin{array}{l}\text { 12M; 6- } \\
\text { hour F2F } \\
\text { (1/month) }\end{array}$ & $\begin{array}{l}\text { 9M; 2-day } \\
\text { F2F (3); 3- } \\
\text { day sim w/ } \\
\text { case study, } \\
\text { media } \\
\text { crisis }\end{array}$ \\
\hline 2 & $\begin{array}{l}\text { Facility } \\
\text { LEAD. 10- } \\
13 \text { (Nurse } \\
\text { Equiv). } \\
\text { Approvals. }\end{array}$ & $\begin{array}{l}\text { LDI. } \\
\text { Approvals. }\end{array}$ & $\begin{array}{l}\text { LDI. } \\
\text { Approvals. }\end{array}$ & $\begin{array}{l}\text { LDI. } \\
\text { GS11-13. } \\
\text { Approvals } \\
\text {. }\end{array}$ & $\begin{array}{l}\text { Facility } \\
\text { LEAD. } \\
\text { GS12-15. } \\
\text { Approvals } \\
\text {. }\end{array}$ & $\begin{array}{l}\text { GS11-14. } \\
\text { Approvals } \\
\text {. }\end{array}$ & $\begin{array}{l}\text { Facility } \\
\text { LEAD. GS } \\
11-13 . \\
\text { Approvals. }\end{array}$ & $\begin{array}{l}\text { Facility } \\
\text { Program } \\
\text { Leadership } \\
\text { Academy. }\end{array}$ \\
\hline 3 & $\begin{array}{l}\text { Varies } \\
\text { between } \\
\text { VISN sites }\end{array}$ & $\begin{array}{l}\text { Varies } \\
\text { between } \\
\text { VISN sites }\end{array}$ & $\begin{array}{l}\text { Varies } \\
\text { between } \\
\text { VISN sites }\end{array}$ & $\begin{array}{l}\text { Varies } \\
\text { between } \\
\text { VISN sites }\end{array}$ & $\begin{array}{l}\text { Varies } \\
\text { between } \\
\text { VISN sites }\end{array}$ & $\begin{array}{l}\text { Varies } \\
\text { between } \\
\text { VISN sites }\end{array}$ & $\begin{array}{l}\text { Offsite } \\
\text { govern } \\
\text { location }\end{array}$ & $\begin{array}{l}\text { Varies } \\
\text { between } \\
\text { VISN sites }\end{array}$ \\
\hline 4 & $30 /$ year & $\begin{array}{l}\text { 56/year (3- } \\
4 / \text { facility) }\end{array}$ & $\begin{array}{l}\text { 〜60/year } \\
\text { (3- } \\
\text { 4/facility) }\end{array}$ & $\begin{array}{l}25- \\
28 / \text { year }\end{array}$ & $\begin{array}{l}30- \\
45 / \text { year }\end{array}$ & 50/year & 30/year & $\begin{array}{l}\text { All } \\
\text { Supervisor } \\
\text { s }(\sim 1300)\end{array}$ \\
\hline 5 & $\begin{array}{r}360^{\circ} \\
\text { survey, } \\
\text { pre- } \\
\text { reading; } \\
\mathrm{MC} \\
\text { assigned } \\
\text { projects }\end{array}$ & $\begin{array}{l}\text { MBTI, pre- } \\
\text { reading; } \\
\text { mentor } \\
\text { selected } \\
\text { project }\end{array}$ & $\begin{array}{l}\text { MBTI, pre- } \\
\text { reading; } \\
\text { mentor } \\
\text { selected } \\
\text { project }\end{array}$ & $\begin{array}{l}360^{\circ} \\
\text { survey; } \\
\text { pre- } \\
\text { reading. } \\
\text { Participa } \\
\text { nt } \\
\text { selected } \\
\text { project. }\end{array}$ & $\begin{array}{l}360^{\circ} \\
\text { survey. } \\
\text { VISN } \\
\text { assigned } \\
\text { project } \\
\text { (from } \\
\text { MCs). }\end{array}$ & $\begin{array}{l}360^{\circ} \\
\text { survey, } \\
\text { MBTI, EI, } \\
\text { pre- } \\
\text { reading. } \\
\text { Mentee } \\
\text { selected } \\
\text { group } \\
\text { projects. }\end{array}$ & $\begin{array}{l}\text { No pre- } \\
\text { surveys; } \\
\text { MC } \\
\text { assigned } \\
\text { projects. }\end{array}$ & $\begin{array}{l}360^{\circ} \\
\text { survey, } \\
\text { MBTI, pre- } \\
\text { reading, } \\
\text { VISN } \\
\text { assigned } \\
\text { projects. }\end{array}$ \\
\hline 6 & $\begin{array}{l}\text { Participant } \\
\text { s assigned } \\
\text { VHA-CM. } \\
\text { PDPs. }\end{array}$ & $\begin{array}{l}\text { Self- } \\
\text { identified } \\
\text { mentor. } \\
\text { PDPs. }\end{array}$ & $\begin{array}{l}\text { Self- } \\
\text { identified } \\
\text { mentor. } \\
\text { PDPs. }\end{array}$ & $\begin{array}{l}\text { Participa } \\
\text { nt } \\
\text { assigned } \\
\text { senior } \\
\text { leader. } \\
\text { PDPs. }\end{array}$ & $\begin{array}{l}\text { Self- } \\
\text { identified } \\
\text { mentor. } \\
\text { IDPs. }\end{array}$ & $\begin{array}{l}\text { Participa } \\
\text { nt } \\
\text { assigned } \\
\text { senior } \\
\text { leader, } \\
\text { VHA-CM. } \\
\text { PDPs. }\end{array}$ & $\begin{array}{l}\text { Participant } \\
\text { assigned } \\
\text { VHA-CM. } \\
\text { PDPs. }\end{array}$ & $\begin{array}{l}\text { Participant } \\
\text { s assigned } \\
\text { VHA-CM. } \\
\text { PDPs. }\end{array}$ \\
\hline 7 & $\begin{array}{l}360^{\circ} \\
\text { survey, }\end{array}$ & $\begin{array}{l}360^{\circ} \\
\text { survey, } \\
\text { MTBI. }\end{array}$ & $\begin{array}{l}360^{\circ} \\
\text { survey, } \\
\text { MTBI. }\end{array}$ & $\begin{array}{l}360^{\circ} \\
\text { survey, } \\
\text { Impromp } \\
\text { tu } \\
\text { speeches }\end{array}$ & & $\begin{array}{l}360^{\circ} \\
\text { survey, } \\
\text { Learning } \\
\text { needs } \\
\text { assessme } \\
\text { nt; } \\
\text { Program } \\
\text { Assessme } \\
\text { nts }\end{array}$ & $\begin{array}{l}60^{\circ} \\
\text { survey, } \\
\text { Program } \\
\text { Assessmen } \\
\text { ts }\end{array}$ & $\begin{array}{l} \\
360^{\circ} \\
\text { survey, } \\
\text { Program } \\
\text { Assessmen } \\
\text { ts, MTBI. }\end{array}$ \\
\hline
\end{tabular}




\begin{tabular}{|c|c|c|c|c|c|c|c|c|}
\hline 8 & $\begin{array}{l}\text { Book } \\
\text { report and } \\
\text { project } \\
\text { presentati } \\
\text { on. }\end{array}$ & $\begin{array}{l}\text { Project } \\
\text { presentati } \\
\text { on at end. }\end{array}$ & $\begin{array}{l}\text { Project } \\
\text { presentati } \\
\text { on at end. }\end{array}$ & $\begin{array}{l}\text { Project } \\
\text { presentat } \\
\text { ion at } \\
\text { end. }\end{array}$ & $\begin{array}{l}\text { Project } \\
\text { presentat } \\
\text { ion at } \\
\text { end. }\end{array}$ & $\begin{array}{l}\text { Project } \\
\text { presentat } \\
\text { ion at } \\
\text { end. }\end{array}$ & $\begin{array}{l}\text { Project } \\
\text { presentati } \\
\text { on at end. }\end{array}$ & $\begin{array}{l}\text { Tracking } \\
\text { throughou } \\
\text { t, next } \\
\text { leadership } \\
\text { level, } \\
\text { project } \\
\text { presentati } \\
\text { on end. }\end{array}$ \\
\hline 9 & $\begin{array}{l}\text { Program } \\
\text { evals. ROI } \\
\text { through } \\
\text { projects. }\end{array}$ & $\begin{array}{l}\text { Program \& } \\
\text { mentor } \\
\text { evals. } \\
\text { Level III six } \\
\text { months } \\
\text { after end. } \\
\text { ROI } \\
\text { through } \\
\text { projects. }\end{array}$ & $\begin{array}{l}\text { Program \& } \\
\text { mentor } \\
\text { evals. } \\
\text { Level III six } \\
\text { months } \\
\text { after end. } \\
\text { ROI } \\
\text { through } \\
\text { projects. }\end{array}$ & $\begin{array}{l}\text { Follow-up } \\
\text { by VISN. } \\
\text { ROI } \\
\text { through } \\
\text { projects. }\end{array}$ & $\begin{array}{l}\text { Program } \\
\text { evals. ROI } \\
\text { through } \\
\text { projects. }\end{array}$ & $\begin{array}{l}\text { Program } \\
\text { evals. } \\
\text { Level III } \\
\text { six } \\
\text { months } \\
\text { after end. } \\
\text { ROI } \\
\text { through } \\
\text { projects. }\end{array}$ & $\begin{array}{l}\text { Program } \\
\text { evals. ROI } \\
\text { through } \\
\text { projects. }\end{array}$ & $\begin{array}{l}\text { Robust 4- } \\
\text { level eval } \\
\text { after } \\
\text { training. } \\
\text { ROI } \\
\text { through } \\
\text { projects. }\end{array}$ \\
\hline 10 & $\begin{array}{l}\text { Funding to } \\
\text { continue } \\
\text { LDPs - } \\
\text { provides } \\
\text { local } \\
\text { opportunit } \\
\text { ies for } \\
\text { leader } \\
\text { developm } \\
\text { ent. }\end{array}$ & $\begin{array}{l}\text { Funding to } \\
\text { continue } \\
\text { LDPs - } \\
\text { provides } \\
\text { local } \\
\text { opportunit } \\
\text { ies for } \\
\text { leader } \\
\text { developm } \\
\text { ent. }\end{array}$ & None & $\begin{array}{l}\text { Limited } \\
\text { resource } \\
\text { to meet } \\
\text { demand: } \\
\text { money, } \\
\text { human } \\
\text { capital, } \\
\text { instructor } \\
\text { s. }\end{array}$ & $\begin{array}{l}\text { Keep the } \\
\text { F2F } \\
\text { modality, } \\
\text { pre-work, } \\
\text { and } \\
\text { group } \\
\text { project. } \\
\text { Need } \\
\text { more } \\
\text { experime } \\
\text { ntal } \\
\text { training } \\
\text { for in- } \\
\text { between } \\
\text { session. }\end{array}$ & $\begin{array}{l}\text { Funding } \\
\text { to } \\
\text { continue } \\
\text { F2F } \\
\text { program. }\end{array}$ & $\begin{array}{l}\text { LDPs } \\
\text { aligned } \\
\text { with org } \\
\text { vision. } \\
\text { Senior } \\
\text { leader } \\
\text { support } \\
\text { (ELB and } \\
\text { VISN } \\
\text { Director). }\end{array}$ & $\begin{array}{l}\text { Funding to } \\
\text { continue } \\
\text { LDPs - } \\
\text { provides } \\
\text { local } \\
\text { opportunit } \\
\text { ies for } \\
\text { leader } \\
\text { developm } \\
\text { ent. }\end{array}$ \\
\hline
\end{tabular}

Note: 1 = Program Description, 2 = Pre-requisite, 3 = Location, 4 = \# of Participants, 5 = Pre-work, $6=$ Mentor Assignment, 7 = Assessments, 8 = Action Plan/Project Completion \& Reporting, $9=$ Post Assessment, $10=$ Critical Needs

Initially, several dimensions of the VISN program appeared dissimilar; however, interviewee responses to open-ended questions provided clarification which revealed that within each category, the organizational environment and structure of the leadership development programs were quite similar. For example, all eight of the VISNs interviewed conducted one leadership development program per year. The average length of the program was about 9 months $(M=9.1 ; C L$ lower limit = 6 months, upper limit = 12 months). Although there was variation in the length of the program, 
seven of the eight programs included three week-long sessions as their core with additional virtual or online discussions between sessions. Most of the training that occurred during the week-long sessions was focused on building the mentee leader's competencies. The variation in overall length of the program reflected differences in the amount of time that elapsed between each week-long session. However, the content covered during the week-long training sessions was based on the leadership competencies (Figure 1.1.).

As a prerequisite for participation, $88 \%(7 / 8)$ of the programs required mentees to have completed a Tier I program (Facility LEAD or Leadership Development Institute). The Tier I programs were focused on providing the protégés with the knowledge and skills to manage themselves, and plan, coordinate, and perform as a team leader. In addition, all the programs required approval from the facility Director/Senior Leadership Team. This was important because it meant that the protégé was supported by their supervisor and the facility leadership team. Related to site location, all VISNs utilized government locations (no costs); and most programs (7/8) utilized VAMCs within their VISN to minimize travel costs.

Similar variation was noted among the number of annual participants, with 2560 leaders (2-4 from each VAMC) participated in the program annually $(\mathrm{M}=42, \mathrm{CL}$ lower limit $=25$, upper limit $=60$ ). However, mentee qualifications for participation were similar among programs. Prior to the training $75 \%$ of the programs (6/8) required pre-reading and $87.5 \%$ of the programs $(7 / 8)$ required either a 360 -degree surveys or a 
Myers-Briggs Type Indicator (MBTI) survey prior to the training sessions. All programs also required that protégé participated in a small group project that was either assigned by the VISN (2/8), assigned by the facility (2/8), assigned by a mentor (2/8), or chosen by the participant (2/8).

Finally, initial results suggested substantial variation between programs regarding the means by which mentors and mentees were matched. The results showed that each program required protégés to have a mentor. Five of the eight programs (62.5\%) assigned a VHA certified mentor to the participants, while the other three programs encouraged participants to find their own mentor (a more senior leader in the organization).

The results also showed that assessments (both personal and organizational) had been incorporated into the VISN LEAD programs to ensure their effectiveness. For example, all program required participants to conduct formal personal development plans (PDP) and most of the programs (87.5\%) utilized the 360-degree surveys to assess development during the program. From an organizational perspective, the growth of the participants was assessed at program completion as all participants had to participate in a project presentation to complete the LDP. The return-on-investment (ROI) to the VISN and VAMC was primarily assessed through project implementation.

All VISNs conducted program evaluations at the end of the program, but only $25 \%(2 / 8)$ conducted additional mentor evaluations and $50 \%$ of the programs sent an 
additional survey out six months after program completion to assess behavior change following the LDP.

Interestingly, when the program managers were asked about their most critical needs, $62.5 \%$ (5/8) responded funding (primarily for travel and presenters) was needed to maintain the program. All program managers noted that these programs were critical to developing local leaders in their region that could assume current gaps across the VISN. Accordingly, they noted the need to further align these programs with the corporate strategic planning efforts.

Results of the analysis suggest that while there were differences across the programs, each of the VISN programs had the organizational structure necessary to support effective leadership development, to include: key structural and environmental elements, support from the organizational leadership, and assessments throughout the program (including IDPs, 360-degree surveys, and MTBIs). This information was verified through the semi-structure interviews with each program manager that allowed for a discussion with the interviewee rather than a straightforward question and answer format. 


\section{Overview: Part II}

To collect data for Part II, the researcher sent an email (with a link to the survey) to leaders that participated in the VISN LEAD programs. 70 total leaders completed surveys through Survey Monkey (Appendix X) and the spreadsheet was transferred to the Statistical Package for the Social Sciences (SPSS). All the data was entered into SPSS, to include defining and recoding the variables. Missing variables were excluded from analysis. Demographic information was reported on both the mentor and protégé.

\section{Study Demographics, Themes, and Frequencies}

A summary of the distributions of gender, ethnicity, and experience are in Table 4.3.

Table 4.3

Summary of the Distributions for Gender, Ethnicity, and Experience

\begin{tabular}{llcc}
\hline \multicolumn{2}{c}{ Characteristic } & Mentor $(\mathrm{n}=70)$ & Mentee $(\mathrm{n}=70)$ \\
\hline Gender & Male & $22(37.3 \%)$ & $20(33.3 \%)$ \\
& Female & $37(62.7 \%)$ & $40(66.7 \%)$ \\
Ethnicity & White & $53(89.8 \%)$ & $49(81.7 \%)$ \\
& Black & $5(8.5 \%)$ & $9(15.0 \%)$ \\
& Hispanic & $1(1.7 \%)$ & $1(1.7 \%)$ \\
Years of & Al/AN & --- & $1(1.7 \%)$ \\
Experience & $3-4$ & $3(5.2 \%)$ & \\
& $5-9$ & $10(17.2 \%)$ & \\
& $10+$ & $29(50.0 \%)$ & \\
\hline
\end{tabular}

Note: $\mathrm{Al} / \mathrm{AN}=$ American Indian/Alaskan Native. 10 participants did not provide their gender. Missing responses were coded as missing and were not included in percentages.

According to the table above, most of the mentees (66.7\%) and mentors $(62.7 \%)$ were female. $81.7 \%$ of the mentees were White, compared to $15 \%$ Black, and $1.7 \%$ Hispanic and American Indian/Native American, respectively. About $90 \%$ of the mentors were 
White, compared to $8.5 \%$ Black and $~ 2 \%$ Hispanic. $95 \%$ of the mentors had more than three years of experience.

Figure 4.1

Time that Mentee Spent with Mentor per Month

\section{Time Spent with Mentor (hrs/month)}

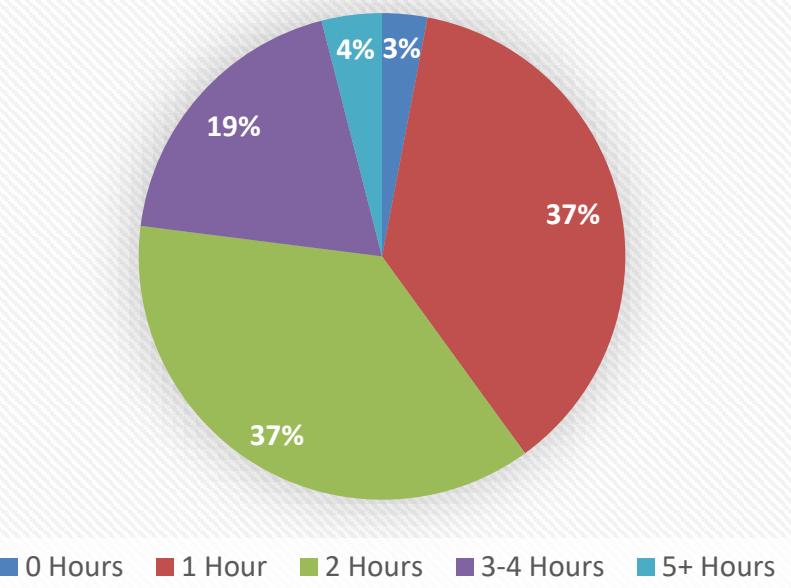

Table 4.4

Summary of the Distributions for the Goodness of Fit Domain

\begin{tabular}{lcccc}
\hline & $\begin{array}{c}\text { Closeness with } \\
\text { Mentor }\end{array}$ & $\begin{array}{c}\text { Meeting } \\
\text { Needs }\end{array}$ & $\begin{array}{c}\text { Intro to Influential } \\
\text { People (Internal) }\end{array}$ & $\begin{array}{c}\text { Intro to Influential } \\
\text { People (External) }\end{array}$ \\
\hline Not At All & $7(10.0 \%)$ & $2(2.9 \%)$ & $22(31.4 \%)$ & $43(61.4 \%)$ \\
Seldom & $10(14.3 \%)$ & $14(20.0 \%)$ & $12(17.1 \%)$ & $12(17.1 \%)$ \\
Occasionally & $18(25.7 \%)$ & $13(18.6 \%)$ & $15(21.4 \%)$ & $9(12.9 \%)$ \\
Quite a Bit & $27(38.6 \%)$ & $29(41.4 \%)$ & $15(21.4 \%)$ & $5(7.1 \%)$ \\
All the Time & $8(11.4 \%)$ & $12(17.1 \%)$ & $6(8.6 \%)$ & $1(1.4 \%)$ \\
\hline
\end{tabular}

Note: $\mathrm{n}=70$

About $37 \%$ of mentees met with their mentors for one hour, $37 \%$ meet with their mentor for two hours, $19 \%$ met with their mentor for 3-4 hours, and $4 \%$ met with their mentor for $5+$ hours per month. Even though $60 \%$ of mentee met with their 
mentor for two or more hours a month, $24 \%$ of mentee stated that they seldom or never felt close to their mentor and $23 \%$ stated they their mentor either did not meet or seldom met their needs or preferences. According to the results, mentors introduced their mentees to influential people inside of the organization (51\% at least occasionally) more often than they introduced mentees to influential people outside of the organization ( $21 \%$ at least occasionally). 


\section{Research Questions:}

Question 1: To what extent do mentees perceive their mentors to be transformational leaders as defined in the literature?

According to Bass \& Riggio (2006), there are four components to transformational leadership: Idealized Influence (II), Inspirational Motivation (IM), Individualized Consideration (IC), and Intellectual Stimulation (IS). Following are the frequencies for each of the transformational leadership characteristics of mentors as observed by the mentee.

Table 4.5

Summary of the Distributions of the Transformational Leadership Characteristics

\begin{tabular}{lcccc}
\hline & II & IM & IC & IS \\
\hline Low & $6(8.6 \%)$ & $10(14.3 \%)$ & $11(15.7 \%)$ & $9(12.9 \%)$ \\
Average & $24(34.3 \%)$ & $18(25.7 \%)$ & $20(28.6 \%)$ & $33(47.1 \%)$ \\
High & $37(52.9 \%)$ & $39(55.7 \%)$ & $36(51.4 \%)$ & $25(35.7 \%)$ \\
\hline
\end{tabular}

Note: $n=70$. Missing data were excluded from the percentage.

Based on the results, $\geq 80 \%$ of mentees felt their mentors exhibited at least average levels of inspirational motivation (IM), idealized influence (II), intellectual stimulation (IS), and individualized consideration (IC). Based on a review of the raw data, $49 \%$ of mentees felt their mentors were at least average in all and high in at least 3 of 4 components; and $13 \%$ of mentees felt their mentor exhibited low transformational leadership characteristics on at least 2 of 4 components. 
Question 2: What transformational leadership characteristics of the mentors are most important to the mentee's growth of leadership capabilities, as perceived by the mentees? Does this perception vary depending on goodness of fit, time with mentor, gender, and race of mentee $\&$ mentor?

Mentee development will be assessed two ways. The first way assesses if there is a relationship between the mentor's demonstration of transformational leadership (TL) characteristics and the presence of human and conceptual skills in the mentee. The second way assesses the relationship between the mentor's demonstration of TL characteristics and the development of these characteristics in the mentees.

\section{A.1. Assessment of relationship between the mentor's demonstration of TL and the presence of human skills in the mentee.}

I began my analysis by conducting crosstabs and correlations analyses (Appendix V) between the mentor's demonstration of TL and the presence of human skills in the mentees. The results showed significant correlations between each component of transformational leadership demonstrated by the mentor (IM, II, IS, and IC) and the presence of human skills in the mentee, suggesting that mentors that demonstrate high leadership characteristics help mentees to develop the necessary skills needed to operate in complex adaptive systems (CAS). To further understand the relationship, a descriptive statistics table (Table 4.6) and a regression analysis was utilized (Table 4.7) to assess the isolated impact of each of the mentor's TL characteristics on the development of the mentee's human skills. 
Table 4.6

Descriptive Statistics Table for Presence of Mentee's Skills

\begin{tabular}{|c|c|c|c|}
\hline & $\mathrm{N}$ & Mean & SD \\
\hline \multicolumn{4}{|l|}{ Mentor's TL Characteristics } \\
\hline Mentor's IM Demonstration & 67 & 2.28 & .74 \\
\hline Mentor's IS Demonstration & 67 & 2.24 & .68 \\
\hline Mentor's IC Demonstration & 67 & 2.37 & .76 \\
\hline Mentor's II Demonstration & 67 & 2.46 & .66 \\
\hline \multicolumn{4}{|l|}{ Goodness of Fit Variables } \\
\hline Time with Mentor (hours/ month) & 70 & 2.84 & .91 \\
\hline How often Mentee felt Close to Mentor & 70 & 3.27 & 1.15 \\
\hline Mentor Met Needs and Preferences & 70 & 3.50 & 1.09 \\
\hline Intro to People (Internal) & 70 & 2.59 & 1.36 \\
\hline Intro to People (External) & 70 & 1.70 & 1.04 \\
\hline \multicolumn{4}{|l|}{ Individual Mentee/Mentor Characteristics } \\
\hline Mentee Gender (Female) & 60 & .67 & .48 \\
\hline Mentee Ethnicity (White vs. Black) & 60 & .15 & .36 \\
\hline Mentee Ethnicity (White vs. NA) & 60 & .012 & .13 \\
\hline Mentee Ethnicity (White vs. Hispanic) & 59 & .02 & .13 \\
\hline Mentor Gender (Female) & 59 & .63 & .49 \\
\hline Mentor Ethnicity (White vs. Black) & 59 & .02 & .13 \\
\hline Mentor Ethnicity (White vs. NA) & 59 & .00 & .00 \\
\hline Mentor Ethnicity (White vs. Hispanic) & 59 & .02 & .13 \\
\hline Mentor Certification Status & 70 & 2.00 & 1.15 \\
\hline Mentor's Years of Experience & 58 & 3.00 & .82 \\
\hline \multicolumn{4}{|l|}{ Mentee Skill Development } \\
\hline Mentee Human Skill & 58 & 20.48 & 6.32 \\
\hline Mentee Conceptual Skill & 55 & 19.98 & 6.87 \\
\hline
\end{tabular}

Note: $\mathrm{SD}=$ Standard deviation.

There was a significant relationship between each of the mentor's TL

characteristics and the mentee's human skills, when controlling for the other variables:

time with mentor, the mentee's gender \& ethnicity, the mentor's gender \& ethnicity, closeness with the mentor, the mentor's certification status, the mentor's ability to meet the mentee's needs, the mentor's years of experience, and the mentor 
introducing the mentee to influential people inside \& outside of the organization. Additionally, the mentor's ability to meet the mentee's need was also significant with Mentor IM, II, and IS characteristics; and the mentor's years of experience was significant with Mentor II $(p<0.05)$. Introduction to influential people inside of the organization and closeness to the mentor also showed significance $(p<0.05)$ with Mentor IS (Table 4.7). The model $\mathrm{R}^{2}$ for each TL characteristics was significant at $\mathrm{p}$ $<0.001$. The IBM SPSS Statistics Processor deleted Mentee Ethnicity (White vs. Hispanic) and Mentor Ethnicity (White vs. NA) variables from the analysis because they were constants or had missing correlations. The results are noted below in Tables 4.7. These results suggest that mentors that demonstrate high transformational leadership behaviors promote stronger human skill development in their mentees. For example, according to Table 4.7, a one-unit change in the mentor's demonstration of Individualized Consideration is associated with an increase of 3.25 in the mentee's human skill scoring. This makes further sense when I evaluate my scales. For IC, one standard deviation (0.74) is almost equivalent to the difference between the responses of frequency (i.e. Seldom $=2$, Occasional $=3$ ). So, as the mentor increases one unit (goes from Seldom to Occasionally) exhibiting the TL behavior of IC, the mentee will increase $\sim 3$ points in their scoring. This is significant because the mean for the mentee is 20.9 (according to Table 4.6) and a 3-point increase in scoring would move the mentee from a moderate demonstration of human skills (Moderate Scoring Range $=14-22$ ) to a high demonstration of human skills (High Scoring Range $=23-30$ ), if they were at the mean. 
Table 4.7

Multiple Regression Analysis Predicting Mentee Human Skill Development from Mentor TL

\begin{tabular}{|c|c|c|c|c|}
\hline & $\begin{array}{c}\text { IM } \\
\beta(S E)\end{array}$ & $\begin{array}{c}\text { II } \\
\beta \text { (SE) }\end{array}$ & $\begin{array}{c}\text { IS } \\
\beta(S E)\end{array}$ & $\begin{array}{c}\text { IC } \\
\beta(S E)\end{array}$ \\
\hline \multicolumn{5}{|l|}{ Mentor TL Characteristics } \\
\hline TL Characteristic & $2.7(1.04)^{*}$ & $\begin{array}{c}4.24 \\
(1.22)^{* * *}\end{array}$ & $2.84(0.1)^{* *}$ & $\begin{array}{r}3.25 \\
(0.94)^{* * *}\end{array}$ \\
\hline \multicolumn{5}{|l|}{ Goodness of Fit } \\
\hline Intro to People (I) & $0.9(0.49)$ & $0.45(0.5)$ & $1.06(0.47)^{*}$ & $0.58(0.49)$ \\
\hline Intro to People (E) & $-0.09(0.62)$ & $0.03(0.59)$ & $-0.09(0.61)$ & $-0.22(0.58)$ \\
\hline Close to Mentor & $1.35(0.68)$ & $0.95(0.66)$ & $1.49(0.66)^{*}$ & $1.47(0.63)^{*}$ \\
\hline Mentor Met Needs & $1.49(0.74)^{*}$ & $1.71(0.66)^{*}$ & $1.51(0.71)^{*}$ & $1.28(0.7)$ \\
\hline Time with Mentor & $0.34(0.65)$ & $0.44(0.61)$ & $0.24(0.65)$ & $0.55(0.61)$ \\
\hline \multicolumn{5}{|l|}{$\begin{array}{l}\text { Individual Mentee/ } \\
\text { Mentor Characteristics }\end{array}$} \\
\hline Mentee Gender (F) & $0.35(1.08)$ & $-0.55(1.06)$ & $-0.08(1.08)$ & $-0.12(1.04)$ \\
\hline Mentor Gender (F) & $-1.05(1.07)$ & $-0.55(1.04)$ & $-1.07(1.06)$ & $-0.27(1.06)$ \\
\hline Mentee Ethnicity (Black) & $-0.46(1.3)$ & $0.19(1.25)$ & $-0.5(1.28)$ & $-0.71(1.23)$ \\
\hline Mentee Ethnicity (AI/AN) & $4.0(3.56)$ & $3.95(3.36)$ & $3.13(3.56)$ & $3.93(3.36)$ \\
\hline $\begin{array}{l}\text { Mentor Ethnicity } \\
\text { (Hispanic) }\end{array}$ & $-6.86(3.65)$ & $-5.67(3.46)$ & $-7.85(3.62)$ & $-6.87(3.46)$ \\
\hline Mentor Cert. Status & $0.73(0.61)$ & $0.57(0.58)$ & $0.66(0.6)$ & $0.73(0.57)$ \\
\hline Mentor Experience & $0.96(0.58)$ & $1.52(0.57)^{*}$ & $0.72(0.58)$ & $0.73(0.55)$ \\
\hline \multicolumn{5}{|l|}{$\begin{array}{l}\text { Mentee Skill } \\
\text { Development }\end{array}$} \\
\hline Human Skills (Constant) & $-3.33(2.96)$ & $-7.17(3.09)$ & $-2.57(2.9)$ & $-3.05(2.8)$ \\
\hline Total $\mathrm{R}^{2}$ & $0.79 * * *$ & $0.82 * * *$ & $0.80 * * *$ & $0.81 * * *$ \\
\hline
\end{tabular}

Note: $\mathrm{n}=67 . \mathrm{SE}=$ Standard Error of $\beta$. TL Characteristic $=$ Mentor's demonstration of TL Characteristic. Significance Levels $={ }^{*} p<0.05,{ }^{* *} p<0.01, * * * p<0.001$.

The researcher also looked at the VIF values to check the assumption of no multicollinearity. All values were substantially less than 10 and the Tolerance of all variables were above 0.2 indicating no multicollinearity (Field, 2009; Menard, 1995). No cases had a standard residual of greater than \pm 3 , less than the expected percentage of cases that we would expect in an ordinary sample (95\%). Accordingly, the sample appears to conform to what we would expect for an accurate model. 


\section{A.2. Assessment of relationship between the mentor's demonstration of TL and the presence of conceptual skills in the mentee.}

To understand the relationship between the mentor's demonstration of transformational leadership and the presence of conceptual skills in the mentee, I conducted regression analyses to assess the isolated impact of each of the mentor's TL characteristics on the development of the mentee's conceptual skills. There was a significant relationship between each of the mentor's TL characteristics and the mentee's conceptual skills, when controlling for the other variables: time with mentor, the mentee's gender \& ethnicity, the mentor's gender \& ethnicity, closeness with the mentor, the mentor's certification status, the mentor's ability to meet the mentee's needs, the mentor's years of experience, and the mentor introducing the mentee to influential people inside \& outside of the organization. There was a significant relationship between the mentor's demonstration of each TL characteristic and the conceptual skills in the mentee. Surprisingly, there was also a significant relationship with the introduction to influential people (Internal) for all the TL behaviors, and mentor's years of experience for IM and II. The results are noted below in Tables 4.8. 
Table 4.8

Multiple Regression Analysis Predicting Mentee Conceptual Skill Development from Mentor TL

\begin{tabular}{|c|c|c|c|c|}
\hline & $\begin{array}{c}\mathrm{IM} \\
\beta(\mathrm{SE})\end{array}$ & $\begin{array}{c}\text { II } \\
\beta(S E)\end{array}$ & $\begin{array}{c}\text { IS } \\
\beta(S E)\end{array}$ & $\begin{array}{c}\text { IC } \\
\beta(S E)\end{array}$ \\
\hline \multicolumn{5}{|l|}{ Mentor TL Characteristics } \\
\hline TL Characteristic & $3.2(1.1)^{* *}$ & $4.93(1.29)^{* * *}$ & $2.9(1.09)^{*}$ & $\begin{array}{c}3.2 \\
(1.0)^{* *}\end{array}$ \\
\hline \multicolumn{5}{|l|}{ Goodness of Fit } \\
\hline Intro to People (I) & $1.60(0.52)^{* *}$ & $1.10(0.53)^{*}$ & $1.81(0.51)^{* * *}$ & $\begin{array}{c}1.37 \\
(0.53)^{*}\end{array}$ \\
\hline Intro to People (E) & $-0.19(0.67)$ & $0.00(0.64)$ & $-0.27(0.68)$ & $-0.38(0.64)$ \\
\hline Close to Mentor & $1.11(0.8)$ & $0.47(0.80)$ & $1.37(0.8)$ & $1.25(0.78)$ \\
\hline Mentor Met Needs & $1.11(0.8)$ & $1.49(0.72)^{*}$ & $1.22(0.81)$ & $1.1(0.78)$ \\
\hline Time with Mentor & $0.80(0.69)$ & $0.96(0.64)$ & $0.75(0.71)$ & $1.08(0.67)$ \\
\hline \multicolumn{5}{|l|}{$\begin{array}{l}\text { Individual Mentee/ Mentor } \\
\text { Characteristics }\end{array}$} \\
\hline Mentee Gender (Female) & $0.72(1.13)$ & $-0.21(1.09)$ & $0.15(1.17)$ & $0.37(1.12)$ \\
\hline Mentor Gender (Female) & $-1.29(1.16)$ & $-0.65(1.12)$ & $-1.31(1.18)$ & $-0.63(1.18)$ \\
\hline Mentee Ethnicity (Black) & $-0.21(1.39)$ & $0.55(1.33)$ & $-0.31(1.41)$ & $-0.47(1.36)$ \\
\hline Mentee Ethnicity (AI/AN) & $3.20(3.76)$ & $3.09(3.53)$ & $2.56(3.87)$ & 3.39 (3.68) \\
\hline Mentor Ethnicity (Hispanic) & $-5.62(3.87)$ & $-4.02(3.67)$ & $-6.61(4.0)$ & $-5.59(3.8)$ \\
\hline Mentor Cert. Status & $0.7(0.7)$ & $0.51(0.66)$ & $0.67(0.71)$ & $0.75(0.69)$ \\
\hline Mentor Experience & $1.33(0.61)^{*}$ & $2.0(060)^{* *}$ & $1.08(0.63)$ & $1.11(0.60)$ \\
\hline \multicolumn{5}{|l|}{ Mentee Skill Development } \\
\hline Conceptual Skills (Constant) & $-7.53(3.21)$ & $-12.11(3.36)$ & $-6.38(3.24)$ & $-7.15(3.14)$ \\
\hline Total R2 & $0.81 * * *$ & $0.83 * * *$ & $0.80 * * *$ & $0.82 * * *$ \\
\hline
\end{tabular}

Note: $\mathrm{n}=67 . \mathrm{SE}=$ Standard Error of $\beta$. TL Characteristic $=$ Mentor's demonstration of TL Characteristic. Significance Levels $={ }^{*} p<0.05,{ }^{* *} p<0.01,{ }^{* *} p<0.001$.

\section{B.1. Assessment of relationship between the mentor's demonstration of Inspirational Motivation behaviors and the subsequent demonstration of those behaviors by the mentee.}

I conducted a regression to assess the relationship between the isolated impact of the mentor's IM characteristics on the development of the mentee's IM behaviors, when controlling for the other variables: time with mentor, the mentee's gender \& ethnicity, the mentor's gender \& ethnicity, closeness with the mentor, the mentor's certification status, the mentor's ability to meet the mentee's needs, the mentor's years 
of experience, and the mentor introducing the mentee to influential people inside $\&$ outside of the organization. There was a significant IM relationship between the mentor and the mentee $(p<0.001)$, when controlling for the other variables. There was also a significant relationship associated with the time spent with the mentor $(p<0.01)$. The IBM SPSS Statistics Processor deleted Mentee Ethnicity (White vs. Hispanic) and Mentor Ethnicity (White vs. NA) variables from the analysis because they were constants or had missing correlations. The results are noted below in Tables 4.9.

Table 4.9

Impact of Mentor's T.L. Characteristics on Corresponding Mentee's T.L. Characteristic

\begin{tabular}{|c|c|c|c|c|}
\hline & $\begin{array}{c}\beta \text { (SE) } \\
\text { IM }\end{array}$ & $\begin{array}{c}\beta \text { (SE) } \\
\quad \text { II }\end{array}$ & $\begin{array}{c}\beta \text { (SE) } \\
\text { IS }\end{array}$ & $\begin{array}{c}\beta \text { (SE) } \\
\text { IC }\end{array}$ \\
\hline \multicolumn{5}{|l|}{ Mentor TL Characteristics } \\
\hline Mentor Characteristics & $1.22(0.50)^{*}$ & $1.80(0.84)^{*}$ & $\begin{array}{c}1.81 \\
(0.66)^{* *}\end{array}$ & $\begin{array}{c}1.03 \\
(0.51)^{*}\end{array}$ \\
\hline \multicolumn{5}{|l|}{ Goodness of Fit } \\
\hline Intro to People (I) & $0.32(0.23)$ & $0.30(0.35)$ & $0.29(0.30)$ & $0.22(0.27)$ \\
\hline Intro to People (E) & $-0.32(0.30)$ & $-0.60(0.42)$ & $-0.17(0.40)$ & $\begin{array}{l}-0.24 \\
(0.32)\end{array}$ \\
\hline Closeness to Mentor & $0.04(0.33)$ & $0.33(0.49$ & $0.28(0.43)$ & $0.34(0.36)$ \\
\hline Mentor Met Needs & $0.43(0.36)$ & $0.92(0.48)$ & $1.02(0.47)^{*}$ & $0.41(0.40)$ \\
\hline Time with Mentor & $\begin{array}{c}0.93 \\
(0.32)^{* *}\end{array}$ & $\begin{array}{c}1.19 \\
(0.44)^{* *}\end{array}$ & $0.71(0.43)$ & $0.59(0.35)$ \\
\hline \multicolumn{5}{|l|}{$\begin{array}{l}\text { Individual Mentee/ } \\
\text { Mentor Characteristics }\end{array}$} \\
\hline Mentee Gender & $0.40(0.51)$ & $-0.20(0.73)$ & $0.17(0.69)$ & $0.16(0.58)$ \\
\hline Mentor Gender & $-0.51(0.50)$ & $-0.70(0.73)$ & $-0.53(0.68)$ & $0.02(0.59)$ \\
\hline Mentee Ethnicity (Black) & $-0.57(0.64)$ & $-0.11(0.92)$ & $-0.04(0.85)$ & $\begin{array}{l}-0.48 \\
(0.71)\end{array}$ \\
\hline Mentee Ethnicity (NA) & $0.96(1.75)$ & $3.59(2.48)$ & $0.51(2.37)$ & $1.58(1.94)$ \\
\hline Mentor Ethnicity (Hispanic) & $-0.06(1.78)$ & $0.69(2.54)$ & $-0.74(2.39)$ & $-0.45(2.0)$ \\
\hline Mentor Certification Status & $0.13(0.30)$ & $0.13(0.42)$ & $0.08(0.40)$ & $0.13(0.33)$ \\
\hline Mentor Experience & $0.33(0.28)$ & $0.25(0.42)$ & $-0.13(0.38)$ & $\begin{array}{l}-0.01 \\
(0.32)\end{array}$ \\
\hline Constant & $-1.40(1.46)$ & $-1.45(2.27)$ & $-0.16(1.94)$ & $0.25(1.63)$ \\
\hline $\mathrm{R}^{2}$ & $0.65 * * *$ & $0.67 * * *$ & $0.67 * * *$ & $0.58 * * *$ \\
\hline
\end{tabular}

Note: $\mathrm{SE}=$ standard error. The mentee's characteristics corresponded with the mentor's demonstration of TL. ${ }^{*} \mathrm{p}<0.05,{ }^{* *} \mathrm{p}<0.01,{ }^{* * *} \mathrm{p}<0.001$ 


\section{B.2. Assessment of relationship between the mentor's demonstration of Idealized Influence behaviors and the subsequent demonstration of those behaviors by the mentee.}

I conducted a regression analysis to assess the relationship between the isolated impact of each of the mentor's T.L. characteristics on the development of the corresponding mentee's T.L. behaviors. There was a significant relationship between the mentor's demonstration of the T.L. characteristic and the mentee's behavior for each characteristic (II ( $p<0.001)$, when controlling for the other variables: time with mentor, the mentee's gender \& ethnicity, the mentor's gender \& ethnicity, closeness with the mentor, the mentor's certification status, the mentor's ability to meet the mentee's needs, the mentor's years of experience, and the mentor introducing the mentee to influential people inside \& outside of the organization. There was also a significant relationship associated with the time spent with the mentor and mentor introduction to people internally $(p<0.01)$. The IBM SPSS Statistics Processor deleted Mentee Ethnicity (White vs. Hispanic) and Mentor Ethnicity (White vs. NA) variables from the analysis because they were constants or had missing correlations. The results are noted above in Tables 4.9.

B.3. Assessment of relationship between the mentor's demonstration of Intellectual Stimulation behaviors and the subsequent demonstration of those behaviors by the mentee.

I conducted a regression to understand the relationship between the isolated impact of the mentor's Intellectually Stimulating characteristics on the development of the mentee's IS behaviors. There was a significant relationship between the mentor's IS 
and the mentee's IS $(p<0.01)$, when controlling for the other variables: time with mentor, the mentee's gender \& ethnicity, the mentor's gender \& ethnicity, closeness with the mentor, the mentor's certification status, the mentor's ability to meet the mentee's needs, the mentor's years of experience, and introducing the mentee to influential people inside \& outside of the organization. In addition, the mentor's ability to meet the mentee's needs was also significant $(p<0.05)$. The IBM SPSS Statistics Processor deleted Mentee Ethnicity (White vs. Hispanic) and Mentor Ethnicity (White vs. NA) variables from the analysis because they were constants or had missing correlations. The results are noted above in Tables 4.9.

\section{B.4. Assessment of relationship between the mentor's demonstration of Individualized Consideration behaviors and the subsequent demonstration of those behaviors by the mentee.}

I conducted a regression to understand the relationship between the isolated impact of the mentor's IC characteristics on the development of the mentee's IC behaviors. There was a significant relationship between the mentor's IC and the mentee's IC $(p=0.05)$, when controlling for the other variables: time with mentor, the mentee's gender \& ethnicity, the mentor's gender \& ethnicity, closeness with the mentor, the mentor's certification status, the mentor's ability to meet the mentee's needs, the mentor's years of experience, and the mentor introducing the mentee to influential people inside \& outside of the organization. The IBM SPSS Statistics Processor deleted Mentee Ethnicity (White vs. Hispanic) and Mentor Ethnicity (White vs. 
NA) variables from the analysis because they were constants or had missing correlations. The results are noted above in Tables 4.9. 


\section{Question 3. How does the mentee's perception of their mentor relate to their}

willingness to become mentors in the VISN LEAD program?

I began my analysis by conducting a correlations analyses between the mentee's willingness to become a certified mentor (measured by the mentee's certification status) and the demonstration of TL characteristics by the mentor. According to the results, none of the TL mentor's characteristics had a significant correlation with the mentee's certification status. One variable, the mentor's certification status, showed a significant positive correlation with the mentee's certification status (Pearson correlation $=-.274, p<0.05)$. To further understand this relationship, I conducted a descriptive statistics table (Table 4.10) and a multiple regression analyses (Tables 4.11) to determine how much of the variation in the mentee's willingness to become a certified mentor was explained by the mentor's certification status, mentee's perception of their mentor, the gender \& ethnicity of the mentor, the gender \& ethnicity of the mentee, how often the mentor introduced the mentee to influential people inside \& outside of the organization, mentee's closeness to the mentor, the ability of the mentor to meet the mentee's needs, the mentee's confidence, and the time spent with the mentor. 
Table 4.10

Descriptive Statistics Table for Mentee Certification Status

\begin{tabular}{lccc}
\hline & Mean & SD & N \\
\hline Mentor TL Characteristics & & & \\
Mentor Demonstration of IC & 2.43 & .75 & 58 \\
Mentor Demonstration of IS & 2.29 & .65 & 58 \\
Mentor Demonstration of IM & 2.52 & .71 & 58 \\
Mentor Demonstration of II & 2.53 & .63 & 58 \\
Goodness of Fit & & & \\
Time Spend with Mentor & 2.84 & .89 & 58 \\
Introduction to Influential People (Internal) & 2.74 & 1.37 & 58 \\
Introduction to Influential People (External) & 1.79 & 1.10 & 58 \\
Closeness to Mentor & 3.38 & 1.17 & 58 \\
Mentor Met Mentee Needs & 3.64 & 1.09 & 58 \\
Individual Mentee/ Mentor Characteristics & & & \\
Mentee's Gender (F) & .66 & .478 & 58 \\
Mentor's Gender (F) & .62 & .49 & 58 \\
Mentee Ethnicity (White vs Black) & .138 & .35 & 58 \\
Mentee Ethnicity (White vs. NA) & .02 & .13 & 58 \\
Mentee Ethnicity (White vs. Hispanic) & .00 & .00 & 58 \\
Mentor Ethnicity (White vs. Black) & .02 & .13 & 58 \\
Mentor Ethnicity (White vs. NA) & .00 & .00 & 58 \\
Mentor Ethnicity (White vs. Hispanic) & .02 & .13 & 58 \\
Mentee Certification status? & .86 & .95 & 58 \\
Mentor's Certification Status? & 2.34 & .83 & 58 \\
Mentor Experience (years) & 3.00 & & \\
\hline Note: SD = Standard Deviation. Mentee's/Mentor's Gender (F) female. & & 58 \\
\hline
\end{tabular}

There was linearity and no homoscedasticity as assessed by visual inspection of a plot of regression standardized residuals against regression standardized predicted values.

There was independence of residuals, as assessed by a Durbin-Watson statistic of 2.288.

There was no evidence of collinearity and the VIF values were all < 10 ( $\max =5.66)$.

There were no extreme cases and all values for Cook's distance were well below 1 (max $=.28)$. The multiple regression model significantly predicted the mentee's mentorship 
program certification status, $F(17,40)=2.00, p<.05)$. According to the results, both the mentor's certification status and the mentor's demonstration of Individualized Consideration (IC) had a negative relationship with the mentee's certification status ( $B=$ $-.32, p<0.05 ; B=-.73, p<0.05 ;$ respectively). Alternatively, the mentor's demonstration of Intellectual Stimulation (IS) had a positive relationship with the mentee's certification status $(B=.80, p<0.01)$. Regression coefficients and standard errors can be found in Table 4.11 (below).

Table 4.11

Regression Coefficients and Standard Error for Mentee Certification Status

\begin{tabular}{lc}
\hline & $\mathrm{B}(\mathrm{SE})$ \\
\hline Mentor TL Characteristics & $-0.00(0.32)$ \\
\hline Mentor's Demonstration of IM & $0.80(0.29)^{* *}$ \\
Mentor's Demonstration of IS & $-0.73(0.33)^{*}$ \\
Mentor's Demonstration of IC & $0.16(0.42)$ \\
Mentor's Demonstration of II & \\
Goodness of Fit & $0.13(0.17)$ \\
Time with Mentor & $-0.09(0.13)$ \\
Intro to People (Internal) & $-0.22(0.16)$ \\
Intro to People (External) & $-0.10(0.18)$ \\
Closeness to Mentor & $0.14(0.20)$ \\
Mentor Met Needs & \\
Individual Mentee/ Mentor & \\
Characteristics & $-0.24(0.27)$ \\
Mentee Gender (Female) & $0.31(0.35)$ \\
Mentee Ethnicity (Black) & $-0.46(0.92)$ \\
Mentee Ethnicity (NA) & $-0.17(0.27)$ \\
Mentor Gender (Female) & $-1.14(0.94)$ \\
Mentor Ethnicity (Hispanic) & $-0.32(0.16)^{*}$ \\
Mentor Certification Status & $-0.21(0.16)$ \\
Mentor Experience (Years) & $1.64(0.86)$ \\
Constant (Mentee Certification Status) & \\
\hline Note: &
\end{tabular}

Note: $R^{2}=.46(p<0.05) .{ }^{*} p<0.05,{ }^{* *} p<0.01$ 


\section{Major Findings:}

The study participants shared their perceptions of the mentoring relationship and the extent to which they viewed their mentor as being a transformational leader. Based on the participants' survey responses and collected artifacts, five major findings were identified in response to the research question.

\section{Major Finding 1: Most Mentors Participating in the Formal Leadership Develop} Programs Were Found to Demonstrate Transformational Leadership Characteristics According to the results in Table 4.5, the majority of protégé felt that their mentors demonstrated transformational characteristics during the LDP ( $81 \%$ demonstrated IM, 87\% demonstrated II, 80\% demonstrated IC, and 83\% demonstrated IS). Since most mentees perceived that their mentor demonstrated transformational leadership characteristics as defined by the literature, we reject the null hypothesis that mentees will not perceive that their mentors demonstrate transformational leadership characteristics.

\section{Major Finding 2: Mentors that Demonstrate Transformational Leadership Characteristics Facilitate the Effective Development and Growth of Mentees}

According to the results in Tables 4.7 - 4.9, there is a significant positive relationship between each of the mentor's TL characteristics and the mentee's: human skills, conceptual skills, and the development of analogous mentee TL characteristics/behaviors, when controlling for the variables time with mentor, the 
mentee's gender \& ethnicity, the mentor's gender \& ethnicity, closeness with the mentor, the mentor's certification status, the mentor's ability to meet the mentee's needs, the mentor's years of experience, and the mentor introducing the mentee to influential people inside \& outside of the organization. For human skills specifically, the results show that mentors that demonstrate TL behaviors promote stronger human skill development in their mentees. For example, according to Table 4.7, a one-unit change in the mentor's demonstration of individualized consideration for their mentee would lead to an increase of 3.25 in the mentee's human skill scoring. This increase was significant and was consistent for IM (increase of 2.7), II (increase of 4.24), and IS (increase of 2.84)

This result makes further sense when the survey scales are evaluated. For IC, a one-unit increase would represent the difference between the responses of frequency (i.e. Seldom $=2$, Occasional $=3$ ). So, as the mentor increases (goes from Seldom to Occasionally) exhibiting the TL behavior of IC, the mentee will increase 3 points in their scoring. This is significant because the mean for the mentee's human skills is 20.5 (according to Table 4.6). A 3-point increase in scoring could move the mentee from a moderate demonstration of human skills (Moderate Scoring Range $=14-22$ ) to a high demonstration of human skills (High Scoring Range $=23-30$ ).

When evaluating factors that positively contribute to the development of the mentee's conceptual skills, the transformational characteristics of the mentor again showed the strongest positive relationships (Table 4.8), followed by the mentor's 
willingness to introduce the mentee to influential people inside of the organization (a significant relationship was observed across all of the TL characteristics). In addition, the mentor's willingness to meet the needs of the mentee and the mentor's experience (observed across the II characteristic) showed a strong positive relationship and contributed to the mentee's development and growth of conceptual skills. Alternatively, the mentor's willingness to meet the need of the mentee (a significant relationship was observed across the IM, II, and IS characteristics) and the mentee's feeling of closeness with their mentor (a significant relationship was observed across the IS and IC characteristics) showed strong positive relationships and contributed to the mentee's development and growth of human skills.

The results also show that mentor's that demonstrate TL characteristics, help to develop those same characteristics/behaviors in their mentees. For example, in Table 4.9, we assessed the relationship between the mentor's demonstration of Intellectual Stimulation (IS) characteristics/behaviors and the subsequent demonstration of those behaviors by the mentee. Results showed that the mentor's behaviors significantly affected the behaviors of the mentee $(B=1.81, S D=0.66, p<0.05)$. More specifically, the results show that as a mentor increases their demonstration of IS behaviors by one unit (frequency of demonstrating the behavior), mentees will also increase there IS behavior by 1.81 (if the other variables are held constant). That is a substantial returnon-investment, visible by the protégé now demonstrating intellectual stimulation by 
challenging their teams and subordinates to be creative and innovative, or challenging their followers to higher levels of performance.

In addition to the mentee's TL characteristics, the results also showed other interesting relationships. For example, mentees that felt close to their mentor or felt that their mentor met their needs (both variables associated with goodness of fit), consistently demonstrated more human skill development than those that did not establish those relationships. Based on these results, we can accept the alternative hypotheses (and reject the null hypotheses) that mentees that perceive their mentors as transformational ( $\mathrm{M}, \mathrm{II}, \mathrm{IS}$, and IC) will be more likely to demonstrate human and conceptual skills; and that mentees that perceive their mentors as transformational (IM, II, IS, and IC) will be more likely to demonstrate TL behaviors, controlling for the Mentoring Process/Good of Fit and Individual Mentor/Mentee Characteristics variables.

\section{Major Finding 3: Spending Time with Mentees Help to Facilitate Development of \\ Critical Transformational Leadership Behaviors}

According to the frequency statistics in Figure 4.1 , about $40 \%$ of protégé met with their mentors one hour or less per month. Another $37 \%$ met with their mentor for two hours a month. The average time that mentors spent with their mentees was about three hours per month, mean $=2.84$ (Table 4.6$)$. Even though $60 \%$ of mentees met with their mentor for two or more hours a month, $24 \%$ of mentees stated that they seldom or never felt close to their mentor (Table 4:4) and 23\% stated that their mentor either did not meet or seldom met their needs or preferences (Table 4:4). 
Study results suggest that the more time mentors spend with their protégé, the more the mentee develops TL behaviors (IM and II) in the mentee. For example, in Table 4.9, there were significant positive relationships associated with time spent with the mentor, when controlling for the mentee's gender \& ethnicity, mentor's gender \& ethnicity, closeness with the mentor, the mentor's certification status, the mentor's ability to meet the mentee's needs, the mentor's years of experience, and the mentor introducing the mentee to influential people insider \& outside of the organization (IM standardized $B=.35, p<0.01 ;$ II standardized $B=.30, p<0.01)$. Specific to Idealized Influence, time with the mentor significantly impacted the ability of the mentee to develop II. This result shows that for every additional 60 minutes spent with the mentor, the mentee demonstrates .30 II behaviors. These results make more sense when we reflect on the scales. The mean for time spent with the mentor was about 3 hours (2.84) and the mean for the mentee's demonstration of II behaviors was 11.13. Per the scale utilized to determine the mentee's demonstrated behaviors (Attachment D), the average range for demonstration of II was 7-11 and the high range was $12-15$. If the mentor increased the amount of time spent with their mentee by three hours to a total of 6 hours per month, the additional time would raise their mentee's score (by .90) to 12.03. According to the scale, this would mean that by increasing time spent with the mentee, the mentor can facilitate the mentee's demonstration of a higher level of II, or consciously acting as a role model and striving to establish trust with their subordinates. 
Major Finding 4: Protégé Develop Leadership Capabilities as They Interact with Other Influential Leaders in the Organization

According to Table 4.8, mentors consistently facilitated the mentee's growth of conceptual skills by introducing them to influential people in the organization (Intro to People). Specifically, each transformational characteristic demonstrated by the mentor significantly impacted the development of conceptual skills for the protégé (IM $\beta=1.60$, $p<0.01 ;$ II $\beta=1.10, p<0.05 ;$ IS $\beta=1.81, p<0.001$; and IC $\beta=1.37, p<0.05)$ when controlling for the Goodness of Fit and Individual Mentee/Mentor Characteristics variables. The mentor's demonstration of Intellectual Stimulation, or challenging the follower to be innovative and creative, was the strongest predictor of conceptual skill development for the mentee $(\beta=1.81, p<0.001)$.

\section{Major Finding 5: The Structure of Formal Leadership Development Programs in Public Organizations Should Support the Development of Transformational Leadership \\ Capabilities}

According to Table 4.11, There was a significant negative relationship between mentors that had obtained certification status (either resident or fellow) and the certification status of the mentee (standardized $B=-.28, p<0.05$ ). According to this result, certified mentors seems to have a negative impact on a mentees decision to obtain certification. Beyond this finding, the results seem inconclusive because one of the TL characteristics of the mentor (Intellectual Stimulation) seems to have a significant positive relationship (standardized $B=.55, p<0.01$ ), while another TL characteristic 
(Individualized Consideration) seems to have a significant negative relationship (standardized $B=-.58, p<0.05)$. It is unclear how a mentor that encourages their mentee to look at problems in a new way or is tolerant of their protégé's extreme position would positively affect the mentee's willingness to obtain certification status; while at the same time the mentor sharing concern for the well-being of the mentee and striving to make them feel important would negatively affect the mentee's certification status. For this reason, we highlight this area as a focus for more extensive research in the future and reject the alternative hypothesis (accept the null) that mentees that perceive their mentors as transformational will be more likely to become certified mentors. 


\section{CHAPTER V: DISCUSSION}

"Words may show a man's wit but actions his meaning." - Benjamin Franklin

\section{Background}

The previous chapters have detailed the background, literature review, methodology, and the results of this doctoral study. In chapter 1 , the background and context were provided to detail the critical need for strong leadership in public organizations. To improve performance and strive during turbulent times, institutions must produce and sustain high quality leadership. Chapter II identified relevant research on leadership and emphasizes the role that mentors play in developing leadership capacity and transferring knowledge. The chapter introduced the Leadership Development Model and detailed several theories that provide a foundation for my research, including the Complexity Leadership Theory (describing how leadership occurs in complex adaptive systems and why conceptual skills are necessary for developing leaders) and the Social Learning Theory (highlights observational learning and imitation as a modeling behavior). It also introduced four critical components to transformational leadership (Bass \& Riggio, 2006): idealized influence, inspirational motivation, individualized consideration, and intellectual stimulation.

Chapter III provided information about the case study, the Veterans Health Administration (VHA) and their Veterans Integrated Service Network (VISN) level 
leadership development program. Additionally, the chapter described the process for selecting participants, gathering data, and the data analysis plan. Chapter IV provided the research findings based on data collected according to the methods, including descriptive data, frequency tables, and regression analyses. Themes were developed from interviews and surveys collected from 70 leaders that participated in one of eighteen VISN programs. Study participants all identified or were assigned a mentor as a core of the program.

\section{Study Purpose}

The purpose of this research study is to further explore formal mentorship programs in the public sector. More specifically, this study seeks to better understand the influence that senior public sector mentors have on the development of protégé skills and behaviors, by utilizing the Veterans Health Administration as a case study. A major function of a case study is to test theories, generalizations, and frameworks by using them to analyze important issues. However, the intent of this study is not just to use the case to compare the utility of the VHA LEAD Program, but to also provide an explanatory account of the individual and organizational elements that influence the development of leader behavior and ensure the sustainability of the mentoring program. This study intends to show that the transformational behaviors of the mentor positively affect the growth and development of the protégé and the sustainability of the mentorship program. 


\section{Research Questions}

This study sought to answer the following research questions:

* To what extent do mentees perceive their mentors to be transformational leaders as defined in the literature?

* What transformational characteristics of the mentors are most important to the mentee's growth of leadership capabilities, as perceived by the mentee? Does this perception vary depending on time with mentor, and gender and race of mentee and mentor?

* How does this perception relate to mentees appraisal of their willingness to become mentors in the VISN LEAD program?

The following findings address each research question in light of the results of this study. 


\section{Discussion of Major Findings}

\section{Major Finding 1: Most Mentors Participating in the Formal Leadership Develop Programs Were Found to Demonstrate Transformational Leadership Characteristics}

The results of this study (Table 4.5) show that most mentees felt that their mentors demonstrated transformational leadership (TL) characteristics during the VISN leadership development programs. This result was expected (since most VISN programs required that mentors selected were certified) and is important because according to Bozeman and Feeney (2008), all mentoring relationships are not transformational or clearly able to assist the protégé in changing their behavior or elevating their performance. Mentoring places more senior leaders in a position where they are the expert and are "expected to facilitate the job, learning, and to some extent the psychological well-being of the mentee" (Middlebrooks \& Haberkorn, 2009, p. 9). As a result, the success of the formal mentoring program depends, in part, on the motivation, knowledge, and abilities of the individuals that fulfill the roles of mentors in the program (Wanberg, Welsh \& Hezlett, 2003). Specific to VISN LEAD programs, the mentors exhibited their motivations and expertise by consistently demonstrating the four components of transformational leadership noted by Bass \& Riggio (2006):

- Idealized Influence (II) - the leader serves as an ideal role model for followers; the leader "walks the talk," and is admired for their charisma and their ethical and moral orientation.

- Inspirational Motivation (IM) - the leader inspires, motivates, and calls out followers to reach ambitious goals, communication confidence in followers. 
- Individualized Consideration (IC) - the leader demonstrates genuine concern for the needs and feelings of followers. This personal attention to each follower is a key element in bringing out their very best efforts and helps them grow beyond their expectations.

- Intellectual Stimulation (IS) - the leader challenges followers to be innovative and creative by challenging followers to question the status quo, challenge assumptions, and examine challenges with new lenses.

Important to note, two of the four T.L. components also address transactional leadership characteristics. At times, transformational leaders utilize transactions to accomplish the vision/mission of the organization and to facilitate change (Bass, 1990). For example, to "inspirationally motivate" or "intellectually stimulate" employees, a transformational leader may offer incentives aimed at keeping employees motivated and productive. This leader may also clearly define performance expectations (utilizing performance management systems) and offer contingent rewards for exceeding the expectations, or detail disciplinary actions associated with not meeting the expectation (these are traditionally considered transactional behaviors).

In addition to utilizing transactions to accomplish organizational goals and objectives, transformational leaders also engage their followers in a way that the followers are inspired (over and above the formal exchange) and empowered to meet the desired goal (Northouse, 2016). Transformational leaders work with the team to ensure they will be successful, they are involved and participate in the process of achieving the goals and objectives with the team. 
Another important point to emphasize is that the mentors were demonstrating these TL characteristics while operating in VHA, a complex adaptive system (CAS) or "neural-like networks of agents" with multiple, overlapping hierarchies that are bonded in a cooperative dynamic by a common goal (Uhl-Bien, Marion, \& McKelvey, 2007, p. 299). The Veterans Health Administration is America's largest integrated health care system, providing care at 1,255 health care facilities and serving 9 million enrolled Veterans each year (www.va.gov/health). Roughly $60 \%$ of all medical residents obtain a portion of their training at VA hospitals and their medical research programs benefit society at-large (https://www.portland.va.gov/about/history.asp). Within this system, a medical center director and senior leadership team could be responsible for managing a budget of $\$ 600$ million dollars, 6,000 employees and volunteers, a $\$ 80$ million dollar research budget including national Centers of Excellence (e.g. epilepsy treatment, cardiac surgery, post-traumatic stress disorder, HIV and renal dialysis), and multiple affiliations with medical, nursing, and professional schools (e.g. Oregon Health \& Science University, Duke University). In addition to managing local operations, these senior leaders must also actively engage and partner with local political leaders, public and non-profit organizations, and private organizations to serve Veterans, their families, caregivers, and survivors. Despite these complexities, employees at every level of VHA are bonded in a cooperative dynamic by the mission of the organization, to honor America's Veterans by providing exceptional health care that improves their health and well-being. This study support Complexity Leadership Theory and confirms the 
necessity of effective leadership development programs in public organizations that equip aspiring senior leaders of tomorrow with the necessary human and conceptual skills to manage complex, wicked problems and to help generate the cultural clarity and consistency among members that enhance the organization's performance (Torfing, 2012).

Baldwin \& Ford (1988) asserted that the quality and nature of a leadership development program contribute to its effectiveness to develop leaders. This study adds to that argument and posits that a mentoring program should be a key component of an effective leadership development program. Mentoring focuses on developing capability and facilitating the protégé's learning. Mentor roles include "advisor, sponsor, tutor, advocate, coach, protector, role model and guide" (Hadden, 1997, p. 17). The roles of a mentor are directed toward the improvement of the protégé's skills, performance, and development that the protégé lacks at the beginning of the relationship. It consists of a trusted person acting as a sounding board, encouraging a range of perspectives and providing the benefits of their own experience.

\section{Implications}

This study has important implications for public administrators and leaders who aim to develop or improve their current mentoring programs in organizations. Specifically, as formal mentoring programs become more popular, there is an opportunity for public administrators to better understand which capabilities are most important to develop in future leaders and to mentor/coach protégé to develop those 
characteristics and behaviors. This study argues that T.L. components should be used as a foundation to build future LDPs and mentoring relationships.

Specific to VA, this means expanding or revamping the current VHA certified mentorship program. The current program guides mentors through extensive training on coaching/mentoring (40 hours), utilizes the GROW Model (Alexander, 2010) to promote goal setting and problem solving, and includes 50 hours of documented mentoring prior to becoming a fellow (25 hours prior to becoming a resident). Despite the effective, structured approach for initial training and certification, there are limited opportunities for formal review or retraining once the mentor becomes a fellow. This gap provides an opportunity to expand the current program by establishing annual refresher training focused on sharpening the mentor's transformational leadership characteristics and behaviors. Additionally, standardized mentoring guides and templates (aligned with the four key transformational components) should be created to provide mentors with sample activities and assignments that can further strengthen their leader's capabilities. Additionally, by instituting a formal feedback survey that is completed by both mentors and mentees following the mentoring process, mentors will be able to receive real-time feedback on opportunities to further transform their behaviors. Finally, there is also an opportunity to create pledge forms that mentors sign prior to becoming a fellow. These forms could reinforce their commitment to the develop of leadership capacity in the organization and ensure they understand their 
commitment to consistently exhibit transformational leadership behaviors and characteristics in the organization.

Another implication for public organizations is related to their performance management systems. Many public organizations have performance management systems that are utilized to communicate the organizational goals to individual employees, allot individual accountability, track progress towards the goals, and evaluate individual performance (Bernecker, Klier, Stern, \& Thiel, 2018). To operate effectively, these systems require leaders that can link performance goals to business priorities, effectively mentor and coach mid-level leaders, and differentiate compensation across levels of performance (Chowdhury, Hioe, \& Schaninger, 2018).

To ensure the provision and sustainability of effective leaders, public organizations must clearly define the characteristics that senior leaders must demonstrate to be effective. This study posits that the four components of transformational leadership should serve as the model to standardize senior leader expectations across the industry. These characteristics include a focus on the psychosocial factors and the career development factors found to be most important for leadership development and mentorship. This study also posits that by purposefully incorporating training components into the mentor development program, an organization can better ensure that the certified mentors have the ability and attitude necessary to promote the development of aspiring senior leaders. 


\section{Major Finding 2: Mentors that Demonstrate Transformational Leadership Characteristics Facilitate the Effective Development and Growth of Mentees}

This study contributes to theory and practice in several ways. Theoretically, while a few studies have examined predictors of leader performance independent from one another, this study integrates several of these components (i.e. mentor behaviors, goodness of fit variables, individual variables) into a single framework under an established theoretical model (i.e. the Leadership Development Model). This study supports the Leadership Development Model, which provided a framework for this study. The model highlights the work of Mumford et al. (2000) and focuses on key career experiences and effectors that impact the development of leaders and their ability to solve new and unusual, ill-defined organizational problem. The model defines mentoring as the informal transmission of knowledge, social capital, and psychological support; and contends that mentoring from trusted leaders is a primary effector of competencies and a secondary effector of leader individual attributes. This study expands the definition of the mentoring to include the formal transmission of knowledge as part of a structured and organized mentoring program. The study further adds that formal mentoring is a primary effector of both, a leader's competencies (e.g. human and conceptual skill development) and their attributes (e.g. demonstration of Idealized Influence marked by charisma and moral orientation).

According to the results in Tables 4.7 - 4.9, the demonstration of TL characteristics by the mentor had the most significant impact on the development of 
the mentee's leadership capabilities (human and conceptual skills and analogous TL behaviors), followed by the mentor's willingness to meet the needs of the mentee. These results support the Social Learning Theory which argues that learning is a cognitive process that can occur through observation and that new behaviors can be acquired by observing and imitating others (Bandura, 1986). According to Bandura (1986), "through modeling, we can transmit skills, attitudes, values, and emotional proclivities" (p. 5). This study supports the SLT by demonstrating that the mentee's observation of their mentor led to increased development of human and conceptual skills in the protégé (the survey asked this question specifically). The observations were also positively linked to the mentee developing and demonstrating similar TL characteristics and behaviors. Bandura (1986) found that individuals change because the skills needed to be effective in their efforts to bring about change were demonstrated. According to Bandura (1986), "through modeling, we can transmit skills, attitudes, values, and emotional proclivities" (p. 5). Results from the study confirmed the importance of modeling behavior.

In addition to the mentee's TL characteristics, the results also showed other interesting relationships. For example, mentees that felt close to their mentor or felt that their mentor met their needs (both variables associated with goodness of fit), consistently demonstrated more human skill development than those that did not establish those relationships. This observation underscores the importance of goodness of fit when matching mentors and protégé. To maximize the development of the 
mentee, programs should support more natural mentoring relationships that occur as individuals selectively come together through personal or professional friendships. Specific to VA and other public organizations, this process may be facilitated by providing the mentees with a list of eligible and available mentors and allowing them to contact prospective mentors to identify their ideal mentor prior to the LDPs. This practice may help to promote effective transformational mentoring relationships, tailored to the individual needs of the protégé and established through person-toperson communication.

Hezlett (2005) measured what protégé learned from mentors and how they learned it. Her results revealed 41 factors that protégés learned from their mentors, with the majority being skilled-based learning and cognitive behaviors. One of the most interesting conclusions from her study was that learning occurred most frequently through protégé observation of mentors (29.3\%), followed by learning from mentor's explanations (24.4\%), and finally by protégés interacting with their mentee (17.1\%). Lankau and Scandura (2002) further noted that role-modeling was one of the most important ways that learning occurred in mentoring and that it was directly associated with skill development for protégés (p. 787). Additionally, they stated that, "Protégés who admire their mentors and view them as role models may be more attentive to their mentors' behaviors and more likely to try behaviors that they observe their mentors accomplishing successfully. 
This study confirms the SLT and that "observational learning" and imitation contribute to the development of critical leader competencies and transformational characteristics/behaviors in protégé. Study results demonstrated a positive, significant relationship between the mentor's demonstration of a transformational leadership characteristic and the subsequent demonstration of the same transformational characteristic by the protégé in all four instances. Additionally, the study confirmed Hezlett's findings and showed a significant relationship between protégé development of human or relational skills and the protégé feeling close to their mentor and feeling that their mentor met their needs. Specific to role-modeling, mentors that demonstrated Idealized Influence (leader served as an ideal role model and was admired) also significantly contributed to their protégé demonstrating the same characteristics.

\section{Implications}

The results consistently showed that "modeling," the behaviors of the mentors significantly affect the characteristics and behaviors of the protégé. From a social learning perspective, if leadership behaviors are learned and sustained via associations with mentors, then it follows that these behaviors could be modified "to the extent that one is able to manipulate those same processes or the environmental contingencies that impinge on them" (Akers and Sellers, 2004: 101). From this perspective, public organizations should focus on developing and implementing programs that use social 
learning variables (i.e. mentoring programs) to teach desired behaviors that influence change in a positive direction.

Public organizations must invest in establishing or strengthening formal leadership development programs that help boost business performance and enhance leadership and team skills (Kur and Bunning, 2002). The programs must promote opportunities for strong senior leaders to develop the capabilities of middle managers and "facilitate the job, learning, and to some extent the psychological well-being of the mentee" (Middlebrooks \& Haberkorn, 2009, p. 9). The program should also consider goodness of fit when matching mentors to mentees. This may not always be achieved by automatically assigning mentors; rather, organizations should consider giving mentees the opportunity to select mentors from an approved list (following research and person-to-person communication), prior to assigning formal mentors. Finally, Part I offers some elements that leadership development programs should consider ensuring effectiveness. For example, formal leadership development programs might consider including a 360- degree surveys (or similar) that provides participants with an opportunity to receive performance feedback from their supervisors, peers, and subordinates to help guide them toward continuous improvement.

The idea behind some of these types of programs is that providing positive experiences and role models for aspiring leaders might serve to expose them to conventional norms and values that promote more effective leadership. If public organizations are going to create and sustain leadership capacity in the organization, 
they must focus on two areas: 1 ) creating programs that identify and build mature transformational leaders/mentors, and 2) establishing a formal development program that facilitates the modeling and transfer of transformational behaviors. Leaders and mentors don't automatically develop the ideal knowledge and behaviors that support the organization's mission and vision. Leading organizations recognize this fact and actively develop programs and processes to identify those same characteristics in "new to the organization" leaders that are hired into the organization. Noted on the application, reinforced through the recruitment process, solidified during orientation the organization must ensure that new leaders understand the culture that they are creating.

Another implication for public organization is related to the power of observation and imitation to change an organization's culture. To positively change the culture, senior leaders must consistently demonstrate the positive T.L. characteristics/behaviors identified in this study. Through observation and imitation, emerging leaders would also begin to exhibit these characteristics and behaviors which would be observed by their colleagues and employees. Over time, the consistent demonstration of these characteristics by employees at every level would result in a positive organizational culture change. 


\section{Major Finding 3: Spending Time with Mentees Help to Facilitate Development of Critical Transformational Leadership Behaviors}

Baugh and Fagenson-Eland (2005) cite frequency of meetings between mentors and protégé as an important factor in the protégé development and posits that communication frequency is positively correlated with positive results in formal programs. Results of this study support their finding and show that communication frequency predicts the development of mentee transformational leadership behaviors. This study expands current research on leadership by suggesting that mentors should spend at least two hours with their mentor per month, with the ideal amount of time being 4-6 hours to maximize the development of T.L. leadership characteristics (i.e. Idealized Influence and Inspirational Motivation) in the mentee.

The quality of the time spent with the mentee is also important. According to this study, even though some mentees spent time with their mentors each month, $24 \%$

of mentees reported that they seldom or never felt close to their mentor (Table 4:4) and $23 \%$ stated that their mentor either did not meet or seldom met their needs or preferences (Table 4:4). Kram (1985) noted that an important function of a mentor is to provide personal support, especially psycho-social support to the mentee. This means that mentors are responsible to tailor the mentoring activities to the individual needs of the protégé so that they transmit the knowledge preferred by the protégé effectively (Bozeman and Feeney, 2008). 


\section{Implications}

These results suggest that if mentors spend about 4-6 hours with their mentee per month (roughly an hour/week), that time will facilitate their development of high levels of transformational leadership behaviors. Although many public programs include mentorship as an important component, there are not always guidelines about how much time mentors should spend with mentees. Significant time with the mentor can help protégé eliminate needless errors and can promote reflection and thought about their actions before performing them. Through informative learning, mentees are also exposed to models and guides that may be useful in the future (Ragin \& Cotton 1999). The VA LDPs should consider including the target for mentors to spend about 4-6 hours a month, during which time the mentor can model behaviors that the protégé can mimic. This modeling helps an individual develop the belief that they can accomplish what someone else has accomplished (McGowan, 1986). In order to serve as a role model, express interest in their hopes and dreams, make them feel their work is important, or inspire them to greater accomplishments, the mentor must spend time with the mentee.

In addition to setting a target for mentors to spend time with mentees, organizations should also provide guidance for how the mentor can provide psychosocial support for the protégé. This is specifically highlighted in the Individualized Consideration T.L. characteristic, which states that the mentor should demonstrate a genuine concern for the needs and feelings of the followers. This could be 
accomplished by spending time during the session asking about some of the mentees current challenges and working through how they can meet those challenges. This research re-emphasizes the importance of devoting personal attention to each mentee and understanding their needs to lift them to extraordinary heights (Boal \& Bryson, 1988). 


\section{Major Finding 4: Protégé Develop Leadership Capabilities as They Interact with Other Influential Leaders in the Organization}

This study highlights the importance of internal networks to a leader's ability to further develop their conceptual skills. Specifically, the findings showed that introduction to influential people inside of the organization helped protégé develop key conceptual skills that allow them to understand complex situations and develop creative and successful solutions (Northouse, 2010). Katz's Three-Skill Approach (Katz, 1955) suggests that as leaders transition from middle management to executives/top management, it becomes more important for them to acquire and consistently demonstrate conceptual skills, or the ability to think through and work with ideas and concepts. Conceptual skills include the ability to formalize and effectively communicate a vision for the future. It includes developing a more global understanding the organization and how the individual components work together to accomplish the mission and goals. These skills are most important at top management levels and are key to a leader's ability to manage organizational changes because as leaders became more familiar with other leaders across the organization, they better understand the bigger picture and how the organizational pieces fit together. Dansky (1996) even noted that networks increase the protégé's exposure and visibility to other networks outside of the protégé's organization, thus facilitating their knowledge and growth.

Another reason these networks are important is because mentees receive feedback through these networks. Feedback is defined as the way the learner responds 
that reverses the direction of change (Northouse, 2004). Learners act upon the world based on what they perceive and thereby change their environment and what they consequently perceive of it. Two primary ways that feedback is provided in organizations is through formal mentoring and peer networks (Northouse, 2004). This study confirms that feedback occurs during the mentoring relationship (i.e. individualized consideration and intellectual stimulation) and recognizes that it can impact what the protégé feels is appropriate for senior level leaders. Through feedback and observational learning, protégé gain invaluable knowledge that allows them to look and act the part of a senior leader.

Higgins and Kram (2001) introduced relationship constellations, where individuals receive mentoring assistance from many people at any one time, including senior colleagues, peers, family, and community members. They classified these constellations as "developmental networks" and detailed their importance to the protégé's career development.

\section{Implication}

In addition to demonstrating and modeling transformational leadership characteristics, mentors can further encourage their protégé's growth by introducing them to other influential leaders in the organization. As such, public organizations should incorporate expectations (into their mentoring program guidelines) for mentors to identify other leaders in the organization that the protégé can also meet with. This time spent with other leaders in the organization would count in the recommended 4-6 
hours that they spend with the mentee and share the responsibility of developing leadership capabilities across the organization.

Introducing mentees to other leaders reveal a delicate balance within mentoring. It acknowledges that the mentee's growth should extend past only what the individual mentor can offer. It is a way of embracing the shared responsibility to develop leader capacity across the organization and requires a trust in other mentors and their abilities to also speak into the life of the protégé. As Steven Spielberg stated, "the delicate balance of mentoring someone is not creating them in your own image, but giving them the opportunity to create themselves." Introduction to other leaders across the organization helps the protégé define and create themselves in a supportive and nurturing environment.

For public organizations (specifically the Department of Veterans Affairs), there are many opportunities to introduce mentee to other influential leaders. Sometimes these opportunities present as detail opportunities, or even the ability to spend time in other areas of the organization to gain additional knowledge or significant processes or programs. Through these challenging experiences, mentees have an opportunity to put learned skills and behaviors into use. There may also be opportunities to share responsibilities with developing leaders. By assigning them cross-divisional projects that require that they work with other leaders in different areas, mentees are provided opportunities to learn more about the overall organization, thus further developing their conceptual skills. LDPs should be careful to promote and provide these 
opportunities to mentees, especially following graduation or completion of the formal LDPs. 


\section{Major Finding 5: The Structure of Formal Leadership Development Programs in Public Organizations Should Support the Development of Transformational Leadership \\ Capabilities}

The Leadership Development Model captures the importance of LDPs and classifies them as "training to develop knowledge and skills" (Northouse, 2004). According to his model, training is a primary effector of competencies. This research supports this relationship, especially since many of the other effectors are established through LDPs. For example, mentees are formally aligned to a certified mentor as part of the program. Additionally, the program facilitates the coaching, peer networks, and the feedback that all affect the development of the leader.

Through the VISN LEAD Program, the Veterans Health Administration has been able to produce a highly diversified and talented cadre of potential leaders across the nation. Despite its success, the program has been challenged to recruit new mentors, willing to assume the responsibilities of an "advisor, sponsor, tutor, advocate, coach, protector, role model, and guide" (Hadden, 1997, p. 17). This observation was confirmed by the results. According to Table 4.10, There was a significant negative relationship between mentors that had obtained certification status (either resident or fellow) and the certification status of the mentee (standardized $B=-.28, p<0.05$ ).

According to this result, certified mentors seems to have a negative impact on a mentees decision to obtain certification. 


\section{Implications}

Leadership development programs provide a proven approach for learning organizations to increase employee leadership abilities and realize positive organizational results. Leadership development focuses at the group and organizational levels, where an environment is created to support the continued development of multiple leaders in the organization towards positive interpersonal communications, networking, organizational cooperation, and organizational culture. Within leadership development programs, mentoring plays a key role in the individual growth and career development of employees.

While mentoring is a critical component of LDPs, mentoring can be a thankless job at times that can become burdensome due to the required time, resources, emotional investment, and mental energy needed to support the protégé. This responsibility can be further impacted as mentors work through diversity challenges or work through situations where mentees may share different ideals or beliefs. Arguably, it is the responsibility of organizations to assist in making this important role and responsibility "desirable." Organizations can recognize and incentivize leaders who have taken on this noble responsibility to ensure they are equipped and motivated to provide this critical function.

Leadership development programs should complement and support the development of the mentee's transformational leadership characteristics and behaviors. For example, by requiring that each mentee completes an individual development plans 
and a 360-degree survey, the program can enforce critical evaluation and reflection necessary for human and conceptual skill growth. Additionally, leadership development programs can be structured to further build important transformational leadership characteristics for protégé through standardized exercises, projects, or assignments. Specific to VA/VHA, there may be an opportunity to standardize how the VISN leadership development programs are structured to ensure that each includes these elements. The standardized training should also define the number and length of faceto-face components (e.g. three week-long sessions that occur once per quarter), homework or expectations for in-between sessions, and the methods that would be utilized to measure learning for participants.

Collins (2001) argues that building lasting organizational greatness requires building multiple generations of leaders. This is the goal of formal leadership programs, to create great leaders that are focused on mentoring others to build critical capacities and achieve organizational needs and objectives. Formal leadership development programs provide a way for public organizations to engage their leaders, achieve transformational outcomes, and establish generations of knowledgeable, well-trained leaders. This study helps the field to better understand how to best develop future leaders able to handle "wicked" and unprecedented changes in the $21^{\text {st }}$ century. 


\section{Conclusion and Final Thoughts}

From the literature review in Chapter 2, we knew that mentorship played a key role in protégé success; however, it was unclear what characteristics of mentors were most important to the mentee's growth (development of human and conceptual skills) and their subsequent change in behavior. This study clarified that four transformational characteristics are important for mentors to demonstrate to support a protege's growth: Idealized Influence, Intellectual Stimulation, Inspirational Motivation, and Individualized Consideration. Each of these characteristics play an important role in developing effective leaders.

The Leadership Skills Model (Figure 2:2) framed leadership as the capabilities (knowledge and skills) that make effective leadership possible and helps to elucidate the capabilities necessary to make an effective leader. However, it did not discuss how these skills were further developed in emerging leaders. The Leadership Development Model built upon the skill model to further illustrates five effectors that impact the development of leadership attributes and competencies and the Social Learning Theory (SLT) was used to understand how imitation, as a modeling behavior, can help individuals learn from example (Bandura, 1977). This study demonstrates that a key way that these skills are acquired are through observation and imitation during the mentoring relationships. Additionally, this study shows that the behaviors of mentors (specifically the demonstration of transformational leadership characteristics) can positively affect those of the protégé and help us to better understand the impact that 
mentor transformational characteristics, goodness of fit characteristics, and individual mentee/mentor characteristics have on protégé skill development and behavior.

From the literature, we also knew that transformational leaders have been associated with creating and inspiring a shared vision for a group. They are expected to impact behavior by lifting those that they lead to extraordinary heights. What was unclear was what type of impact a mentor that exhibits transformational behaviors could have on the behaviors of the protégé. This research suggests that the mentors that consistently demonstrate TL behaviors have a significant impact on the protégé to develop similar characteristics and behaviors, providing the opportunity for cultural change. This study also demonstrates that transformational leaders/mentors can facilitate the protégé's ability to learn new skills (Kirkpatrick Model, Level II) and to exhibit new behaviors (Kirkpatrick Model, Level III). This is over-and-above the results of many studies that just measure participant satisfaction with the program or their mentor.

Finally, this study establishes additional behaviors that mentors should exhibit. For example, the results showed that purposefully introducing mentees to influential people or other key leaders in the organization helped them to develop both human and conceptual skills. As mentee's become more knowledgeable about the different roles and responsibilities across the organization, they are more able to make sense of abstract ideas within the system for their superiors, peers, and subordinates (Northouse, 2010). 
In an interview following his movie premiere, Denzel Washington said, "Show me a successful individual and I'll show you someone who had real positive influences in his or her life. I don't care what you do for a living-if you do it well, I'm sure there was someone cheering you on or showing the way. A mentor." Regardless of the industry, mentorship is critical for protégé interested in continuing their growth and development. As the results have shown, mentors facilitate the development and growth of their protégé's leadership capabilities, to include both skills and behaviors. To maximize these opportunities and ensure the growth of leadership capacity across the organization, it is important that public organizations design LDPs that focus on supporting strong mentorship relationships. 


\section{Research Limitations}

There are several limitations to my research study. One limitation of this study is the ability to generalize the findings and results across industries. This study examined the leadership development programs of the Department of Veterans Affair's Veterans Health Administration to assess the impact of transformational mentor behaviors on the skill development and behaviors of aspiring senior leaders or protégé. VHA is the largest and most complex integrated health care system in the nation and it employs over 360,000 employees across 18 varied geographical regions. For this reason, the study results may be generalized to large health care systems and to public organizations interested in developing and preparing future senior executives and organizational leaders.

In addition, the study may also be generalized to other public, private, and nongovernmental organizations. According to Morgan (2006), these institutional forms share common boundaries when it comes to organizational theory; and as specifically outlined by the Complexity Learning Theory, each of these organizations operate in complex environments where there leaders are required to manage the diverse needs of the organization and pursue collective goals. For this reason, it is probable that the study is capable of explaining and predicting the production of public sector innovation (in this case, the production of future leaders) in general-purpose governments and forprofit private agencies (Davis, 2018); but future research is necessary to confirm this possibility. The Center of Creative Leadership (www.ccl.org) also suggests that leaders 
from both public and private health systems manage similar leadership challenges and require similar leadership capabilities to manage unique challenges.

In addition to validating the findings in different industries, this sample was also limited by not having enough sample representativeness to determine if the findings were consistent across race, gender, and ethnicity groups (Lankau \& Scandura, 2002). Because minorities represented a small portion of the sample, the results may not be representative of all ethnicity groups or be applicable in health care settings with many minority leaders. Ely \& Rhode (2010) raised important issues about access to mentoring relationships and other leadership development opportunities for minorities and women. Specifically, Ely \& Rhode (2010) noted the woeful unavailability of mentoring at the workplace for minority populations and leaders that can put them at a distinct disadvantage with respect to job advancement and career opportunities. The lack of representation for minority groups in this study limits our ability to further understand these dynamic relationships (e.g. success factors, outcomes) in non-White, non-male populations.

Another limitation of the study is that most of the data in Part I and Part II was self-reported data which can rarely be independently verified and is thus subject to common method bias. This bias was unavoidable because study participants were anonymous and voluntarily participated in the study. Accordingly, there was no other self-report constructs that could not be used to assess mentor behavior and no reason to believe that respondents were untruthful (Conway \& Lance, 2010). 
Other limitations of this study include the researcher inability to directly connect the results in Part I with Part II. Initially, the researcher planned to ask more descriptive questions on the survey to leaders (i.e. what is your facility/VISN) to determine if there was a relationship between structural program components and leader development. This potential identifier was removed during the IRB review process to ensure the data was de-identified. An additional limitation was the limited time available to complete the research. Ideally, this research would examine and measured a change in protégé behavior over time (a longitudinal study). However, because of the limited time available, the data received originates from 1-2 encounters with the research subjects and represent a cross-sectional sample. Missing data from participants is also a limitation when fewer data points can be included in the study due to missing items from the surveys (Smith, et al., 2005). 


\section{Implications for Future Research}

This research showed that mentors play an important role in the development of protégé leadership capabilities (skills and behaviors). More specifically, it showed that through modeling transformational leadership behaviors, mentors can facilitate the development of these analogous characteristics in mentees. Based on this study, there are several interesting areas to examine in future research. For example, even though this study demonstrated that mentor's that possess transformational leadership characteristics play a critical role in the development of protégé, it is still unclear how the organization ensured that its mentors had transformational characteristics. Did the organization purposefully look for their characteristics during the hiring processes or were they developed during the lower level leadership programs? It's also unclear what activities may be associated with developing the different type of transformational leadership characteristics. Future studies may examine these questions and help elucidate specific activities that public organizations can ensure they incorporate into their program. This study provides a model for key activities that can be incorporated in that study.

Another interesting topic could be identifying if there are specific "transactional factors" that could have explained the observed results. This study assumed that the transformational behaviors (e.g. Inspirational Motivation and Intellectual Consideration) included and utilized transactional factors during the mentoring relationships; but 
future research may focus on further defining and incorporating these factors to evaluate whether they could have explained the observed results.

It is also unclear what impact that ethnicity plays in ensuring transformational skill development, or if there are key differences across ethical groups. While this study included four ethnicity groups (Whites, Blacks, Hispanics, and American Indian/Alaskan Natives), there was very low enrollment for two of the ethnicity groups (Hispanics and $\mathrm{Al} / \mathrm{AN}=<2 \%$ ). In future research, a cluster or stratified sampling approach could be used to ensure different ethnic groups are significantly represented.

Finally, research opportunities exist to better understand if the results hold true across other public (i.e. non health care related), private, and non-governmental organizations. Increasing the sample size and including a more diverse sample may also provide additional insight into this question. There could also be additional qualitative research to further explore and explain the results obtained through the surveys. For example, a focus group with VHA leaders will help to better understand why introducing them to influential leaders inside of the organization is linked to the development of conceptual skills, or what characteristics contribute or detract from their willingness to become a certified mentor. These case studies can also explore the differences in program structure and effectiveness to identify a standard model that can be employed by public organizations to develop senior public administrators and leaders. Future studies may also be useful in examining additional characteristics of mentors that are also important to the mentee's development of leadership capabilities. 


\section{References}

Adams, W. (2015). Chapter 19: Conducting Semi-Structured Interviews in Handbook of Practical Program Evaluation, $4^{\text {th }}$ Ed. Jossey-Bass.

Akers, R. L. \& Sellers, C. S. (2004). Criminological Theories: Introduction, Evaluation, and Application ( $4^{\text {th }}$ ed). Los Angeles: Roxbury Publishing.

Allen, T. D., Poteet, M. L., \& Burroughs, S. M. (1997). The mentor's perspective: a qualitative inquiry and future research agenda. Journal of Vocational Behavior, 51, 70-89.

Allen, T. D., Russell, J. E. \& Maetzke, S. B. (1997). Formal peer mentoring: Factors related to protégé's satisfaction and willingness to mentor others. Group and Organization Management, 22, 488-507.

Alexander, G. (2010) [2006]. "Behavioural coaching-the GROW model" In Passmore, Jonathan (ed.). Excellence in coaching: the Industry guide (2nd ed.). London; Philadelphia: Kogan, 83-93.

Ardichvili, A., Natt och Dag, K., \& Manderscheid, S. (2016). Leadership Development: Current and Emerging Models and Practices. Advances in Developing Human Resources, 18 (3), 275-285.

Avolio, B. J. (1999). Full Leadership Development. Thousand Oaks, CA: Sage.

Auster, D. (1984). Mentors and protégés: power-dependent dyads. Sociological Inquiry, 54(2), 142-153.

Ayers, R. (2015). Aligning Individual \& Organizational Performance: Goal Alignment in Federal Government Agency Performance Appraisal Programs. Public Personnel Management, 44(2), 169-191.

Baldwin, T. \& Ford, K. (1988). Transfer Of Training: A Review And Directions For Future Research. Personnel Psychology, Spring, Vol. 41 Issue 1, 63-105.

Bandura, A. (1977). Social Learning Theory. General Learning Press.

Bandura, A. (1986). Social Foundations of Thought and Action: A Social Cognitive Theory. Englewood Cliffs, NJ: Prentice-Hall. 
Barling, J., Christie, A., \& Turner, N. (2008). Pseudo-Transformational Leadership: Towards the Development and Test of a Model. Journal of Business Ethics, 81, 851861.

Bass, B. M. (1985). Leadership \& Performance Beyond Expectations. New York: Free Press.

Bass, B. M. (1998). Transformational leadership: Industrial, military, and educational impact. Mahwah, NJ: Erlbaum.

Bass, B. M. \& Riggio, R. E. (2006). Transformational Leadership (Second ed.). Mahwah, NJ: Lawrence Erlbaum Associates.

Bass, B. M., Waldman, D. A., Avolio, B. J., \& Bebb, M. (1987). Transformational leadership and the falling dominoes effect. Group and Organization Studies, 12, 73 87.

Bauer, J. E., Duffy, G. L., \& Westcott, R. T. (2006). The quality improvement handbook (2nd ed.). American Society for Quality. Quality Press, Milwaukee.

Baugh, S. \& Fagenson-Eland, E. (2008). Formal mentoring programs: A "poor cousin" to informal relationships?" In B. R. Ragins \& K. E. Kram (Eds.), The handbook of mentoring at work: Theory, research, and practice (pp. 249-272). Thousand Oaks, CA: Sage.

Bernecker, A., Klier, J., Sebastian, S. \& Thiel, L. (2018). Sustaining high performance beyond public-sector pilot projects. McKinsey \& Company. Found on 1/30/2020 at http://www.mckinsey.com/industries/public-sector/our-insights/sustaining-highperformance-beyond-public-sector-pilot-projects\#.

Bersin Associates. (2009). Leadership development: Is it really worth the money? Retrieved on $1 / 7 / 2020$ from http://www.bersin.com/blog/post/2009/11/Leadership-Development---Is-It-ReallyWorth-the- Money.aspx.

Bertrand, J. W. M. \& Fransoo, J. C. (2002). Operations management research methodologies using quantitative modeling. Operations Management Research, 22(2), 241-264. 
Black, A. M. \& Earnest, G. W. (2009). Measuring the outcomes of leadership development programs. Journal of Leadership and Organizational Studies 16(2), 184196.

Boal, K. B. \& Bryson, J. M. (1988). Charismatic leadership: A phenomenological and structural approach. In J. G. Hunt, B. R. Baliga, H. P. Dachler, \& C. A. Schriesheim (Eds.), Emerging leadership vistas (pp. 11 -28). Lexington, MA7 Lexington Books.

Bodinson, G. (2005). Change Healthcare organizations from good to great. Quality Progress, 38(11), 22-29.

Boerner, S., Eisenbeiss, S., \& Griesser, D. (2007). Follower Behavior and Organizational Performance: The Impact of Transformational Leaders. Journal of Leadership and Organizational Studies, Vol. 13:3.

Bozeman, B. \& M. K. Feeney. (2008). Public management mentoring: What affects outcomes? Journal of Public Management Research and Theory. Advance Access published on March 27, 2008.

Bozeman, B. \& M. K. Feeney. (2009). Public management mentoring: A Three-Tier Model. Review of Public Personnel Administration, 29:2, 134-157.

Bradbury, H. \& Lichtenstein, B. (2000). Relationality in organizational research: Exploring the space between. Organization Science, 11, 551-564.

Burns, J. M. (1978). Leadership. New York: Harper \& Row.

Busch, J. W. (1985). Mentoring among graduate schools of education: Mentor's perceptions. American Educational Research Journal, 22, 257-265.

Chao, G., Walz, P., \& Gardner, P. (1992). Formal and informal mentorships: A comparison on mentoring functions and contrast with non-mentored counterparts. Personnel Psychology, 45(3), 619-937.

Christie, A., Barling, J., \& Turner, N. (2011). Pseudo-Transformational Leadership.: Model Specification and Outcomes. Journal of Applied Social Psychology, 41(12), 29432984.

Clarke, N. (2004). HRD and the challenges of assessing learning in the workplace. International Journal of Training and Development, 8, 140-156. 
Clawson, J. G. (2002). Level three leadership: Getting below the surface (2nd ed.). Upper Saddle River, NJ: Prentice Hall.

Collins, J. (2001). Good to great: Why some companies make the leap...and others don't. Harper Collins Publisher. New York: NY.

Congressional Budget Office Report (2013). Found on 1/18/2020 at www.cbo.gov/.

Connelly, M. S., Gilbert, J. A., Zaccaro, S. J., Threlfall, K. V., Marks, M. A., \& Mumford, M. D. (2000). Exploring the Relationship of Leadership Skills and Knowledge to Leader Performance. The Leadership Quarterly, 11, 65-86.

Cozby, P. C. (2001). Measurement Concepts. Methods in Behavioral Research (7 $7^{\text {th }}$ ed.). California: Mayfield Publishing Company.

Cromwell, S. E. \& Kolb, J. A. (2004). An examination of work environment support factors affecting transfer of supervisory skills training to the workplace. Human Resource Development Quarterly, 15, 449-471.

Creswell, J. W. (2005). Educational research: Planning, conducting, and evaluating quantitative and qualitative research. Upper Saddle River, NJ: Merrill Prentice Hall.

Dansky, K. (1996). The Effect of Group Mentoring on Career Outcomes. Group and Organization Management,21(1), 5-21.

Davis, C. (2018). Modeling the Co-Production of Public Sector Innovation: Strategic Dimensions of Organizational Innovation within the Public Maritime Ports of the Pacific Northwest. Dissertations and Theses, Portland State University, Paper 4231.

Day, D.V. (2001). Leadership development: A review in context. Leadership Quarterly, 11, 581-613.

Deci, E. \& Ryan, R. (2008). Facilitating optimal motivation and psychological well-being across life's domains. Canadian Psychology/Psychologiecanadienne, 49(1),14-23.

DeGroot, T., Kiker, D., \& Cross, Thomas. (2000). A Meta-Analysis to Review Organizational Outcomes Related to Charismatic Leadership. Canadian Journal of Administrative Sciences / Revue Canadienne des Sciences de l'Administration.

DeLong, T., Gabarro, J., \& Lees, R. (2008). Why mentoring matters in a hypercompetitive world. Harvard Business Review, 86(1), 115-121. 
Denscombe, M. (2010). The Good Research Guide for Small-Scale Social Research Projects, $4^{\text {th }}$ Ed., Butterworth-Heinemann.

Dhar, V., \& Mishra, P. (2004). Leadership Effectiveness: A Study of Constituent Factors. Journal of Mgmt Research, 11(4): 254.

DiCicco-Bloom B, Crabtree BF. (2006). The qualitative research interview. Med Educ. 40: 314-21.

Drath, W. (2001). The Deep Blue Sea: Rethinking the Source of Leadership. San Francisco, CA: Jossey-Bass.

Dugan, B. A. \& O'Shea, P. G. (2014). Leadership development: Growing talent strategically. Society for Human Resource Management (SHRM) and Society for Industrial and Organizational Psychology (SIOP) Science of HR White Paper Series.

Dvir, T., Eden, D., Avolio, J., \& Shamir, B. (2002). Impact of Transformational Leadership on Follower Development \& Performance: A Field Experiment. Academy of Management Journal 45 (4), 735-744.

Dyer, L. (2001). Some thoughts on dynamic organizations: Lots of stuff we need to know. Paper presented at the Conference on Dynamic Organizations, Cornell University.

Eby, L. T., \& T. D. Allen. (2002). Further Investigation of Protégés' Negative Mentoring Experiences Patterns and Outcomes. Group \& Organization Management 27 (4):456479.

Eby, L. T., McManus, S., Simon, S. A., \& Russell, J. E. A. (2000). An examination of negative mentoring experiences from the protégé's perspective. Journal of Vocational Behavior, 57, 1-21.

Elenkov, D. S. (2002). Effects of leadership on organizational performance in Russian companies. J Business Review, 55 (6), 467-480.

Ely, R. J. \& Rhode, D. L. (2010). "Women and Leadership: Defining the Challenges," in Handbook of Leadership Theory and Practice. Harvard Business Press.

Enright, K. P. (2006). Investing in leadership volume 2: Inspiration and ideas from philanthropy's latest frontier. Washington, DC: Grantmakers for Effective Organizations. 
Feeney, M. \& Bozeman, B. (2008). Mentoring and network ties. Human Relations, 61(12), 1651-1676.

Field, A. (2009). Discovering Statistics Using IBM SPSS Statistics: And Sex and Drugs and Rock ' $n$ ' Roll ( $3^{\text {rd }}$ ed.). London, Sage.

Fielden, S. L., Davidson, M. J., \& Sutherland, V. J. (2009). Innovations in coaching and mentoring: implications for nurse leadership development. Health Services Management Research 22 (2), 92-99.

Fink, A. (2006). How to conduct surveys (3rd ed.). Thousand Oaks, CA: Sage.

Flynn, C. B., Walker, A. G., \& Svyantek, D. J. (2019). Predicting Leader Performance: Field Test of an Integrated Model. Quarterly Review of Business Disciplines, 6 (1), 1-23.

Fox, R. L., \& Schuhmann, R. A. (2001). Mentoring experience of women city managers: Are women disadvantaged? American Review of Public Administration, 31 (4), 381392.

Frich, J. C., Brewster, A. L., Cherlin, E. J., \& Bradley, E. H. (2014). Leadership development programs for physicians: a systematic review. J Gen Intern Med.

Fuller, J. B., Patterson, C. E. P., Hester, K., \& Stringer, D. Y. (1996). A quantitative review of research on charismatic leadership. Psychological Reports, 78, 271-287.

Fulmer, R. M. \& Wagner, S. (1999). Leadership: Lessons from the Best. Training \& Development 53(3), 28-33.

Gleick, J. (1987). Chaos. Harmondsworth: Penguin.

Grant, A. M., \& Berry, J. (2011). The necessity of others is the mother of invention: Intrinsic and prosocial motivations, perspective-taking, and creativity. Academy of Management Journal, 54: 73-96.

Grove, J. T., Kibel, B. M., \& Haas, T. (2005). EvaluLEAD. A guide for shaping and evaluating leadership development programs. Oakland CA: Sustainable Leadership Initiative. Public Health Institute.

Hadden, R. (1997, April). Mentoring and coaching. Executive Excellence, 14(4), 17. 
Hambley, L. A., O’Neill, T. A., \& Kline, T. J. B. (2007). Virtual team leadership: The effects of leadership style and communication medium on team interaction styles and outcomes. Organizational Behavior and Human Decision Processes, 103 (1), 1-20.

Head, B. W. (2008). Wicked Problems in Public Policy. Public Policy 3(2), 101.

Heidkamp, M., Mabe, W., \& DeGraaf, B. (2012). The public workforce system: Serving older job seekers and the disability implications of an aging workforce. New Brunswick, NJ: NTAR Leadership Center, Rutgers University.

Heifetz, R. A., \& Laurie, D. L. (2001). The work of leadership. In G. Goleman, W. Peace, W. Pagonis, T. Peters, G. Jones, \& H. Collingwood (Eds.), Harvard Business Review on breakthrough leadership (pp. 131-141). Boston: Harvard Business School Press.

Hersey, P., Blanchard, K., and Johnson, D. (2007). Management of Organizational Behavior. 9th ed. Upper Saddle River, NJ: Prentice Hall.

Higgins, M.C. (2001). Changing careers: The effects of social context. Journal of Organizational Behavior, 22, 595-618.

Howell, J. M. \& Hall-Merenda, K. E. (1999). The ties that bind: The impact of leadermember exchange, transformational and transactional leadership, and distance on predicting follower performance. Journal of Applied Psychology, 84(5), 680-694.

Hubbard, B. (2005). Investing in leadership volume 1: A grant maker's framework for understanding nonprofit leadership development. Washington, DC: Grantmakers for Effective Organizations.

Hurst (1995). Crisis and Renewal: Meeting the Challenge of Organizational Change. Harvard Business School Press, Boston.

Inzer, L. \& Crawford, C. (2005). A Review of Formal and Informal Mentoring: Processes, Problems, and Design. Journal of Leadership Education, 4(1), 31-50,

Institute of Medicine. (2008). Retooling for an Aging America: Building the Healthcare Workforce. Found at http://www.nap.edu/openbook.php?record id=12089.

Jackson, S.L. (2011). Research Methods and Statistics: A Critical Approach, $4^{\text {th }}$ Ed., Cengage Learning. 
Johnson, K. K. P., Yust, B. L., \& Fritchie, L. L., (2001). Views on mentoring by clothes and textiles faculty. Clothing and Textiles Research Journal, 19(1), 31-40.

Judge, T. A. \& Piccolo, R. F. (2004). Transformational and Transactional Leadership: A Meta-Analytic Test of Their Relative Validity. Journal of Applied Psychology, 89(5), 755-768.

Katz, R. (1955). Skills of an Effective Administrator; Performance depends on fundamental skills rather than personality traits. Harvard Business Review, Vol.33 No.1, pp.33-42.

Keller, R. (2006). Transformational Leadership, Initiating Structure \& Substitutes for Leadership: A Longitudinal Study of Research \& Development Project Team Performance. Journal of Applied Psychology 91 (1), 202-210.

Kim, S. (2007). "Learning goal orientation, formal mentoring, and leadership competence in HRD: a conceptual model." Journal of European Industrial Training, 31, pp. 181-94.

Kirkpatrick, D. L. (1994). Evaluating Training Programs. San Francisco: Berrett-Koehler Publishers, Inc. Kotter (2011).

Kosoko-Lasaki, O., Sonnino, R. E., \& Voytko, M. L. (2006). Mentoring for women and underrepresented minority faculty and students: experience at two institutions of higher education. J Natl Med Assoc., 98(9), 1449-59.

Kotter, J. P., \& Heskett, J. L. (1992). Corporate culture and performance. New York: The Free Press.

Kotter, J. (2011). Change Management vs. Change Leadership - What's the Difference? Found at http://www.forbes.com/sites/johnkotter/2011/07/12/changemanagement-vs-change-leadership-whats-the-difference/ on 1/18/2020.

Kouzes, J. M. \& Posner, B. Z. (2003). The Leadership Challenge (3rd Ed). San Francisco, CA: Jossey-Bass.

Kram, K. E. (1985). Mentoring at work. Glenview, IL: Scott, Foresman.

Kunich, J. \& Lester, R. (1999). Leadership and the art of mentoring: Tool kit for the time machine. Journal of Leadership and Organizational Studies, 6(1/2), 17-35. 
Kur, Ed \& Bunning, Richard. (2002). Assuring Corporate Leadership for the Future. Journal of Management Development. 21. 761-779.

Kvale, S. (1996). Interviews an Introduction to Qualitative Research Interviewing. Sage Publications.

Lab OPM (2018). "Problem Framing for Solution Finding." Found at lab.opm.gov on 5/17/2019.

Lankau, M. J., \& Scandura, T. A. (2002). An investigation of personal learning in mentoring relationships: Content, antecedents, and consequences. Academy of Management Journal, 45(4), 779-790.

Lauber, D. (2012). Mentoring vs. Coaching: Tools for Professional Development. Found on 1/18/2020 at http://lightboxleadership.com/.

Lawrence, P., \& Lorsch, J. (1967). “Differentiation and Integration in Complex Organizations" Administrative Science Quarterly 12, 1-30.

Lewis, C. \& Malmgren, P. (2018). The Leadership Lab: Understanding Leadership in the 21 Century. United Kingdom: Kogan Page.

Lin, C. S., Huang, P. C., Chen, S. J., \& Huang, L. C. (2017). Pseudo-transformational leadership is in the eyes of the subordinates. J. Business Ethics, 141, 179-190.

Lowe, K. B., Kroeck, K. G., \& Sivasubramaniam, N. (1996). Effectiveness correlates of transformational and transactional leadership: A meta-analytic review of the MLQ literature. The Leadership Quarterly, 7(3), 385-415.

Martineau, J., \& Hannum, K. (2004). Evaluating the impact of leadership development: A professional guide. Greensboro, NC: Center for Creative Leadership.

McCormick, K. \& Salcedo, J. (2017). SPSS Statistics for Dummies, $3^{\text {rd }}$ Ed. John Wiley \& Sons. Haboken, NJ.

McGonagill, G. and Reinelt, C. (2011). Leadership Development in the Social Sector: A Framework for Supporting Strategic Investments. Grand Valley State.

McGowan, M. L. (1986). Self-efficacy: Operationalizing challenge education.

McNamara, C. (1999). General Guidelines for Conducting Interviews. Minnesota, MN. 
Melum, M. (2002). “Developing high-performance leaders." Quality Management in Health Care, 11, pp. 55-68.

Menard, S.W. (1995). Applied Logistic Regression Analysis. Michigan: Sage Publications.

Meyer, J., Paul, M. \& Taulbee, W. (2005). Stream ecosystem function in urbanizing landscapes. Journal of the North American Benthological Society,24, 602-612.

Middlebrooks, A. \& Haberkorn, J. (2009). Implicit Leader Development - The Mentor Role as Prefatory Leadership Context. Journal of Leadership Studies, 2(4).

Miles, M. B., Huberman, A. M., \& Saldana, J. (1994). Qualitative Data Analysis: A Methods Sourcebook. Sage: Washington D.C.

Mincemoyer, C. C., \& Thomson, J. S. (1998). Establishing effective mentoring relationships for individuals and organizational success. Journal of Extension [Online], 36(2).

Moon, S. (2007). Empirical quantitative case study in operations management: A paper establishing the methodological framework for a research. Newcastle University Business School, UK.

Morgan, Gareth. (2006). Images of organizations, Updated ed. Thousand Oaks, CA: Sage Publications, Inc.

Mullen, E. J., \& Noe, R. A., (1999). The mentoring information exchange: When do mentors seek information from their protégés? Journal of Organizational Behavior, $20,233-242$.

Mumford, M. D., Marks, M. A., Connelly, M. S., Zaccaro, S. J., \& Reiter-Palmon, R. (2000). Development of Leadership Skills: Experience and Timing. Leadership Quarterly, 11, 87-114.

Mumford, M. D., Zaccaro, S. J., Connelly, M. S., Marks, M. A. (2000). Leadership Skills: Conclusions \& future directions. The Leadership Quarterly, 11(1), 155-170.

Mumford, M. D., Zaccaro, S. J., Harding, F. D., Jacobs, T. O., \& Fleishman, E. A. (2000). Leadership skills for a changing world: Solving complex social problems. The Leadership Quarterly, 11(1), 11-35. 
Mumford, M. D., Zaccaro, S.J., Johnson, J.F., Diana, M., Gilbert, J.A., \& Threlfall, K.V. (2000). Patterns of leader characteristics: Implications for performance and development. The Leadership Quarterly, 11(1), 115-133.

National Academy of Public Administration. (2008). Recruiting and Retaining a Diverse High-Performing Workforce. Retrieved on 1/18/2020 at https://www.napawash.org/.

Northouse, P. (2007). Leadership: Theory and practice (4th ed.). Thousand Oaks, CA: Sage Publications, Inc.

Northouse, P. (2013). Leadership: Theory and Practice (Sixth ed.). Thousand Oaks, CA: Sage Publications, Inc.

Northhouse, P. (2010). Introduction to Leadership: Concepts and Practice ( $2^{\text {nd }}$ ed.). Thousand Oaks, Sage.

Oakland, J. S. (2004). Oakland on quality management. Elsevier Butterworth-Heineman, New York.

Olivares, O. J., Peterson, G., \& Hess, K. P. (2007). An existential-phenomenological framework for understanding leadership development experiences. Leadership and Organization Development Journal, 28, 76-91.

O'Reilly, C. (1989). Corporations, culture, and commitment: Motivation and social control in organizations. California Management Review, 314: 9-25.

Paradis, E., O’Brien, B., Nimon, L., Bandiera, G., \& Martimianakis, M. A. (2016). Design: selection of data collection methods. Journal of Graduate Medical Education, 8(2), 263-264.

Parks, S. D. (2005). Leadership can be taught: A bold approach for a complex world. Boston, MA: Harvard Business Review Press.

Patton, M. Q. (1990). Qualitative Evaluation and Research Methods (2nd ed.). Newbury Park, CA: Sage Publications, Inc.

Pillai, R., \& Williams, E. A. (2004). Transformational leadership, self-efficacy, group cohesiveness, commitment, and performance. Journal of Organizational Change Management, 17(2), 144-159. 
Podsakoff, P. M., MacKenzie, S. B., Moorman, R. H., \& Fetter, R. (1990).

Transformational leader behaviors and their effects on followers' trust in leader, satisfaction, and organizational citizenship behaviors. Leadership Quarterly, 1(2), 107-142.

Popper, M. (2005). Main principles and practices in leader development. Leadership and Organization Development Journal. 26 (1), 62-75.

Price, T. L. (2003). The Ethics of Authentic Transformational Leadership. Leadership Quarterly, 14, 67-81.

Raghuram, S., Hill, N. S., Gibbs, J. L., \& Maruping, L. M. (2018). Virtual work: Bridging research clusters. Academy of Management Annals.

Ragins, B. (1997). Antecedents of diversified mentoring relationships. Journal of Vocational Behavior, 51(1), 90-109.

Ragin, B. \& Cotton, J. (1999). Mentor functions and outcomes: A comparison of men and women in formal and informal mentoring relationships. Journal of Applied Psychology, 84, 529-550.

Roche, G. R. (1979). Much Ado About Mentors. Harvard Business Review, pp. 14-28.

Sambunjak, D., Straus, S. E., \& Marusic, A. (2006). Mentoring in academic medicine: a systematic review. JAMA, 296(9), 1103-15.

Sashkin, M., \& Rosenbach, W. E. (2001). Visionary Leadership Theory: A Current Overview of a Model, Measures, and Research, 9-114.

Scandura, T. A. (1992). Mentorship and career mobility: An empirical investigation. Journal of Organizational Behavior, 13, 169-174.

Scandura, T. A. (1998). Dysfunctional mentoring relationships and outcomes. Journal of Management, 24, 449-467.

Schreier, M. (2014). Qualitative content analysis. The SAGE Handbook of Qualitative Data Analysis, 170-183.

Schuh, S., Zhang, X., \& Tian, P. (2013). For the good or the bad? Interactive effects of transformational leadership with moral and authoritarian leadership behaviors. Journal of Business Ethics, 116, 629-640. 
Selltiz, C., Jahoda, M., Deutsch, M. \& Cook, S. W. (1965). Research methods in social relations. Revised edn. New York: Holt, Rinehart \& Winston.

Shin, S. J., \& Zhou, J. (2003). Transformational Leadership, Conservation, and Creativity Evidence from Korea.The Academy of Management Journal 46 (6), 703-714.

Silver, D., Hubert, T., Schrittwieser, J., Antonoglou, I., Lai, M., Guez, A., Lanctot, M., Sifre, L., Kumaran, D., Graepel, T., Lillicrap, T., Simonyan, K., \& Hassabis, D. (2018). “A General Reinforcement Learning Algorithm that Masters Chess, Shogi, and Go through Self-Play. Science, 632(6419), 1140-1144.

Smith, W. J., Howard, J. T., \& Harrington, K. V. (2005). Essential formal mentor characteristics and functions in governmental and non-governmental organizations from the program administrator's and the mentor's perspective. Public Personnel Management, 34(1), 31-58.

Steinhilber, S. \& Estrada, C. A. (2015). To Lead or Not to Lead? Structure \& Content of Leadership Development Programs. J. Gen Intern Med, 30 (5): 543-545.

Tague, N.R. (2005). The Quality Toolbox, $2^{\text {nd }}$ Edition. Quality Press, Milwaukie.

Taleb, N. N. (2007). Black Swan and Domains of Statistics. The American Statistician, August 2007, 61(3).

Taylor, G. (2013). Implementing and Maintaining a Knowledge Sharing Culture via Knowledge Management Teams: A Shared Leadership Approach. Journal of Organizational Culture, Communications, and Conflict 17(1).

Thomas, D. A. \& Gabarro, J. (1999). Breaking Through: How People of Color and the Companies They Work for Can Overcome Barriers. Boston, MA: Harvard Business School Press.

Torfing, J. \& Sorenson, E. (2012). Introduction: Collaborative innovation in the public sector. The Innovation Journal, 17(1), 1.

Tsen, L. C., Borus, J. F., Nadelson, C. C., Seely, E. W., Haas, A., \& Fuhlbrigge, A. L. (2012). The development, implementation, and assessment of an innovative faculty mentoring leadership program. Acad Med., 87(12), 1757-61. 
Uhl-Bien, M., Marion, R., \& McKelvey, B. (2007). Complexity Leadership Theory: Shifting leadership from the industrial age to the knowledge era. The Leadership Quarterly, 18(4), 298-318.

United States Office of Personnel Management. (2008). Found on 1/11/2020 at https://www.opm.gov/policy-data-oversight/training-and-development/careerdevelopment/bestpractices-mentoring.pdf.

Vaismoradi, M., Jones, J., Tusunen, H., \& Snelgrove, S. (2016). Theme Development in Qualitative Context Analysis \& Thematic Analysis. Journal of Nursing Education \& Practice, 6(5), 100.

Vaismoradi, M., Turunen, H., \& Bondas, T. (2013). Content analysis and thematic analysis: Implications for conducting a qualitative descriptive study. Nurs Health Sci., 15(3), 398-405.

Van Velsor, E. and McCauley, C. (2004). Our View of Leadership Development. In C. D.

Wanberg, C. R., Welsh, E. T., \& Hezlett, S. A. (2003). Mentoring research: A review and dynamic process model. Research in Personnel and Human Resource Management, 22, 39-124.

Watson Wyatt. (2003). Demographics and destiny: Winning the war for talent. Retrieved on $1 / 5 / 2020$ from www.watsonwyatt.com.

Weinberg, F. \& Lankau, M. (2011). Formal Mentoring Programs: A Mentor-Centric and Longitudinal Analysis. Journal of Management, 37(6): 1527-1557.

Wenzel, R., \& Van Quaquebeke, N. (2018). The double-edged sword of big data in organizational and management research: A review of opportunities and risks. Organizational Research Methods, 21 (3), 548-591.

Wiseman, L. \& McKeown, G. (2010). Multipliers: how the best leaders make everyone smarter. New York: HarperCollins.

Wong, J. \& Modrow, R. (2004). Le leadership est-ilune solution? Healthcare Management Forum, 17:32-39.

Yin, R. K. (2009). Case study research (4th ed.). Thousand Oaks, CA: Sage. 
Yukl, G. A. (1989). Managerial leadership: A review of theory and research. Journal of Management, 15(2), 251-289.

Yukl, G. (2006). Leadership in organizations (6th ed.). Upper Saddle River, NJ: PearsonPrentice Hall.

Yukl, G. (2008). How leaders influence organizational effectiveness. The Leadership Quarterly, 19(6), 708-722.

Zaccaro, S. J. (2001). The Nature of Executive Leadership: A Conceptual and Empirical Analysis of Success. Washington, DC: American Psychological Association.

Zhou, J., \& George, J. M. (2001). When job dissatisfaction leads to creativity: Encouraging the expression of voice. Academy of Management Journal, 44: 682-696. 


\section{Appendix A: Program Administrator Interview Script}

\section{(Adapted from EES evaluation tool)}

Purpose: Identify what factors are associated with programs most successful with obtaining organizational outcomes. Identify best practices associated with program implementation.

Program Description:

Scope -

Modality -

Frequency and Length of Program -

Program Location -

Participants -

Target Audience -

Do you require that participants have pre-work? If so, please circle and describe all applicable.

Reading material

Pre-Assessment/Test

Readiness Assessment

Assignment

Research

Selection of Project

Which Learning Methods do you use? Please indicate and describe.

Lecture

Case Studies

Role Plays

Simulation

Discussion

Activities

Project Assignments

Action Plan Development

Personal Development Plans

Does your training include any Conference Components? Please indicate and describe. Breakout sessions

Networking

Mentoring 
Do you perform any assessments during the program? Please indicate and describe. Competency Assessments

Pre/Post Tests

Skill Assessments

Team Assessments

Was there any follow-up during or after the program? Please indicate and describe.

Assignments

Action Plans 


\section{Appendix B: Protégé Survey}

Purpose: Understand the relationship between the mentor and mentee.

Part I: Conceptualization of Mentoring Experience

$\begin{array}{ccccc}\text { Not at All } & \text { Seldom } & \text { Occasionally } & \text { Quite a Bit } & \text { All the time } \\ 1 & 2 & 3 & 4 & 5\end{array}$

How frequently did you meet with your mentor (hours per month)?
a) 0
b) 1
c) 2
d) $3-4$
e) $>5$

How often did you feel close to your mentor? 12345

How well did your mentor meet your needs and preferences? 12345

How frequently did your mentor introduce you to influential people inside of this organization? 12345

How frequently did your mentor introduce you to influential people outside of the organization? 12345

\section{Part II: Conceptualization of Mentor as a Transformational Leader}

Please rate the extent to which your mentor conducted the following activities.

$\begin{array}{ccccc}\text { Not at All } & \text { Seldom } & \text { Occasionally } & \text { Quite a Bit } & \text { All the time } \\ 1 & 2 & 3 & 4 & 5\end{array}$

Transformational Leadership: Idealized Influence

1. Strived to establish trust with me

2. Expressed interest in my hopes and dreams

3. Consciously acted as a role model

Transformational Leadership: Inspirational Motivation

4. Provided a vision of excellence

5. Made me feel my work was significant

Transformational Leadership: Intellectual Stimulation

6. Encouraged me to look at problems in a new way

7. Presented a tolerance of my mistakes or seemingly extreme positions

8. Challenged me to question or justify my own values and beliefs 
Transformational Leadership: Individualized Consideration

9. Showed concern for my well-being, beyond their professional duties

10. Strived to make me feel like I was important to them

Prior to providing the survey to participants, the titles were removed and the questions were randomized.

Scoring:

For questions $1-3$, a total score of $\geq 11$ will indicate that the mentor exemplified this component of transformational leadership.

For questions 4-5, a total score of $>7$ will indicate that the mentor exemplified this component of transformational leadership.

For questions 6-8, a total score of $\geq 11$ will indicate that the mentor exemplified this component of transformational leadership.

For questions $9-15$, a total score of $>7$ will indicate that the mentor exemplified this component of transformational leadership.

\section{Part III: Skills Inventory}

Instructions: Read each item carefully and determine what influence your mentor had on your skill development in that area. Indicate your response to each item by circling one of the five numbers to the right of each item.

$\begin{array}{ccccc}\text { Not at all } & \text { Slightly } & \text { Somewhat } & \text { Very } & \text { Extremely } \\ \text { Influential } & \text { Influential } & \text { Influential } & \text { Influential } & \text { Influential } \\ 1 & 2 & 3 & 4 & 5\end{array}$

My mentor was to my ability to...

1. Understand the details of how things work. 12345

2. Adapt ideas to people's needs. 12345

3. Work with abstract ideas. 12345

4. Understand technical things. 12345

5. Understand other people that I work with. 12345

6. See the big picture. 12345

7. Make things work. 12345

8. Create a supportive communication climate. 12345

9. Think through complex organizational problems. 12345

10. Follow directions and filling out forms. 12345

11. Understand the social fabric of the organization. 12345

12. Identify and analyze strategies for my organization's growth. 12345

13. Completing assigned tasks. 12345

14. Get all parties to work together. 12345

15. Create a mission statement. 12345

16. Understand how to do the basic things required of me. 12345 
17. Consider how my decisions affect the lives of others. 12345

18. Think about organizational values and philosophy. 12345

Scoring:

The skills inventory is designed to measure three broad types of leadership skills: technical, human, and conceptual. Score the questionnaire by doing the following. First, sum the responses on items $1,4,7,10,13$, and 16. This is your technical skill score. Second, sum the responses on items $2,5,8,11,14$, and 17 . This is your human skill score.

Third, sum the responses on items $3,6,9,12,15$, and 18 . This is your conceptual skill score.

Total scores: Technical skill Human skill Conceptual skill

Scoring Interpretation

23-30 High Range 14-22 Moderate Range 6-13 Low Range

\section{Part IV: Conceptualization of Mentee as a Transformational Leader}

Please rate the extent to which you conduct the following activities for those you lead.

Not at All

1
Seldom

2
Occasionally

3
Quite a Bit

4
All the time 5

Transformational Leadership: Idealized Influence

11. Strive to establish trust with them

12. Express interest in their hopes and dreams

13. Consciously act as a role model

Transformational Leadership: Inspirational Motivation

14. Provide a vision of excellence

15. Made them feel their work was significant

Transformational Leadership: Intellectual Stimulation

16. Encourage them to look at problems in a new way

17. Present a tolerance of their mistakes or seemingly extreme positions

18. Challenged them to question or justify their own values and beliefs

Transformational Leadership: Individualized Consideration

19. Show concern for their well-being, beyond their professional duties

20. Strived to make them feel like they were important to me

Prior to providing the survey to participants, the titles were removed and the questions were randomized. 
Scoring:

For questions $1-3$, a total score of $\geq 11$ will indicate that the mentee exemplified this component of transformational leadership.

For questions $4-5$, a total score of $>7$ will indicate that the mentee exemplified this component of transformational leadership.

For questions $6-8$, a total score of $\geq 11$ will indicate that the mentee exemplified this component of transformational leadership.

For questions 9-15, a total score of $>7$ will indicate that the mentee exemplified this component of transformational leadership.

Part V: Perceived Impact on your psychological capital - confidence, optimism, hope, resilience.

As a result of having a mentor, do you have more confidence to take on challenging tasks.
Not at all
A little
Quite a Bit
A great deal

What are current barriers to applying skills acquired from the LEAD program?

What would enable your ability to apply the skills acquired from the LEAD program?

\section{Part VI: Historical Review:}

Demographic information about protégé:

Gender:

Ethnicity:

Certification Status

Demographic information about mentor:

Gender:

Ethnicity

Certification Status

Years of Experience in VHA or equivalent 
Purpose: Document provided to study participant's explaining the study and its purpose.

The Portland State University

Information Sheet

\section{EXPLORING THE ROLE OF TRANSFORMATIONAL LEADERS IN THE MENTORSHIP OF TOP-LEVEL ADMINISTRATORS: A CASE STUDY OF THE VETERANS HEALTH ADMINISTRATION (VHA) VISN LEAD PROGRAM}

December 21, 2015

\section{Introduction}

You are being asked to participate in a research study that is being conducted by Frederick White, Ph.D. student at Portland State University's Hatfield School of Government. This data will be used for his dissertation. Frederick has been working in the field of public administration for 12 years and has been conducting research in Portland State University's Department of Public Administration for 7 years. Frederick also works at VA Portland Health Care System as the Executive Assistant to the Director and the Acting Compliance and Business Integrity Officer. He has been an employee within the Department of Veterans Affairs for over 12 years.

This research is studying the impact that mentors have on the behaviors and the development of their mentee's leadership skills. You are being asked to participate in this study because you were a participant in the VISN LEAD Program in your VISN.

This form will explain the research study, and will also explain the possible risks as well as the possible benefits to you. We encourage you to talk with your family and friends before you decide to take part in this research study. If you have any questions, please ask one of the study investigators.

\section{What will happen if I decide to participate?}

If you agree to participate, you will be asked to complete a short, 30-minute electronic survey (via Survey Monkey) about your mentoring experience and the skills that you developed while you were in the program. 


\section{How long will I be in this study?}

Participation in this study will include completing the survey and sending it back to the Principal Investigator via Survey Monkey. You will have two weeks to complete the survey.

\section{What are the risks or side effects of being in this study?}

The primary risk related to participating in this study is the possible inconvenience of the time involve in answering questions during the survey. There are risks of stress, emotional distress, inconvenience and possible loss of privacy and confidentiality associated with participating in a research study. All safeguards will be taken to ensure the privacy and confidentiality of all data collected. All participants will be assured that they may refuse to answer any question. For more information about risks and discomforts, ask the investigator.

\section{What are the benefits to being in this study?}

There is no direct benefit to participants, but the information you provide and the results from the study may help improve the VISN LEAD programs and the development of future leaders across the nation.

\section{How will my information be kept confidential?}

Every measure will be taken to protect the security of all your personal information, but we cannot guarantee confidentiality of all study data. Once submitted, the survey will not have any identifiers (it will be anonymous).

Information contained in your study records is used by study staff and, in some cases it will be shared with the sponsor of the study. The Portland State University Institutional Review Board (IRB) that oversees human subject research and/or other entities may be permitted to access your records, and there may be times when we are required by law to share your information. It is the investigator's legal obligation to report child abuse, child neglect, elder abuse, harm to self or others or any life-threatening situation to the appropriate authorities, and; therefore, your confidentiality will not be maintained. There may also be a need to share the data with VA Central Office or other stakeholders responsible for the overall implementation of VISN LEAD programs in VHA. Any data shared with other participants outside of VA/VHA personnel would only be shared as deidentified data; files would contain no names or other personal identifiers would be included, other potentially identifying information (such as the site of the program) would also be removed. Data would be recorded as de-identified interview forms. A separate key would be kept by the principal investigator in a file on a secure, restricted access VA server behind the VA firewall. Your name will not be used in any published reports about this study.

You will not be paid for taking part in this study. 
You can also stop your participation in the study at any time. Your participation in this study is completely voluntary. You have the right to choose not to participate or to withdraw your participation at any point in this study without penalty or loss of benefits to which you are otherwise entitled.

\section{Whom can I call with questions or complaints about this study?}

If you have any questions, concerns or complaints at any time about the research study, Frederick White will be glad to answer them at (503) 721-1098.

If you need to contact someone after business hours or on weekends, please call (504) 606-2716 and ask for Frederick White.

\section{Whom can I call with questions about my rights as a research participant?}

If you have questions regarding your rights as a research participant, you may call the PSU Office for Research Integrity at (503) 725-2227 or 1(877) 480-4400. The ORI is the office that supports the PSU Institutional Review Board (IRB). The IRB is a group of people from PSU and the community who provide independent oversight of safety and ethical issues related to research involving human participants. For more information, you may also access the IRB website at https://sites.google.com/a/pdx.edu/research/integrity. 


\section{Appendix D: Decoding the Data}

Transitional leadership variables:

Transformational Leadership - Idealized Influence (MTLII)

- $\quad$ Strived to establish Trust (MTrust)

- Expressed Interest in my Hopes and Dreams (Minter)

- Consciously acted as a role model (MModel).

Transformational Leadership - Inspirational Motivation (MTLIM)

- Provided a vision of excellence (MVision)

- Made me feel my work was significant (MSign)

Transformational Leadership - Intellectual Stimulation (MTLIM)

- Encouraged me to look at problems in a new way (MEnc)

- Presented a tolerance of seemingly extreme positions (MTol)

- Challenged me to question or justify my own values or beliefs (MChal).

Transformational Leadership - Individualized Consideration (MTLIC)

- Shared concern for their well-being, beyond their professional duties (MWell)

- Strived to make me feel like I was important to them (MImp).

For each survey question, participants could answer one of the following:

Not at All (1) Seldom (2) Occasionally (3) Quite a Bit (4) All the Time (5).

For MTLII and MTLIS, participant mentors scores would be considered:

- $\quad$ High if they were $12-15$.

- Average if they were 7-11.

- Low if they were $\leq 6$.

For MTLIM and MTLIC, participant mentor scores would be considered:

- High if they were 8-10.

- Average if they were 5-7.

- Low if they were $\leq 4$. 
Skill Inventory Variables:

The skills inventory was used to measure three broad types of leadership skills: technical, human, and conceptual. These skills were combined into categories based on the items below:

Technical (items 1, 4, 7, 10, 13, and 16)

Human $(2,5,8,11,14$, and 17)

Conceptual (items 3, 6, 9, 12, 15, and 18)

\section{Scoring Interpretation}

23-30 High Range 14-22 Moderate Range 6-13 Low Range

Technical (TLSDTechnical)

- 1 . I enjoy getting into the details of how things work. 12345 (SDHow)

- 4. Technical things fascinate me. 1234 5(SDTech)

- 7. One of my skills is being good at making things work. 1234 5(SDEng)

- 10. Following directions and filling out forms comes easily 12345 for me.(SDFol)

- 13. I am good at completing the things I've been 12345 assigned to do.(SDTasks)

- 16. I understand how to do the basic things required 12345 of me.(SDBasic) Human (TLSDHuman)

- 2. As a rule, adapting ideas to people's needs is 12345 easy for me.(SDAdapt)

- 5. Being able to understand others is the most important 12345 part of my work.(SDPeople)

- 8. My main concern is to have a supportive 12345 communication climate.(SDComm)

- 11. Understanding the social fabric of the organization 12345 is important to me. (SDSOc)

- 14. Getting all parties to work together is a challenge 12345 I enjoy.(SDCollab)

- 17. I am concerned with how my decisions affect the 12345 lives of others.(SDDec)

Conceptual (TLSDConceptual)

- 3. I enjoy working with abstract ideas. 12345 (SDIdeas)

- 6. Seeing the big picture comes easy for me. 12345 (SDBig)

- 9. I am intrigued by complex organizational problems. 12345 (SDThink)

- 12 . I would enjoy working out strategies for my 12345 organization's growth. (SDStrat)

- 15. Creating a mission statement is rewarding work. 12345 (SDMiss)

- 18. Thinking about organizational values and philosophy 12345 appeals to me. (SDOrg) 


\section{Appendix E: Cross-Tab and Correlation Data}

Table E1 - Crosstab of Mentor's IM vs. Mentee's Human Skills Development

\begin{tabular}{|c|c|c|c|c|c|c|}
\hline & \multicolumn{3}{|c|}{ Mentor's Inspirational Motivation } & \multirow[b]{2}{*}{ Total } \\
\hline & & & 1.00 & 2.00 & 3.00 & \\
\hline \multirow{6}{*}{$\begin{array}{l}\text { Mentee's Human } \\
\text { Skills }\end{array}$} & 1.00 & Count & 6 & 3 & 0 & 9 \\
\hline & & $\%$ within IM & $85.7 \%$ & $18.8 \%$ & $0.0 \%$ & $15.5 \%$ \\
\hline & 2.00 & Count & 1 & 11 & 10 & 22 \\
\hline & & $\%$ within IM & $14.3 \%$ & $68.8 \%$ & $28.6 \%$ & $37.9 \%$ \\
\hline & 3.00 & Count & 0 & 2 & 25 & 27 \\
\hline & & $\%$ within IM & $0.0 \%$ & $12.5 \%$ & $71.4 \%$ & $46.6 \%$ \\
\hline \multirow{2}{*}{\multicolumn{2}{|c|}{ Total }} & Count & 7 & 16 & 35 & 58 \\
\hline & & $\%$ within IM & $100.0 \%$ & $100.0 \%$ & $100.0 \%$ & $100.0 \%$ \\
\hline
\end{tabular}

Table E2 - Chi-Square Tests of Mentor's IM

\begin{tabular}{|l|r|r|r|}
\hline & \multicolumn{1}{|c|}{ Value } & Df & Asymp. Sig. (2-sided) \\
\hline Pearson Chi-Square & $45.511^{\mathrm{a}}$ & 4 & .000 \\
Likelihood Ratio & 43.255 & 4 & .000 \\
Linear-by-Linear & 32.752 & & .000 \\
Association & 58 & & \\
N of Valid Cases & & & \\
\hline
\end{tabular}

a. 4 cells $(44.4 \%)$ have expected count less than 5 . The minimum expected count is 1.09 .

Table E3 - Crosstab of Mentor's IS vs. Mentee's Human Skills Development

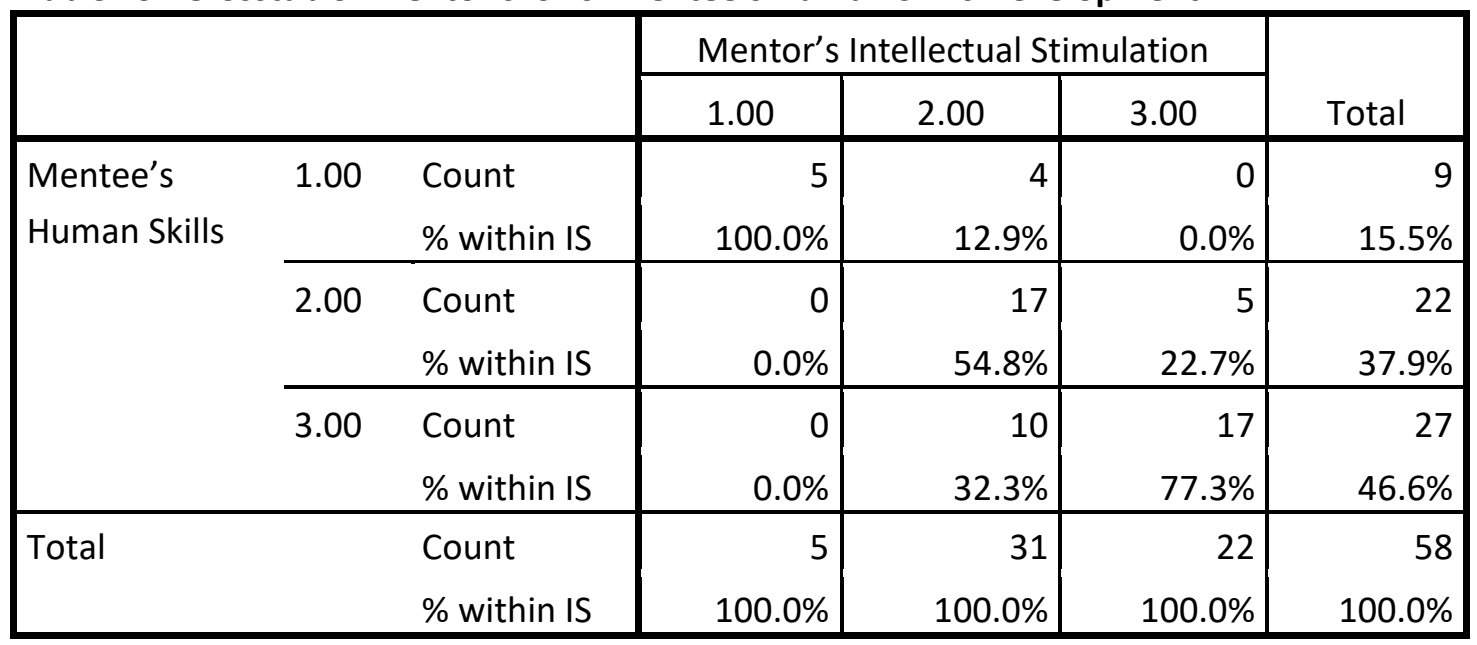


Table E4 - Chi-Square Tests of Mentor's IS

\begin{tabular}{|l|r|r|rr|}
\hline & Value & Df & \multicolumn{2}{|c|}{ Asymp. Sig. (2-sided) } \\
\hline Pearson Chi- & 40.27 & & & .000 \\
Square & $0^{\mathrm{a}}$ & & & \\
Likelihood Ratio & 34.46 & & \\
& 2 & & & \\
Linear-by-Linear & 23.80 & & \\
Association & 8 & & & .000 \\
N of Valid Cases & 58 & & \\
\hline
\end{tabular}

a. 5 cells $(55.6 \%)$ have expected count less than 5 . The minimum expected count is .78 .

Table E5 - Crosstab of Mentor's II vs. Mentee's Human Skills Development

\begin{tabular}{|lll|r|r|r|r|}
\hline & & \multicolumn{2}{|c|}{ Mentor's Idealized Influence } & \\
\cline { 3 - 6 } & & 1.00 & 2.00 & 3.00 & Total \\
\hline Mentee's Human & 1.00 & Count & 4 & 5 & 0 & 9 \\
Skills & \% within II & $100.0 \%$ & $23.8 \%$ & $0.0 \%$ & $15.5 \%$ \\
\cline { 2 - 6 } & 2.00 & Count & 0 & 14 & 8 & 22 \\
& \% within II & $0.0 \%$ & $66.7 \%$ & $24.2 \%$ & $37.9 \%$ \\
\cline { 2 - 6 } & Count & 0 & 2 & 25 & 27 \\
& \% within II & $0.0 \%$ & $9.5 \%$ & $75.8 \%$ & $46.6 \%$ \\
\hline Total & Count & 4 & 21 & 33 & 58 \\
& \% within II & $100.0 \%$ & $100.0 \%$ & $100.0 \%$ & $100.0 \%$ \\
\hline
\end{tabular}

Table E6 - Chi-Square Tests of Mentor's II

\begin{tabular}{|c|c|c|c|}
\hline & Value & Df & Asymp. Sig. (2-sided) \\
\hline Pearson Chi-Square & $46.263^{a}$ & 4 & .000 \\
\hline Likelihood Ratio & 45.816 & 4 & .000 \\
\hline Linear-by-Linear & 32318 & 1 & (ח) \\
\hline Association & & 1 & .000 \\
\hline $\mathrm{N}$ of Valid Cases & 58 & & \\
\hline
\end{tabular}

a. 4 cells (44.4\%) have expected count less than 5 . The minimum expected count is .62 . 
Table E7 - Crosstab of Mentor's IC vs. Mentee's Human Skills Development

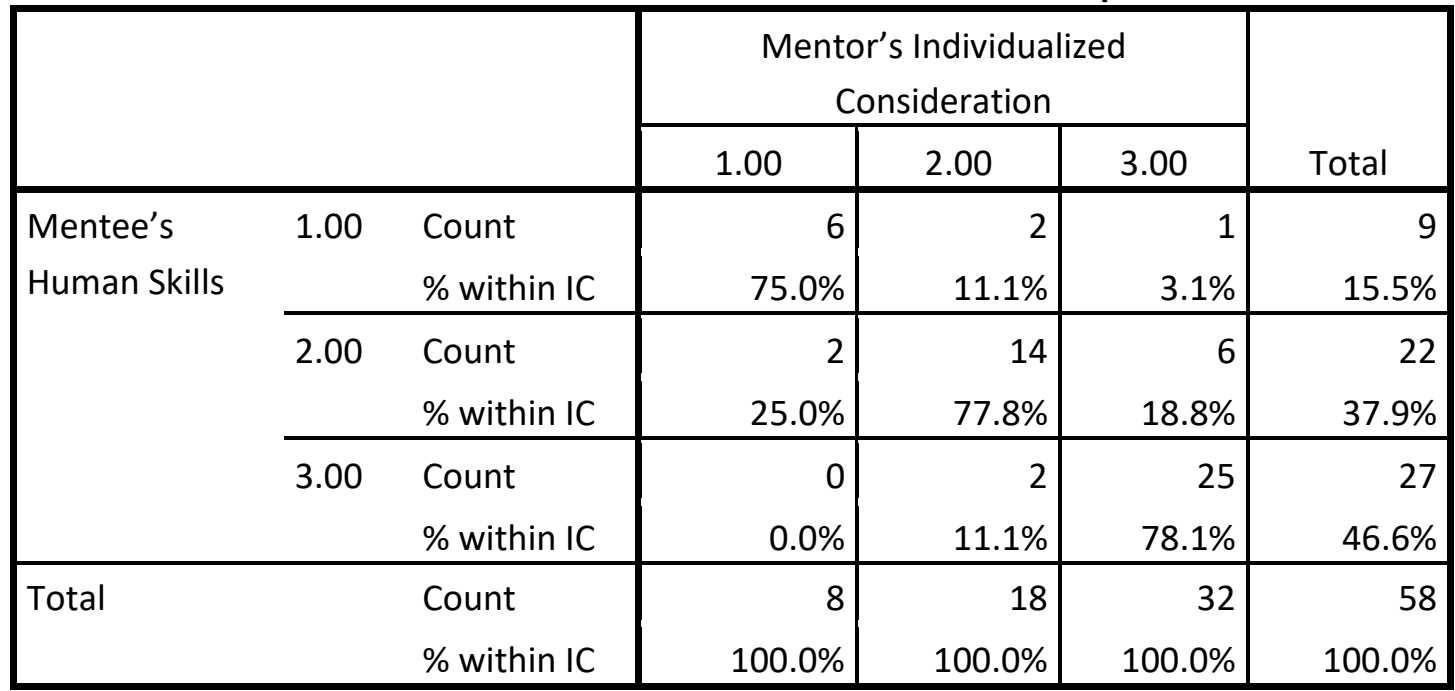

Table E8 - Chi-Square Tests of Mentor's IC

\begin{tabular}{|l|r|r|rr|}
\hline & \multicolumn{1}{|c|}{ Value } & \multicolumn{1}{|c|}{ Df } & Asymp. Sig. (2-sided) \\
\hline Pearson Chi-Square & $48.058^{\mathrm{a}}$ & 4 & & .000 \\
Likelihood Ratio & 44.506 & 4 & .000 \\
Linear-by-Linear & 31.699 & & 1 & .000 \\
Association & 58 & & & \\
N of Valid Cases & & & \\
\hline
\end{tabular}

a. 5 cells (55.6\%) have expected count less than 5 . The minimum expected count is 1.24.

Table E9 - Crosstab of Mentor's IM vs. Mentee's Conceptual Skills Development

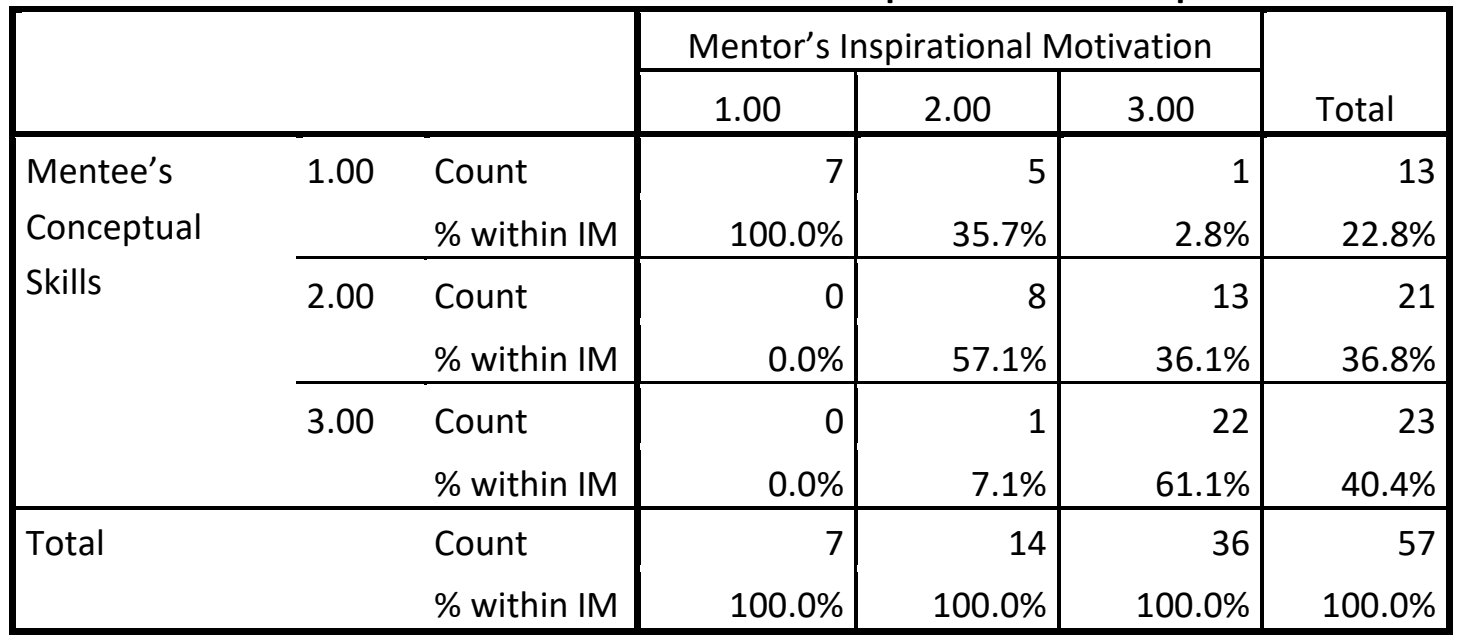


Table E10 - Chi-Square Tests of Mentor's IM vs. Conceptual Skills

\begin{tabular}{|l|r|r|r|}
\hline & \multicolumn{1}{|c|}{ Value } & Df & $\begin{array}{c}\text { Asymp. Sig. (2- } \\
\text { sided) }\end{array}$ \\
\hline Pearson Chi-Square & $40.290^{\mathrm{a}}$ & 4 & .000 \\
Likelihood Ratio & 42.270 & 4 & .000 \\
Linear-by-Linear & 30.393 & & .000 \\
Association & 57 & & \\
N of Valid Cases & & & \\
\hline
\end{tabular}

a. 4 cells (44.4\%) have expected count less than 5 . The minimum expected count is 1.60 .

Table E11 - Crosstab of Mentor's IS vs. Mentee's Conceptual Skills Development

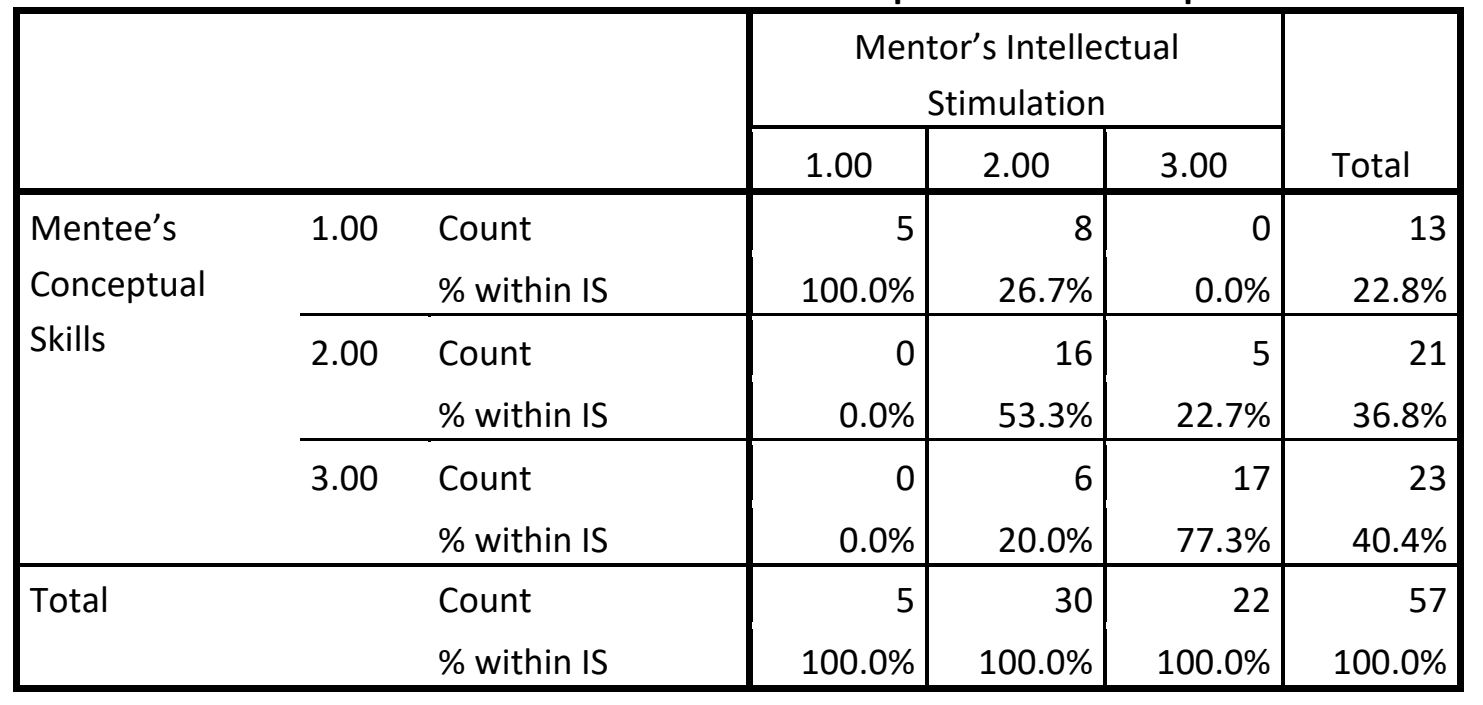

Table E12 - Chi-Square Tests of Mentor's IS vs. Conceptual Skills

\begin{tabular}{|l|r|r|r|}
\hline & \multicolumn{1}{|c|}{ Value } & Df & \multicolumn{2}{|c|}{$\begin{array}{c}\text { Asymp. Sig. (2- } \\
\text { sided) }\end{array}$} \\
\hline Pearson Chi-Square & $36.052^{\mathrm{a}}$ & 4 & .000 \\
Likelihood Ratio & 37.957 & 4 & .000 \\
Linear-by-Linear & 26.968 & & 1 \\
Association & 57 & & .000 \\
N of Valid Cases & & & \\
\hline
\end{tabular}

a. 3 cells (33.3\%) have expected count less than 5 . The minimum expected count is 1.14 . 
Table E13 - Crosstab of Mentor's II vs. Mentee's Conceptual Skills Development

\begin{tabular}{|lll|r|r|r|r|}
\hline & & \multicolumn{2}{|c|}{ Mentor's Idealized Influence II } & \\
\cline { 3 - 6 } & & 1.00 & 2.00 & 3.00 & Total \\
\hline Mentee's & 1.00 & Count & 4 & 9 & 0 & 13 \\
Conceptual & & \% within II & $100.0 \%$ & $47.4 \%$ & $0.0 \%$ & $22.8 \%$ \\
\cline { 2 - 6 } & \multirow{2}{*}{2.00} & Count & 0 & 9 & 12 & 21 \\
& & \% within II & $0.0 \%$ & $47.4 \%$ & $35.3 \%$ & $36.8 \%$ \\
\cline { 2 - 6 } & \multirow{2}{*}{3.00} & Count & 0 & 1 & 22 & 23 \\
& & \% within II & $0.0 \%$ & $5.3 \%$ & $64.7 \%$ & $40.4 \%$ \\
\hline Total & Count & 4 & 19 & 34 & 57 \\
& \% within II & $100.0 \%$ & $100.0 \%$ & $100.0 \%$ & $100.0 \%$ \\
\hline
\end{tabular}

Table E14 - Chi-Square Tests of Mentor's II vs. Conceptual Skills

\begin{tabular}{|l|r|r|r|}
\hline & \multicolumn{1}{|c|}{ Value } & Df & $\begin{array}{c}\text { Asymp. Sig. (2- } \\
\text { sided) }\end{array}$ \\
\hline Pearson Chi-Square & $37.707^{\mathrm{a}}$ & 4 & .000 \\
Likelihood Ratio & 45.179 & 4 & .000 \\
Linear-by-Linear & 31.660 & & 1 \\
Association & 57 & & .000 \\
N of Valid Cases & & \\
\hline
\end{tabular}

a. 4 cells $(44.4 \%)$ have expected count less than 5 . The minimum expected count is .91 .

Table E15 - Crosstab of Mentor's IC vs. Mentee's Conceptual Skills Development

\begin{tabular}{|c|c|c|c|c|c|c|}
\hline & & & \multicolumn{3}{|c|}{$\begin{array}{c}\text { Mentor's Individualized } \\
\text { Consideration }\end{array}$} & \multirow[b]{2}{*}{ Total } \\
\hline & & & 1.00 & 2.00 & 3.00 & \\
\hline \multirow{6}{*}{$\begin{array}{l}\text { Mentee's } \\
\text { Conceptual } \\
\text { Skills }\end{array}$} & 1.00 & Count & 8 & 4 & 1 & 13 \\
\hline & & $\%$ within IC & $100.0 \%$ & $25.0 \%$ & $3.0 \%$ & $22.8 \%$ \\
\hline & 2.00 & Count & 0 & 12 & 9 & 21 \\
\hline & & $\%$ within IC & $0.0 \%$ & $75.0 \%$ & $27.3 \%$ & $36.8 \%$ \\
\hline & 3.00 & Count & 0 & 0 & 23 & 23 \\
\hline & & $\%$ within IC & $0.0 \%$ & $0.0 \%$ & $69.7 \%$ & $40.4 \%$ \\
\hline \multirow[t]{2}{*}{ Total } & & Count & 8 & 16 & 33 & 57 \\
\hline & & $\%$ within IC & $100.0 \%$ & $100.0 \%$ & $100.0 \%$ & $100.0 \%$ \\
\hline
\end{tabular}


Table E16 - Chi-Square Tests of Mentor's IC vs. Conceptual Skills

\begin{tabular}{|l|r|r|r|}
\hline & \multicolumn{1}{|c|}{ Value } & Df & Asymp. Sig. (2-sided) \\
\hline Pearson Chi-Square & $53.413^{\mathrm{a}}$ & 4 & .000 \\
Likelihood Ratio & 57.135 & & 4 \\
Linear-by-Linear & 35.720 & & .000 \\
Association & 57 & & .000 \\
N of Valid Cases & & & \\
\hline
\end{tabular}

a. 4 cells (44.4\%) have expected count less than 5 . The minimum expected count is 1.82 .

According to Tables E1 - E16, we see significant correlations between each component of transformational leadership demonstrated by the mentor (IM, II, IS, and IC) and the presence of human and conceptual skills in the mentees:

- IM x Human, Pearson Chi-Square value 45.511 ( $p<0.001)$.

- IS x Human, Pearson Chi-Square value $40.270(p<0.001)$.

- II x Human, Pearson Chi-Square value 46.263 ( $p<0.001)$.

- IC x Human, Pearson Chi-Square value 48.058 ( $p<0.001)$.

- IM x Conceptual, Pearson Chi-Square value 40.290 ( $p<0.001)$.

- IS x Conceptual, Pearson Chi-Square value 36.052 ( $p<0.001)$.

- II x Conceptual, Pearson Chi-Square value 37.707 ( $p<0.001)$.

- IC x Conceptual, Pearson Chi-Square value $53.413(p<0.001)$.

The correlation results above suggest that mentors that demonstrate high transformational leadership characteristics help mentees to develop the necessary skills needed to operate in complex adaptive systems (CAS). To further understand the relationship, I conducted a correlation matrix and regression analysis (below) to assess the relationship between the mentor's demonstration of TL and the presence of human skills in the mentee. 
Table E17 - Correlations Analysis of Mentee's Human Skills and Related Variables.

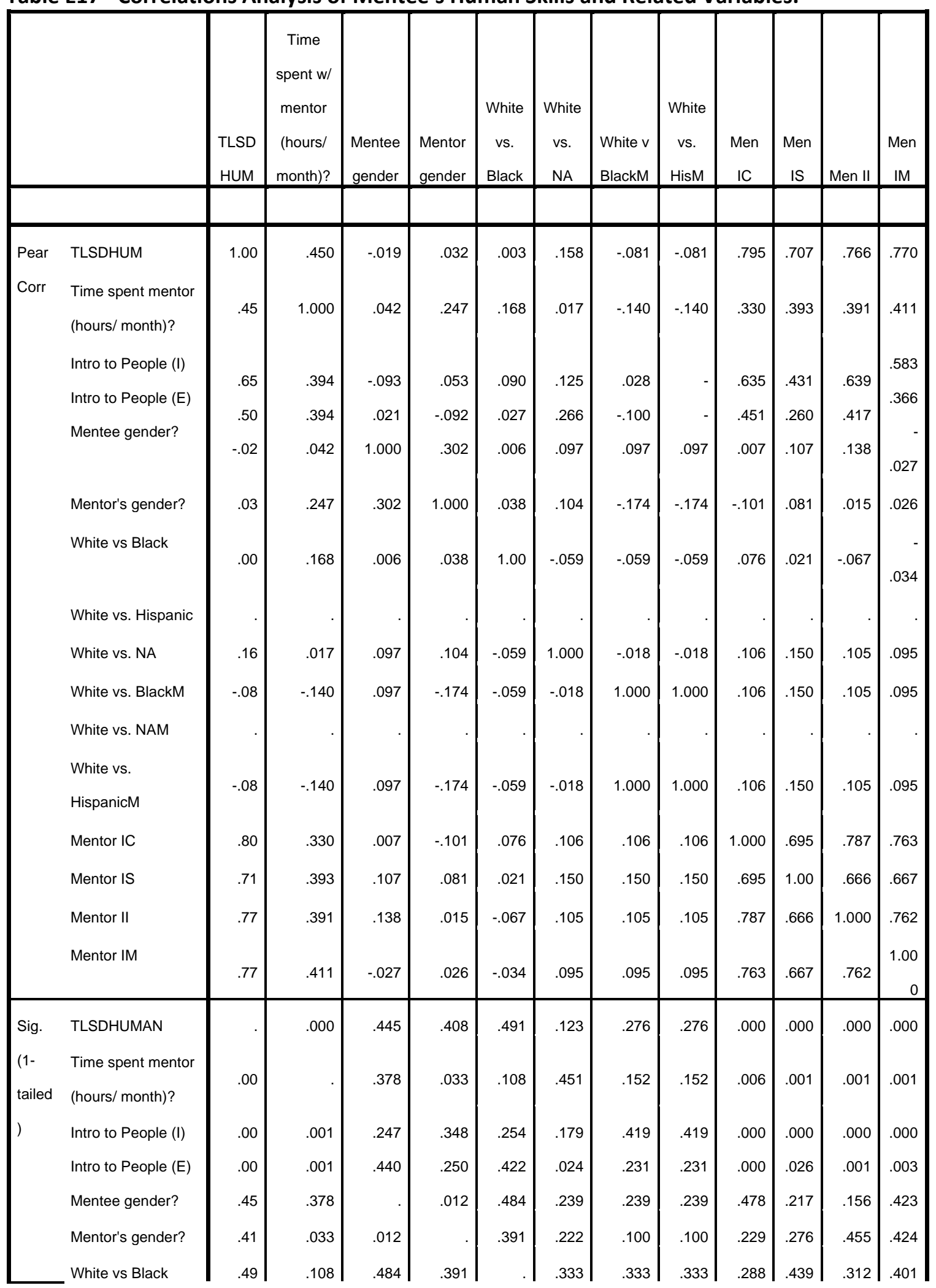




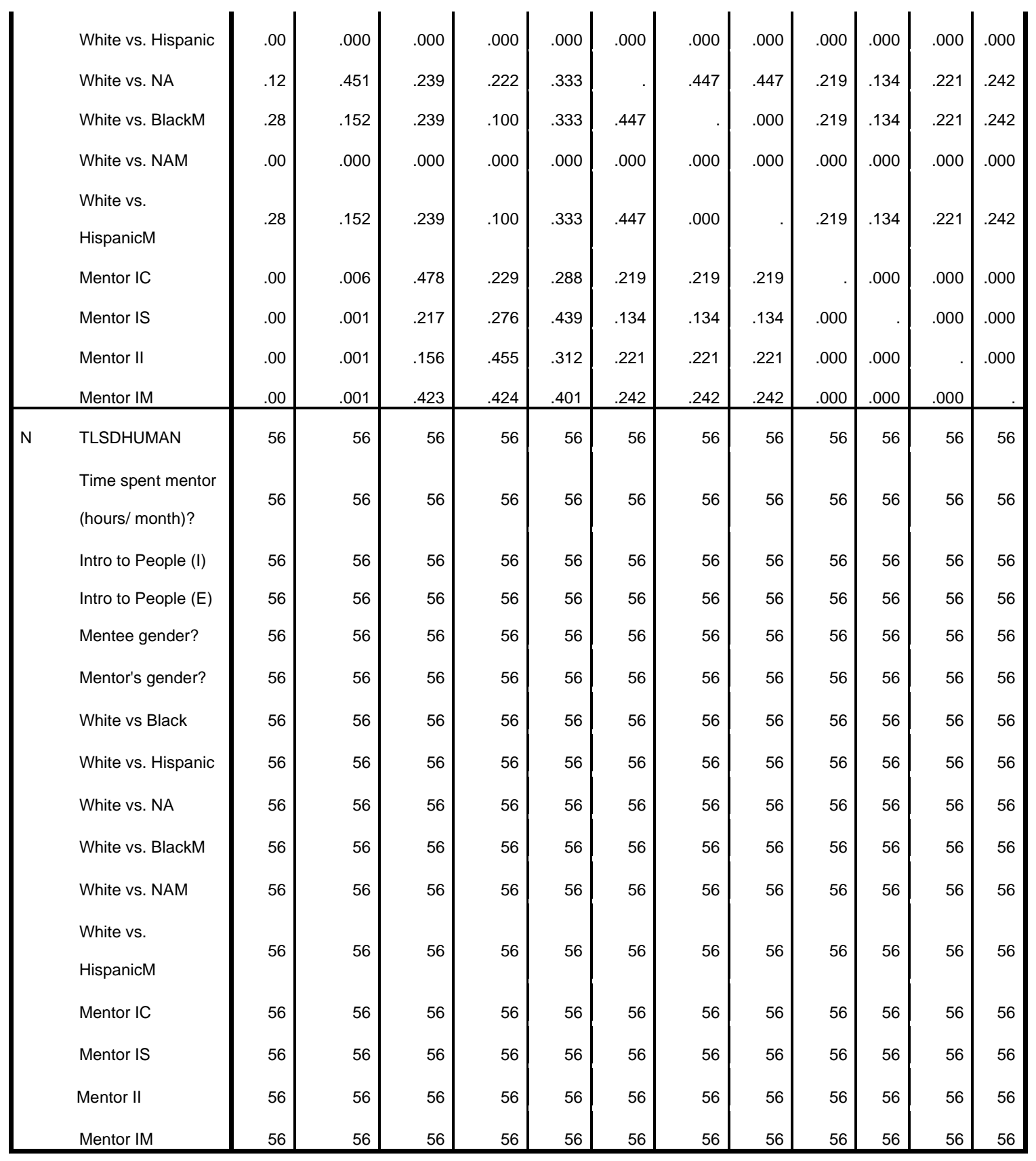

